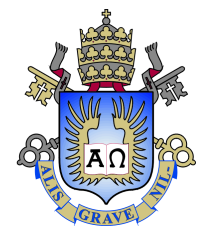

Martha Salles França

\title{
Simulador de Rede para Escoamento Bifásico em Capilares com Constrição
}

Dissertação apresentada como requisito parcial para obtenção do grau de Mestre pelo Programa de Pós-graduação em Petróleo e Energia do Departamento de Engenharia Mecânica do Centro Técnico Científico da PUC-Rio.

Orientador: Prof. Márcio da Silveira Carvalho 


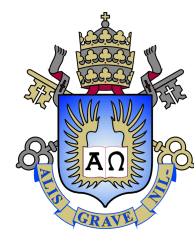

Martha Salles França

\section{Simulador de Rede para Escoamento Bifásico em Capilares com Constrição}

Dissertação apresentada como requisito parcial para obtenção do grau de Mestre pelo Programa de Pós-graduação em Petróleo e Energia do Departamento de Engenharia Mecânica do Centro Técnico Científico da PUC-Rio. Aprovada pela Comissão Examinadora abaixo assinada.

Prof. Márcio da Silveira Carvalho

Orientador

Departamento de Engenharia Mecânica - PUC-Rio

Prof. Luis Fernando Alzuguir Azevedo Departamento de Engenharia Mecância - PUC-Rio

Prof. Marcos Vitor Barbosa Machado

Petróleo Brasileiro

Dr. Rodrigo de Souza Portugal OGX Petróleo e Gás Participações

Prof. Márcio da Silveira Carvalho

Coordenador Setorial do Centro Técnico Científico - PUC-Rio 
Todos os direitos reservados. É proibida a reprodução total ou parcial do trabalho sem autorização da universidade, do autor e do orientador.

\section{Martha Salles França}

Graduou-se em Engenharia de Petróleo pela Pontifícia Universidade Católica do Rio de Janeiro em 2010. Atua como consultora de Reservatórios na Landmark/Halliburton desde 2011.

Ficha Catalográfica

França, Martha Salles

Simulador de Rede para Escoamento Bifásico em Capilares com Constrição / Martha Salles França ; orientador: Márcio da Silveira Carvalho. - 2017.

119 f. : il. color. ; $30 \mathrm{~cm}$

Dissertação (Mestrado)-Pontifícia Universidade Católica do Rio de Janeiro, Departamento de Engenharia Mecânica, 2017.

Inclui bibliografia

1. Engenharia Mecânica - Teses. 2. Meio poroso; 3. Modelo de rede de poros; 4. Escoamento imiscível; 5. Pressão capilar; 6. Molhabilidade. I. Carvalho, Márcio da Silveira II. Pontifícia Universidade Católica do Rio de Janeiro. Departamento de Engenharia Mecânica. III. Título. 


\section{Agradecimentos}

A Deus por tudo.

Aos meus pais e meu irmão por todo incentivo em todas as minhas conquistas acadêmicas, profissionais e pessoais.

Ao meu orientador, Professor Marcio Carvalho, pela dedicação e auxílio para realização deste trabalho.

À Halliburton, principalmente ao meu gerente Carlos Henrique, por todo o período concedido e incentivo para realização do mestrado.

À CAPES e à PUC-Rio pelos auxílios concedidos.

Aos professores da Pós-graduação da Engenharia Mecânica da PUC-Rio, principalmente a Prof. Angela Nieckele, Prof. Luis Fernando Azevedo, Prof. Paulo Roberto e Prof. Ivan Fabio, por todo conhecimento compartilhado.

Ao Toni Pacheco por toda ajuda e discussões que contribuíram bastante com este trabalho.

À amiga e pesquisadora Ranena Ponce pela disponibilidade e discussões que colaboraram muito com este trabalho.

À amiga Leticia Mota pela colaboração neste trabalho.

Aos amigos Cris, Leo e Gabriel pelos bons momentos e companhia nesta jornada.

À amiga Bianquinha por toda força e orações.

Ao Leslie Lamport pela criação do LaTeX que facilitou muito a elaboração desta tese. 


\section{Resumo}

França, Martha Salles; Carvalho, Márcio da Silveira. Simulador de Rede para Escoamento Bifásico em Capilares com Constrição. Rio de Janeiro, 2017. 119p. Dissertação de Mestrado Departamento de Engenharia Mecânica, Pontifícia Universidade Católica do Rio de Janeiro.

A compreensão dos mecanismos e fenômenos de transporte relacionados ao fluxo multifásico em meios porosos é de grande relevância para diversas aplicações práticas como captura e sequestro de dióxido de carbono, transporte em células de combustível e recuperação avançada de reservatórios de hidrocarbonetos. A geometria do espaço poroso e as interações dos fluidos com sua parte sólida determinam propriedades macroscópicas como porosidade, permeabilidades relativas e pressão capilar. Porém, a visão em escala microscópica fornece uma melhor descrição e entendimento dos processos físicos e químicos do escoamento de fluidos no espaço poroso. Neste trabalho desenvolvemos um simulador de rede de poros para análise do escoamento bifásico de fluidos imiscíveis tanto para o processo de drenagem quanto para o de embebição. O modelo de rede $240 \times 40$ tem capilares com raios médios na ordem de $52.35 \mu \mathrm{m}$ com constrição. Os padrões de escoamento e eficiências de deslocamento foram obtidos para diferentes razões de viscosidade e números de capilaridade. Os resultados encontrados, considerando deslocamento pistão, foram similares a de experimentos realizados previamente, injetando água no meio saturado de óleo. Na drenagem, a saturação residual de óleo cai com o aumento do número de capilaridade. O padrão de escoamento observado é de fingerings viscosos e, a frente de deslocamento torna-se mais estável com o aumento da razão de viscosidade. $\mathrm{Na}$ embebição, para números de capilaridade mais baixos, o escoamento foi dominado por fingers capilares. Para números de capilaridade altos, fingers viscosos foram predominantes e, com o aumento da razão de viscosidade, a frente apresentou maior estabilidade.

\section{Palavras-chave}

Meio poroso; Modelo de rede de poros; Escoamento imiscível; Pressão capilar; Molhabilidade. 


\section{Abstract}

França, Martha Salles; Carvalho, Márcio da Silveira (Advisor). Network Simulator for Two-Phase Displacement in Constricted Capillary Channels. Rio de Janeiro, 2017. 119p. Dissertação de Mestrado - Departamento de Engenharia Mecânica, Pontifícia Universidade Católica do Rio de Janeiro.

Understanding the mechanisms and transport phenomena of multiphase flow in porous media has great relevance in several practical applications, such as capture and sequestration of carbon dioxide, transport in fuel cells and enhancement hydrocarbon recovery. The geometry of pore space and the fluid interactions with the solid determine macroscopic properties such as porosity, relative permeabilities and capillary pressure. However, microscopic analysis provides a better description and comprehension of physical and chemical processes of fluid flow in the pore space. In this work, we developed a pore-network simulator to analyze immiscible two-phase flow for both drainage and imbibition processes. The $240 \times 40$ pore-network model has constricted capillary channels with radius on the order of $52.35 \mu \mathrm{m}$. Flow patterns and displacement efficiencies evaluation were obtained at different viscosity ratios and capillary numbers. The results, considering piston-like displacement, were similar to experiments realized previously, injecting water in an oil saturated medium. In the drainage process, the oil saturation reduces with increasing capillary number. The observed flow pattern is viscous fingerings and the front is stable with the higher viscosity ratio. In imbibition, the flow was dominated by capillary fingers at low capillary numbers. At high capillary numbers, viscous fingers were predominant and, with increasing viscosity ratio, the front presented higher stability.

\section{Keywords}

Porous media; Pore-network model; Immiscible displacement; Capillary pressure; Wettability. 


\section{Sumário}

1 Introdução $\quad 17$

2 Conceitos Fundamentais $\quad 19$

2.1 Escoamento Macroscópico em Meios Porosos 19

2.1.1 Lei de Darcy 20

2.1.2 Escoamento Bifásico 21

2.2 Fenômenos Microscópicos 24

2.2.1 Tensão Interfacial e Molhabilidade 24

2.2.2 Drenagem e Embebição 26

2.2.3 Fluxo em uma Garganta de Poro 27

2.2.4 Padrões de Escoamento 31

2.2.4.1 Fingering Viscoso 31

2.2.4.2 Fingering Capilar 31

2.2.4.3 Deslocamento Estável 32

2.2.4.4 Diagrama de Fases $\quad 32$

2.2.5 Mecanismos de Deslocamento 33

2.3 Modelos de Rede de Poros 34

2.3.1 Visualização do Escoamento em Micromodelos $\quad 35$

2.3.2 Modelos Numéricos de Rede de Poros 37

3 Metodologia $\quad 43$

3.1 Modelagem de Rede de Poros 43

3.1.1 Especificações do Microchip e o Modelo de Poros 46

3.1.2 Modelagem Numérica 51

3.1.2.1 Dimensionamento do Modelo de Rede e Parâmetros do Escoamento 53

3.1.2.2 Geometria , Conexões e Condições Iniciais 54

3.1.2.3 Cálculo da Pressão Capilar e Condutância 56

3.1.2.4 Cálculo de Pressões e Vazões 57

3.1.2.5 Cálculo do Tempo de Deslocamento e Posicionamento das Interfaces 58

3.1.2.6 Atualização dos Modelos de Interfaces e Criação de Novas Interfaces 60

3.1.2.7 Cálculo de Saturação nos Capilares 67

3.1.2.8 Condições Iniciais, de Contorno e de Controle 67

4 Resultados e Discussões $\quad 68$

$\begin{array}{ll}\text { 4.1 Resultados para Drenagem } & 68\end{array}$

4.1.1 Comparação com o Experimento 68

4.1.2 Variação de Razão de Viscosidade 76

4.2 Resultados para Embebição $\quad 89$

4.2.1 Comparação com o Experimento 90

4.2.2 Variação de Razão de Viscosidade $\quad 98$

4.3 Tempos de Simulação 114

5 Conclusão e Trabalhos Futuros $\quad 115$ 
Referências bibliográficas

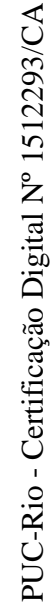




\section{Lista de figuras}

Figura 2.1 Desenho esquemático do experimento de Darcy. Adaptado de Dake, 1983 (1).

Figura 2.2 Exemplo de Curva de Permeabilidade relativa do Óleo e da Água em função da saturação de água.

Figura 2.3 Ângulo de Contato $\theta$ de uma gota de água aderida à superfície sólida em presença de óleo.

Figura 2.4 Variações dos ângulos de contato $(\theta)$ e a molhabilidade.

Figura 2.5 Esquema de escoamento em um tubo de raio $R$ mostrando o perfil de velocidade, em cor vermelha.

Figura 2.6 Representação de uma garganta de poro de raio $R$ e com uma interface de fluido não-molhante e molhante.

Figura 2.7 Diagrama de Fase do Lenormand mostrando os três diferentes padrões de fluxo para drenagem. Adaptado de Sinha e Wang, 2007 (2).

Figura 2.8 Desenho esquemático de como ocorre o preenchimento de poros quando o fluido sai de uma garganta.

Figura 2.9 Desenho esquemático de como ocorre o snap-off para drenagem e para embebição.Para a drenagem: (a) o óleo como fluido não-molhante se aproxima da constrição da garganta; (b) a água como fluido molhante se acumula em camadas até que a pressão capilar caia e o óleo avance; (c) a água separa o óleo em duas gotas. Para embebição:(a) a água como fluido molhante se acumula em camadas na parede; (b)a água separa o óleo, fluido não-molhante, em duas gotas. Adaptado de Al-Gharbi e Blunt, 2005 (3).

Figura 2.10 Micromodelo utilizado por Berejnov, Djilali e Sinton. Adaptado de Berejnov, Djilali e Sinton, 2008 (4).

Figura 2.11 Mapa conceitual para construção do Reservoir-on-aChip. Adaptado de Gunda et al., 2011 (5).

Figura 2.12 Arranjos de rede criados por Fatt(6): (1) Rede hexagonal; (2) Rede quadrada; (3) Rede hexagonal dupla; (4) Rede hexagonal tripla.

Figura 2.13 Fluxo de água considerando $C a=10^{-8}$, nos tempos 0 , $6.33,140,227,432$ e no estado final de regime permanente (7).

Figura 2.14 Gráfico de saturação de óleo residual versus número de capilaridade, Ca, para embebição em simulações de uma rede 15x30, para valores de razão de viscosidade de 50, 1 e 0.2 (8).

Figura 2.15 Fluido não molhante alcançando o final de uma garganta e três novas interfaces são posicionadas à uma distância $\delta$ do início da garganta (9).

Figura 2.16 Padrões de Escoamento com a variação do número de capilaridade $(C a)$ e razão de viscosidade $(M)$. (Modificada de Aker et al. (9)) 
Figura 2.17 Padrões de escoamento para diferentes vazões de injeção, implicando em diferentes números de capilaridade para uma rede $2 \mathrm{D}(10)$.

Figura 3.1 Modelo de Rede de Poros e Gargantas. Os poros estão representados como os círculos vermelhos tracejados e suas numerações se encontram no centro deste círculo. As gargantas são as setas pretas com suas numerações correspondentes. A ponta da seta indica o sentido de conexão da garganta que conecta dois poros. Os poros 1 e 7 são a entrada e a saída do escoamento respectivamente.

Figura 3.2 Microchip desenvolvido pela Dolomite Microfluidics (11) 46

Figura 3.3 Dimensões do microchip desenvolvido pela Dolomite Microfluidics (11)

Figura 3.4 (a) Imagem do microchip tirada do microscópio. Destacado pelo quadrado amarelo, o padrão de grid de 8 x 8 que se repete pela área porosa. (b) Os canais em vermelho possuem constrição de $63 \mu \mathrm{m}$, os de cor verde com $85 \mu \mathrm{m}$ e os azuis não possuem constrição.

Figura 3.5 Representação do microchip através do modelo de rede

Figura 3.6 Imagem do modelo de rede construído através da repetição do grid padrão obtido pela fotografia do microscópio. Os canais em vermelho possuem constrição de $63 \mu \mathrm{m}$, os de cor verde com $85 \mu \mathrm{m}$ e os azuis não possuem constrição.

Figura 3.7 Fluxograma da Simulação de Rede de Poros

Figura 3.8 Modelos de Interfaces. A letra $\mathrm{O}$ e W indicam a presença da fase óleo e água, respectivamente. Ninterfaces é o número de interfaces do capilar e Inter faceModel indica o modelo de interface para cada interface presente no capilar. Os índices de 1 a 3 são referências às 3 interfaces.

Figura 3.9 Representação de um capilar com constrição. Podemos observar o comprimento em que o raio do capilar não é afetado pela constrição, $L / 2-L_{\text {const }}$, e o comprimento em que é afetado, $L_{\text {const }}$. $R_{c}$ é o raio da constrição.

Figura 3.10 Posicionamento das interfaces. $x$ indica o posicionamento das interfaces nos capilares. Os índices de 1 a 3 são referências às 3 interfaces.

Figura 3.11 Curva da pressão capilar variando com a posição da interface, sendo o módulo no centro do capilar igual a $2 \sigma / R_{c}$ e $R_{c}=42.5 \times 10^{-6} \mathrm{~m}$

Figura 3.12 Cálculo de pressão capilar total considerando diferentes números de interfaces e óleo como fluido molhante.

Figura 3.13 Pressão em função do tempo para diferentes valores de percentuais de deslocamento, mostrando suavidade quando o deslocamento máximo é de 1\%. Adaptado de Aker, 1996 (9). 
Figura 3.14 Exemplos de atualizações de número e modelos de interfaces em casos em que as interfaces completam o capilar. (1)Para velocidade positiva, ou seja, o capilar completando para direita, reduzimos o número de interface de 1 para 0. (2)Para velocidade negativa, ou seja, o capilar completando para esquerda, reduzimos o número de interface de 2 para 1. (3)Para velocidade positiva, reduzimos o número de interface de 3 para 2. Após as reduções, fazemos as atualizações dos modelos das interfaces.

Figura 3.15 Regras para criação de novas interfaces para os capilares que saem do nó. À esquerda, apresentamos os capilares no momento em que os nós, representados pelo círculo, foram preenchidos com um fluido em preto. O número de interfaces está indicado abaixo de cada capilar. À direita, mostramos a criação de uma nova interface de comprimento $d n$. Quando a primeira interface está a uma distância do nó menor que $d n$, ocorre a redução do número de interfaces.

Figura 3.16 Regras para criação de novas interfaces para os capilares que entram no nó. À esquerda, apresentamos os capilares no momento em que os nós, representados pelo círculo, foram preenchidos com um fluido em preto. O número de interfaces está indicado abaixo de cada capilar. À direita, mostramos a criação de uma nova interface de comprimento $d n$. Quando a última interface está a uma distância do nó maior que $L-d n$, propomos uma redução do número de interfaces.

Figura 3.17 Modelo proposto por Aker et al. (9) no qual um capilar pode conter no máximo 2 interfaces. (a) O capilar 1 é preenchido e 3 novas interfaces de comprimento $\delta d$ são acrescentadas aos outros capilares. Observa-se que os capilares 3 e 4 já possuíam 2 interfaces e foi acrescentada uma terceira. (b) A redução de 3 para 1 interface ocorre. (Modificada de Aker et al. (9))

Figura 3.18 Análise da redução de interfaces juntamente ao modelo de pressão capilar sugerido por Aker et. al (9), descrito na Subseção 2.3.2. (a) O capilar possui um volume de fluido molhante representado na cor preta. Este volume está centralizado no capilar, obtendo valores de pressão capilar praticamente iguais. Devido aos diferentes modelos de interfaces, estas pressões se anulam. A terceira interface criada, também de cor preta, possui um volume ínfimo não impactando na resultante $P_{\text {captotal }}$. (b) Quando se reduz de 3 interfaces para 1, juntam-se os dois volumes e desloca-se o volume resultante para o início do capilar. Assim, a resultante $P_{\text {cap } p_{\text {total }}}$ é positiva, modificando consideravelmente o estado original de pressões. 
Figura 3.19 Criação de novas interfaces para os capilares com três interfaces, respeitando a matriz de incidência. À esquerda, apresentamos os capilares no momento em que os nós, representados pelo círculo, foram preenchidos com um fluido em preto. O número de interfaces está indicado abaixo de cada capilar. À direita, mostramos a criação de uma nova interface de comprimento $d n$. Para os capilares que saem do nó, checamos se a primeira interface está a uma distância do nó menor que $d n$. Para os capilares que entram no nó, checamos se a última interface está a uma distância do nó maior que $L-d n$. Na ocorrência destes dois casos, propomos a redução de 3 para 2 interfaces.

Figura 3.20 Criação interface respeitando a matriz de incidência. À esquerda, apresentamos os capilares no momento em que os nós, representados pelo círculo, foram preenchidos com um fluido em preto. O número de interfaces está indicado abaixo de cada capilar. No centro, apresentamos a criação de uma nova interface de comprimento $d n$, resultando em 4 interfaces. À direita observamos o estado do capilar após a redução para 2 interfaces.

Figura 4.1 Escoamento por Drenagem, $M=1 / 16$ e $C a=3.51 \times$ $10^{-5}$. À direita da imagem mostramos as saturações de água no chip e os tempos correspondentes.

Figura 4.2 Pressão na Entrada x Tempo, $M=1 / 16$ e $\mathrm{Ca}=$ $3.51 \times 10^{-5}$.

Figura 4.3 Saturação de Água x Tempo, $M=1 / 16$ e $C a=3.51 \times 10^{-5} .71$

Figura 4.4 Escoamento por Drenagem, $M=1 / 16$ e $C a=4.38 \times$ $10^{-6}$. À direita da imagem mostramos as saturações de água no chip e os tempos correspondentes.

Figura 4.5 Pressão na Entrada x Tempo, $M=1 / 16$ e $C a=$ $4.38 \times 10^{-6}$.

Figura 4.6 Saturação de Água x Tempo, $M=1 / 16$ e $C a=4.38 \times 10^{-6} .72$

Figura 4.7 Escoamento por Drenagem, $M=1 / 16$ e $C a=5.48 \times$ $10^{-7}$. À direita da imagem mostramos as saturações de água no chip e os tempos correspondentes.

Figura 4.8 Pressão na Entrada x Tempo, $M=1 / 16$ e $C a=$ $5.48 \times 10^{-7}$.

Figura 4.9 Saturação de Água x Tempo, $M=1 / 16$ e $C a=5.48 \times 10^{-7} .74$

Figura 4.10 Escoamento por Drenagem, $M=1 / 16$ e $C a=2.74 \times$ $10^{-7}$. À direita da imagem mostramos as saturações de água no chip e os tempos correspondentes.

Figura 4.11 Pressão na Entrada x Tempo, $M=1 / 16$ e $C a=$ $2.74 \times 10^{-7}$.

Figura 4.12 Saturação de Água x Tempo, $M=1 / 16$ e $C a=2.74 \times 10^{-7} .75$

Figura 4.13 Comparação entre o Modelo Numérico e o Experimento através do gráfico de $\mathrm{Ca} \times S_{o r}$.

Figura 4.14 Escoamento por Drenagem, $M=1 / 2$ e $C a=3.51 \times 10^{-5}$. À direita da imagem mostramos as saturações de água no chip e os tempos correspondentes. 
Figura 4.15 Pressão na Entrada x Tempo, $M=1 / 2$ e $C a=3.51 \times 10^{-5} .78$

Figura 4.16 Saturação de Água x Tempo, $M=1 / 2$ e $C a=3.51 \times 10^{-5} .78$

Figura 4.17 Escoamento por Drenagem, $M=1 / 2$ e $C a=4.38 \times 10^{-6}$.

À direita da imagem mostramos as saturações de água no chip

e os tempos correspondentes.

Figura 4.18 Pressão na Entrada x Tempo, $M=1 / 2$ e $C a=4.38 \times 10^{-6} .79$

Figura 4.19 Saturação de Água x Tempo, $M=1 / 2$ e $C a=4.38 \times 10^{-6} .80$

Figura 4.20 Escoamento por Drenagem, $M=1 / 2$ e $C a=5.48 \times 10^{-7}$.

À direita da imagem mostramos as saturações de água no chip

e os tempos correspondentes.

Figura 4.21 Pressão na Entrada x Tempo, $M=1 / 2$ e $C a=5.48 \times 10^{-7} .81$

Figura 4.22 Saturação de Água x Tempo, $M=1 / 2$ e $C a=5.48 \times 10^{-7}$. 81

Figura 4.23 Escoamento por Drenagem, $M=1 / 2$ e $C a=2.74 \times 10^{-7}$.

À direita da imagem mostramos as saturações de água no chip

e os tempos correspondentes.

Figura 4.24 Pressão na Entrada x Tempo, $M=1 / 2$ e $C a=2.74 \times 10^{-7} .82$

Figura 4.25 Saturação de Água x Tempo, $M=1 / 2$ e $C a=2.74 \times 10^{-7} .83$

Figura 4.26 Escoamento por Drenagem, $M=1 / 50$ e $C a=3.51 \times$

$10^{-5}$. À direita da imagem mostramos as saturações de água no

chip e os tempos correspondentes.

Figura 4.27 Pressão na Entrada x Tempo, $M=1 / 50$ e $C a=$ $3.51 \times 10^{-5}$.

Figura 4.28 Saturação de Água x Tempo, $M=1 / 50$ e $C a=3.51 \times 10^{-5} .85$

Figura 4.29 Escoamento por Drenagem, $M=1 / 50$ e $C a=4.38 \times$ $10^{-6}$. À direita da imagem mostramos as saturações de água no chip e os tempos correspondentes.

Figura 4.30 Pressão na Entrada x Tempo, $M=1 / 50$ e $C a=$ $4.38 \times 10^{-6}$.

Figura 4.31 Saturação de Água x Tempo, $M=1 / 50$ e $C a=4.38 \times 10^{-6} .86$

Figura 4.32 Escoamento por Drenagem, $M=1 / 50$ e $C a=5.48 \times$ $10^{-7}$. À direita da imagem mostramos as saturações de água no chip e os tempos correspondentes.

Figura 4.33 Pressão na Entrada x Tempo, $M=1 / 50$ e $C a=$ $5.48 \times 10^{-7}$.

Figura 4.34 Saturação de Água x Tempo, $M=1 / 50$ e $C a=2.74 \times 10^{-7} .87$

Figura 4.35 Escoamento por Drenagem, $M=1 / 50$ e $C a=2.74 \times$ $10^{-7}$. À direita da imagem mostramos as saturações de água no chip e os tempos correspondentes.

Figura 4.36 Pressão na Entrada x Tempo, $M=1 / 50$ e $C a=$ $2.74 \times 10^{-7}$.

Figura 4.37 Saturação de Água x Tempo, $M=1 / 50$ e $C a=5.48 \times 10^{-7} .88$

Figura 4.38 Gráfico de $C a \times S_{\text {or }}$ para $M=1 / 50, M=1 / 16$ e $M=1 / 2.89$

Figura 4.39 Escoamento por Embebição, $M=1 / 16$ e $C a=3.51 \times$ $10^{-5}$. À direita da imagem mostramos as saturações de água no chip e os tempos correspondentes.

Figura 4.40 Pressão na Entrada x Tempo, $M=1 / 16$ e $C a=$ $3.51 \times 10^{-5}$. 
Figura 4.41 Heat Map de vazão nos capilares juntamente com a imagem do escoamento para os instantes $6.354 \mathrm{~s}$ e $8.473 \mathrm{~s}, M=$ $1 / 16$ e $C a=3.51 \times 10^{-5}$.

Figura 4.42 Saturação de Água x Tempo, $M=1 / 16$ e $C a=3.51 \times 10^{-5} .93$

Figura 4.43 Escoamento por Embebição, $M=1 / 16$ e $C a=5.48 \times$ $10^{-7}$. À direita da imagem mostramos as saturações de água no chip e os tempos correspondentes.

Figura 4.44 Pressão na Entrada x Tempo, $M=1 / 16$ e $C a=$ $5.48 \times 10^{-7}$.

Figura 4.45 Saturação de Água x Tempo, $M=1 / 16$ e $C a=5.48 \times 10^{-7} .95$

Figura 4.46 Escoamento por Embebição, $M=1 / 16$ e $C a=2.74 \times$ $10^{-7}$. À direita da imagem mostramos as saturações de água no chip e os tempos correspondentes.

Figura 4.47 Pressão na Entrada x Tempo, $M=1 / 16$ e $C a=$ $2.74 \times 10^{-7}$.

Figura 4.48 Saturação de Água x Tempo, $M=1 / 16$ e $C a=2.74 \times 10^{-7} .97$

Figura 4.49 Comparação entre o Modelo Numérico e o Experimento através do gráfico de $\mathrm{Ca} \times S_{o r}$.

Figura 4.50 Escoamento por Embebição, $M=1 / 2$ e $C a=3.51 \times$ $10^{-5}$. À direita da imagem mostramos as saturações de água no chip e os tempos correspondentes.

Figura 4.51 Pressão na Entrada x Tempo, $M=1 / 2$ e $C a=3.51 \times 10^{-5} .101$

Figura 4.52 Saturação de Água x Tempo, $M=1 / 2$ e $C a=3.51 \times 10^{-5} .101$

Figura 4.53 Escoamento por Embebição, $M=1 / 2$ e $C a=4.38 \times$ $10^{-6}$. À direita da imagem mostramos as saturações de água no chip e os tempos correspondentes.

Figura 4.54 Pressão na Entrada x Tempo, $M=1 / 2$ e $C a=4.38 \times 10^{-6} .103$

Figura 4.55 Saturação de Água x Tempo, $M=1 / 2$ e $C a=4.38 \times 10^{-6} .103$

Figura 4.56 Escoamento por Embebição, $M=1 / 2$ e $C a=5.48 \times$ $10^{-7}$. À direita da imagem mostramos as saturações de água no chip e os tempos correspondentes.

Figura 4.57 Pressão na Entrada x Tempo, $M=1 / 2$ e $C a=5.48 \times 10^{-7} .105$

Figura 4.58 Saturação de Água x Tempo, $M=1 / 2$ e $C a=5.48 \times 10^{-7} .105$

Figura 4.59 Escoamento por Embebição, $M=1 / 2$ e $C a=2.74 \times$ $10^{-7}$. À direita da imagem mostramos as saturações de água no chip e os tempos correspondentes.

Figura 4.60 Pressão na Entrada x Tempo, $M=1 / 2$ e $C a=2.74 \times 10^{-7} .106$

Figura 4.61 Saturação de Água x Tempo, $M=1 / 2$ e $C a=2.74 \times 10^{-7} .107$

Figura 4.62 Escoamento por Embebição, $M=1 / 50$ e $C a=3.51 \times$ $10^{-5}$. À direita da imagem mostramos as saturações de água no chip e os tempos correspondentes.

Figura 4.63 Pressão na Entrada x Tempo, $M=1 / 50$ e $\mathrm{Ca}=$ $3.51 \times 10^{-5}$.

Figura 4.64 Saturação de Água x Tempo, $M=1 / 50$ e $C a=3.51 \times 10^{-5} .109$

Figura 4.65 Escoamento por Embebição, $M=1 / 50$ e $C a=4.38 \times$ $10^{-6}$. À direita da imagem mostramos as saturações de água no chip e os tempos correspondentes. 
Figura 4.66 Pressão na Entrada x Tempo, $M=1 / 50$ e $C a=$ $4.38 \times 10^{-6}$.

Figura 4.67 Saturação de Água x Tempo, $M=1 / 50$ e $C a=4.38 \times 10^{-6} .111$

Figura 4.68 Escoamento por Embebição, $M=1 / 50$ e $C a=2.74 \times$ $10^{-7}$. À direita da imagem mostramos as saturações de água no chip e os tempos correspondentes.

Figura 4.69 Pressão na Entrada x Tempo, $M=1 / 50$ e $C a=$ $2.74 \times 10^{-7}$.

Figura 4.70 Saturação de Água x Tempo, $M=1 / 50$ e $C a=5.48 \times 10^{-7} .113$

Figura 4.71 Gráfico de $C a \times S_{\text {or }}$ para $M=1 / 50, M=1 / 16$ e $M=1 / 2.114$ 


\section{Lista de tabelas}

Tabela 3.1 Parâmetros para o dimensionamento da rede de poros $\quad 53$

Tabela 4.1 Parâmetros de Entrada - Experimento (12) e Modelo Numérico

Tabela 4.2 Eficiências de Deslocamento (Drenagem) - Experimento (12) e Simulador $\quad 75$

Tabela 4.3 Eficiências de Deslocamento (Drenagem) - Simulador 88

Tabela 4.4 Parâmetros de Entrada - Experimento (12) e Modelo Numérico 90

Tabela 4.5 Eficiências de Deslocamento (Embebição) - Experimento (12) e Simulador $\quad 97$

Tabela 4.6 Eficiências de Deslocamento (Embebição) - Simulador 113

Tabela 4.7 Especificações da Máquina utilizada nas Simulações 114 


\section{Introdução}

O entendimento dos fenômenos relacionados ao movimento de um ou mais fluidos imiscíveis em meios porosos é de grande importância para diversas aplicações práticas como captura e sequestro de dióxido de carbono para redução de emissão de gases na atmosfera, transporte em células de combustível, secagem de pasta de papel e recuperação avançada de reservatórios de hidrocarbonetos. A geometria do espaço poroso e as interações dos fluidos com sua parte sólida determinam propriedades macroscópicas como porosidade, permeabilidades relativas e pressão capilar. Por sua vez, a visão em escala microscópica fornece não somente uma melhor descrição como uma melhor compreensão dos processos físicos e químicos do escoamento de fluidos no espaço poroso.

Diversos estudos relacionados ao comportamento do escoamento de fluidos em microescala têm sido desenvolvidos nas últimas décadas. Estes abrangem tanto experimentos a partir da visualização do escoamento em micromodelos como modelagem numérica de rede de poros e gargantas. Este último funciona como uma ferramenta complementar aos experimentos e, em algumas vezes, os substituem fornecendo um conhecimento mais detalhado dos processos.

Este trabalho tem como objetivo o desenvolvimento de um simulador de rede de poros para análise do escoamento bifásico de fluidos imiscíveis tanto para o processo de drenagem quanto para o de embebição. O modelo representa, em nós e capilares, a geometria e conexões de um microchip, construído pela Dolomite Microfluidics. A rede $240 \times 40$ tem capilares com raios médios de aproximadamente $52.35 \mu \mathrm{m}$ com constrição. O simulador, escrito em Matlab, segue uma modelagem dinâmica na qual a vazão de injeção constante é imposta e a pressão de saída é zero. O mecanismo de deslocamento pistão é considerado, não sendo capaz de simular a presença simultânea das fases em uma mesma seção transversal.

Nos testes computacionais foram utilizados três valores de razão de viscosidade $(1 / 50,1 / 16$ e $1 / 2)$ e números de capilaridade da ordem de $10^{-7}$ a $10^{-5}$. O intervalo destes dois parâmetros contempla valores considerados nos experimentos realizados com o microchip, fornecidos pelo Laboratório de Microhidrodinâmica e Escoamento em Meios Porosos da PUC-Rio (12). Assim, 
além de avaliar os diferentes padrões de escoamento, foi possível comparar as eficiências de deslocamento do modelo numérico com o experimental.

Os capítulos seguintes foram estruturados de forma a facilitar a compreensão da modelagem numérica da rede de poros proposta. No Capítulo 2 são abordados os conceitos básicos da física do escoamento de fluidos tanto do ponto de vista macroscópico quanto do ponto de vista microscópico. Além disto, apresentamos trabalhos experimentais e numéricos anteriores sobre microfluídica. O Capítulo 3 descreve a modelagem numérica em detalhe acompanhada de diagramas de fluxo. No Capítulo 4 são discutidos os resultados obtidos pelos testes computacionais e, no Capítulo 5, apresentamos as conclusões e sugestões de melhorias quanto a modelagem numérica. 


\section{2}

\section{Conceitos Fundamentais}

Este capítulo tem como objetivo revisar alguns aspectos básicos da física do escoamento de fluidos tanto do ponto de vista macroscópico quanto do ponto de vista microscópico, fornecendo uma base de conhecimento para o melhor entendimento da modelagem numérica da rede de poros proposta nesta dissertação. Ao final do capítulo, são apresentados alguns trabalhos anteriores, mostrando a evolução da ciência e tecnologia relacionadas à microfluídica tanto na abordagem experimental quanto na numérica.

\section{1}

\section{Escoamento Macroscópico em Meios Porosos}

Um meio poroso consiste de uma matriz sólida com espaços vazios, chamados de poros, onde os fluidos são alojados. Os poros são conectados por uma ou mais gargantas possibilitando o escoamento destes fluidos. Tendo isto em mente, é possível evidenciar alguns exemplos de meios porosos do nosso cotidiano como a esponja de cozinha, filtros de cerâmica, rochas, solos, etc.

Nesse contexto, a modelagem de fluxo pode ser avaliada em diferentes escalas. A escala macroscópica tenta descrever a física microscópica utilizando propriedades ou funções que representam grupos de poros e gargantas. Um exemplo disto ocorre na produção de petróleo na qual as estruturas das rochas reservatórios, de dimensões quilométricas e extremamente complexas a nível microscópico, são analisadas em escalas de 1 metro. Esta modelagem leva a aproximações onde variações microscópicas no escoamento do fluido são, por vezes, negligenciadas.

Duas propriedades importantes para a descrição macroscópica do meio poroso são a porosidade $(\phi)$ e a permeabilidade $(k)$. A porosidade é definida como razão entre o volume de poros e o volume total do meio, variando entre 0 e 1. A permeabilidade se caracteriza pela "facilidade" que um fluido escoa através do meio poroso, dependendo somente da geometria da estrutura porosa. Apesar de não existir uma fórmula que generalize esta grandeza, muitos cientistas já encontraram algumas correlações com a porosidade dependendo do tipo e condição da rocha. 


\subsection{1}

\section{Lei de Darcy}

Em 1856, o engenheiro francês Henry Darcy publicou seu trabalho de tratamento de água na cidade de Dijon. Este tratava-se da elaboração de um filtro, conforme mostrado na Figura 2.1, que constituía de um cilindro de ferro contendo um pacote de areia não consolidada de cerca de $1 \mathrm{~m}$ de comprimento entre duas telas permeáveis. Manômetros foram conectados nos extremos do cilindro. Ao escoar a água através do pacote de areia, Darcy observou que a velocidade da água era proporcional à diferença das alturas manométricas (1).

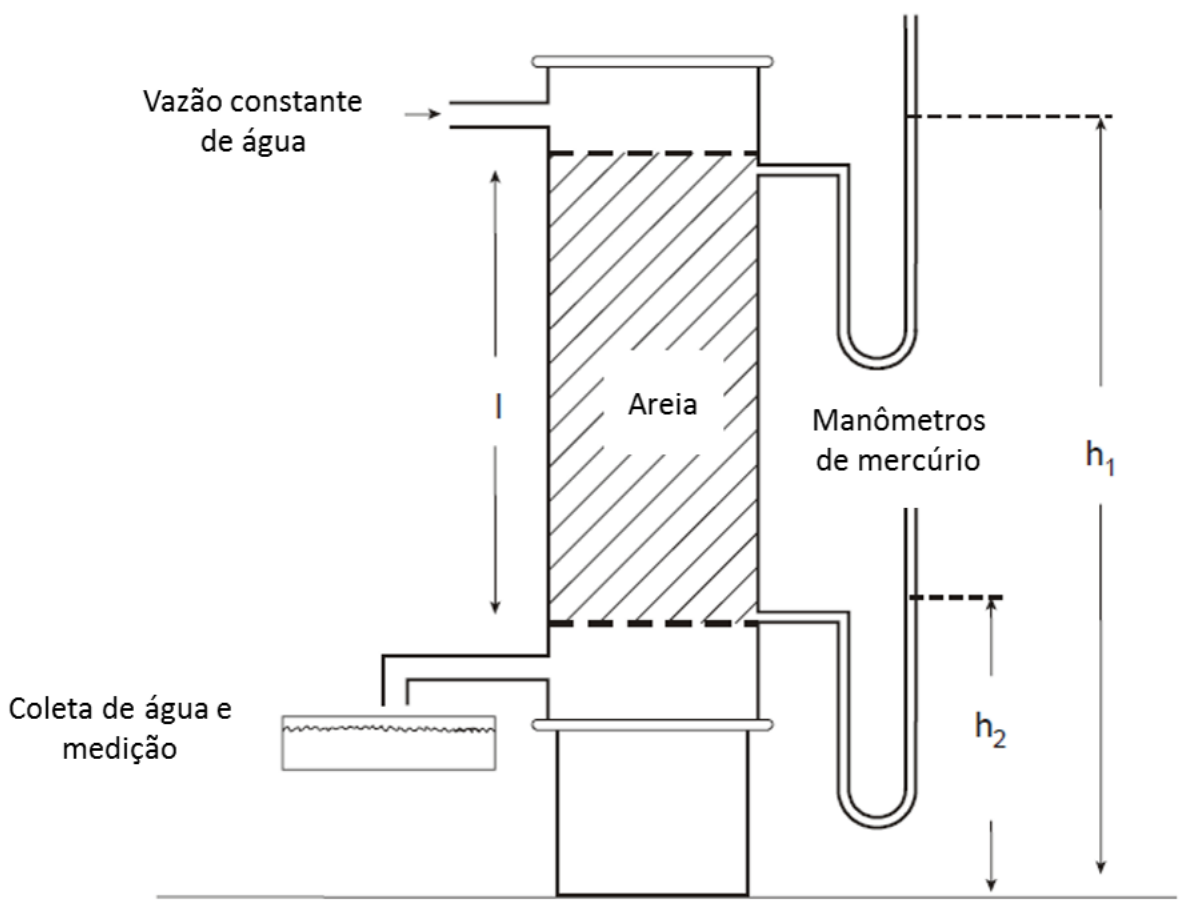

Figura 2.1: Desenho esquemático do experimento de Darcy. Adaptado de Dake, $1983(1)$.

Com os resultados do seu experimento, a seguinte relação (Equação 2-1) foi obtida considerando as premissas de (1) efeitos gravitacionais desprezados, (2) fluxo isotérmico e permanente, (3) fluido incompressível, homogêneo e de viscosidade invariável com a pressão, (4) meio poroso homogêneo, que não reage com o fluido e (5) escoamento horizontal:

$$
\frac{q}{A}=-\frac{k}{\mu L} \Delta p
$$

onde $q$ representa a vazão de fluido $\left(\mathrm{cm}^{3} / s\right), A$ é a área transversal $\left(\mathrm{cm}^{2}\right), \Delta p$ o diferencial de pressão $(\mathrm{atm}), \mu$ a viscosidade do fluido $(c p), L$ o comprimento do 
meio poroso $(\mathrm{cm})$ e $k$ a constante de proporcionalidade $\left(\mathrm{cm}^{2}\right)$, que mais tarde, foi denominada de permeabilidade absoluta (tradicionalmente reportada na unidade Darcy, $1 D \cong 9.87 \times 10^{-13} \mathrm{~m}^{2}$ ). O sinal negativo se deve ao fato do escoamento seguir para regiões de maior para menor pressão. Esta equação é a mais utilizada na prática para o estudo de fluxo de fluidos em meios porosos (13).

\subsection{2}

\section{Escoamento Bifásico}

A equação de Darcy, vista na Subseção 2.1.1, é utilizada para descrever o fluxo macroscópico de um fluido no meio. O escoamento de dois ou mais fluidos no meio poroso causa interações microscópicas gerando mudanças no gradiente de pressão devido à pressão capilar. Além disto, a presença de duas ou mais fases altera a capacidade que cada uma tem de escoar. Esta capacidade é denominada como permeabilidade efetiva e depende fortemente da saturação da fase em questão, molhabilidade e a consolidação do meio poroso. Com todos os aspectos citados, é notável a necessidade de incorporar alguns efeitos microscópicos para uma melhor descrição do fluxo bifásico. Outro conceito importante é a permeabilidade relativa, definida como a razão entre a permeabilidade efetiva e a absoluta. A Figura 2.2 mostra um típico comportamento da permeabilidade relativa do óleo $\left(k_{r o}\right)$ e da água $\left(k_{r w}\right)$ em função da saturação de água $\left(S_{w}\right)$. No início da injeção, a água tende a ocupar os poros menores que não contribuem tanto para o escoamento. Logo, a permeabilidade relativa da água é zero até a saturação crítica de água $\left(S_{w c}\right)$ e, a partir deste ponto, a permeabilidade relativa da água aumenta até o seu máximo, podendo chegar até 1 . Já a permeabilidade relativa do óleo começa a decair até alcançar a saturação de óleo residual $\left(S_{\text {or }}\right)$ que indica a fração de óleo presa no meio poroso.

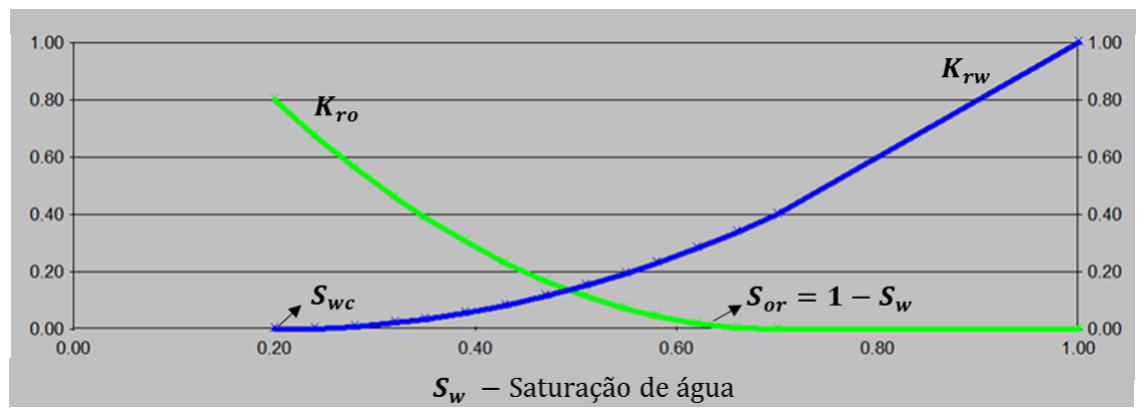

Figura 2.2: Exemplo de Curva de Permeabilidade relativa do Óleo e da Água em função da saturação de água. 
Reescrevendo a equação de Darcy para a fase água e para a fase óleo presentes no escoamento e considerando as mesmas premissas da Equação 2-1 temos que:

$$
\begin{gathered}
\frac{q_{w}}{A}=-k \frac{k_{r w}}{\mu_{w}} \nabla p_{w} \mathrm{e} \\
\frac{q_{o}}{A}=-k \frac{k_{r o}}{\mu_{o}} \nabla p_{o}
\end{gathered}
$$

onde $w$ é o índice que representa a fase água e $o$ é o índice da fase óleo, $A$ é a área transversal $\left(\mathrm{cm}^{2}\right), k$ a permeabilidade absoluta (Darcy), $\mu$ a viscosidade $(c p), q$ é a vazão $\left(\mathrm{cm}^{3} / s\right), k_{r}$ a permeabilidade relativa e $p$ a pressão em cada fase $(\mathrm{atm})$. A diferença de pressão da fase óleo (não molhante) e da fase água (molhate) define a pressão capilar, $p_{c}$,

$$
p_{c}=p_{o}-p_{w} .
$$

A partir da Lei de Darcy para fluxo bifásico, da equação da continuidade e do conceito de fluxo fracionário obtemos a velocidade do escoamento em função da saturação de água, conhecida como Equação de Buckley e Leverett. Esta equação é um exemplo de análise macroscópica para fluxo unidirecional que depende da permeabilidade relativa.

Primeiramente, temos que a velocidade total de Darcy, $v_{t}$, é igual a soma da velocidade de Darcy relacionada à fase óleo, $v_{o}$, com velocidade de Darcy relacionada à fase água, $v_{w}$, isto é

$$
v_{t}=v_{o}+v_{w},
$$

sendo que:

$$
\begin{aligned}
& v_{o}=\frac{q_{o}}{A} \\
& v_{w}=\frac{q_{w}}{A} .
\end{aligned}
$$


O fluxo fracionário de um fluido é definido como o quociente entre a velocidade de Darcy deste fluido e velocidade total de Darcy:

$$
\begin{aligned}
& f_{o}=\frac{v_{o}}{v_{t}} \\
& f_{w}=\frac{v_{w}}{v_{t}} .
\end{aligned}
$$

Utilizando as Equações 2-3 e 2-2 e substituindo nas Equações 2-8 e 29, considerando escoamento horizontal e desprezando o gradiente de pressão capilar, temos que:

$$
f_{w}=\frac{1}{1+\frac{k_{r_{o}}}{\mu_{o}} \frac{\mu_{w}}{k_{r w}}} .
$$

Sabe-se que a soma das saturações das fases, $S$, é igual a 1 ,

$$
S_{w}+S_{o}=1
$$

Para o acompanhamento das mudanças de saturação durante o escoamento em meio poroso é preciso aplicar a equação da continuidade:

$$
\frac{\partial}{\partial t}(\phi \rho)+\nabla \cdot(\rho \vec{v})=0
$$

onde $\rho$ é massa específica $\left(\mathrm{kg} / \mathrm{cm}^{3}\right), t$ é o tempo, $\vec{v}$ o vetor velocidade $(\mathrm{cm} / \mathrm{s})$ e $\phi$ a porosidade.

Considerando meio rígido e fluido incompressível podemos definir a equação da continuidade para a fase água e a fase óleo como:

$$
\begin{gathered}
\phi \frac{\partial S_{w}}{\partial t}+\frac{\partial \overrightarrow{v_{w}}}{\partial x}=0 \mathrm{e} \\
\phi \frac{\partial S_{o}}{\partial t}+\frac{\partial \overrightarrow{v_{o}}}{\partial x}=0,
\end{gathered}
$$

onde $x$ é o posicionamento ao longo do sistema. Com as equações anteriores, temos seis parâmetros desconhecidos: $q_{w}, q_{o}, S_{w}, S_{o}, p_{w}$ e $p_{o}$. De acordo com Aker et al. (9), para resolver esta sequência de equações, Buckley and Leverett 
sugeriram que a pressão capilar fosse uma função da saturação de água,

$$
p_{c}\left(S_{w}\right)=p_{o}-p_{w}
$$

Desprezando o gradiente de pressão capilar, temos que:

$$
\frac{\partial p_{w}}{\partial x}=\frac{\partial p_{o}}{\partial x}
$$

Adicionando o conceito de fluxo fracionário, obtemos a equação de Buckley e Leverett:

$$
\begin{gathered}
\frac{\partial S_{w}}{\partial t}+v_{t}\left(S_{w}\right) \frac{\partial S_{w}}{\partial x}=0 \mathrm{e} \\
v_{t}\left(S_{w}\right)=\frac{q_{t}}{\phi A}\left(\frac{d f}{d S_{w}}\right)
\end{gathered}
$$

onde $q_{t}=q_{o}+q_{w}$.

\section{2}

\section{Fenômenos Microscópicos}

O conhecimento dos efeitos microscópicos em um escoamento fornece uma descrição em detalhe das configurações das diferentes fases no meio poroso, nos possibilitando trabalhar com uma melhor caracterização do mesmo. Também, a análise dessas estruturas locais de interfaces dos fluidos permite avaliar com mais acurácia a eficiência de um método de recuperação. Neste capítulo são introduzidos os dois conceitos básicos para o entendimento do fluxo na escala de poros: a tensão interfacial e a molhabilidade, e os tipos deslocamentos presentes: drenagem e embebição. Além disto, analisamos as equações que governam o fluxo em um capilar, os padrões e mecanismos de deslocamento estudados pela microfluídica.

\subsection{1}

\section{Tensão Interfacial e Molhabilidade}

A tensão interfacial é observada quando dois fluidos imiscíveis estão em contato. Na interface destes fluidos ocorrem interações, decorrentes de forças atrativas, entre as moléculas dos diferentes tipos. Assim, a tensão interfacial é 
medida pelo quociente entre a força que atravessa uma linha da superfície pelo comprimento da própria linha.

A relação entre a pressão de dois fluidos imiscíveis em contato e a tensão interfacial é dada pela Equação de Young-Laplace:

$$
\Delta p=\sigma\left(\frac{1}{R_{1}}+\frac{1}{R_{2}}\right)
$$

onde $\Delta p$ é a diferença de pressão entre os fluidos, $\sigma$ é a tensão interfacial e, $R_{1}$ e $R_{2}$ são os raios de curvatura da interface.

No caso de uma superfície esférica, os raios de curvatura $R_{1}$ e $R_{2}$ são iguais, logo:

$$
\Delta p=\frac{2 \sigma}{R}
$$

Outro conceito fundamental para a física microscópica em meios porosos é a molhabilidade. Esta é definida como a tendência de um fluido de se espalhar ao longo da superfície de um sólido, na presença de outros fluidos imiscíveis. Observando a Figura 2.3, temos que a tensão interfacial ou de adesão, $\sigma$, é:

$$
\sigma=\sigma_{s o}-\sigma_{s w}=\sigma_{w o} \cos \theta_{w o}
$$

onde $\sigma_{s o}$ é tensão interfacial entre o sólido e o óleo, $\sigma_{s w}$ a tensão interfacial entre o sólido e a água, $\sigma_{w o}$ a tensão interfacial entre a água e o óleo e $\theta_{w o}$ é o ângulo de contato.

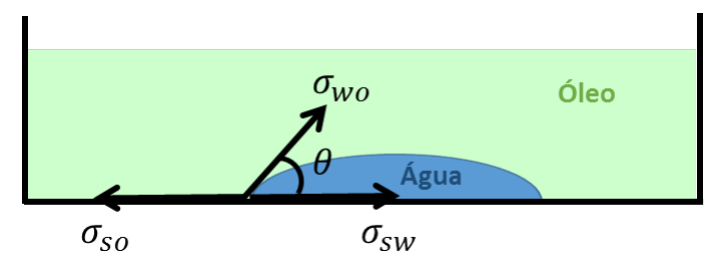

Figura 2.3: Ângulo de Contato $\theta$ de uma gota de água aderida à superfície sólida em presença de óleo. 
A Figura 2.4 mostra as variações de formatos de gotas com seus respectivos ângulos de contato indicando o estado de molhabilidade. Para $\theta<90^{\circ}$, temos que o fluido mais denso é molhante, para $\theta>90^{\circ}$ o fluido mais denso é não-molhante e, para $\theta=90^{\circ}$, a molhabilidade é neutra.

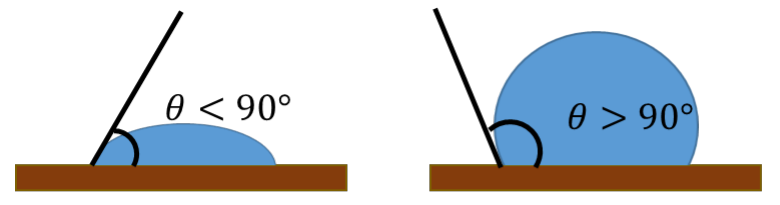

(a) Fluido molhante (b) Fluido não-molhante

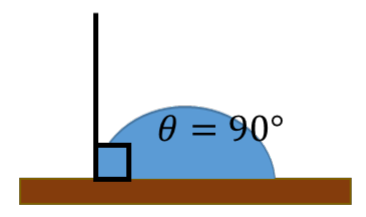

(c) Molhabilidade neutra

Figura 2.4: Variações dos ângulos de contato $(\theta)$ e a molhabilidade.

Para escoamento bifásico em um meio poroso, a relação entre o ângulo de contato e a pressão capilar é tratada da seguinte forma:

$$
p_{c}=\frac{2 \sigma}{R} \cos \theta=p_{n m}-p_{m}
$$

onde $R$ é raio do capilar, $p_{n m}$ é a pressão do fluido não-molhante e $p_{m}$ a pressão do fluido molhante.

\subsection{2}

\section{Drenagem e Embebição}

A propriedade de molhabilidade discutida na Subseção 2.2.1 é de grande impacto para os dois tipos de deslocamento no escoamento bifásico em um meio poroso: drenagem e embebição. O processo de drenagem ocorre quando o fluido não-molhante desloca o fluido molhante. Já a embebição ocorre quando o fluido molhante desloca o não-molhante.

Em um típico deslocamento por drenagem, o fluido não-molhante avança pelos capilares de raios maiores, nos quais há maior facilidade para vencer a pressão capilar, de acordo com a Equação 2-22. Na embebição, como o fluido molhante já tem preferência para o deslocamento, em escoamentos com forças capilares dominantes, os capilares de maior constrição são preenchidos inicialmente. 


\subsection{3}

\section{Fluxo em uma Garganta de Poro}

Para um modelo de simulação em microescala é necessária a avaliação da velocidade do escoamento em função do gradiente de pressão ao longo da conexão entre dois poros, esta conexão é chamada de garganta de poro. Em vista disto, nesta subseção, apresentamos o fluxo em uma garganta pelo modelo de escoamento de Hagen-Poiseuille, a partir da equação de NavierStokes. Com o cálculo da vazão volumétrica em função do gradiente, usaremos uma adaptação para incorporar os efeitos da pressão capilar conhecida como Equação de Washburn.

A equação de Navier-Stokes em coordenadas cilíndricas é mostrada a seguir (Equações 2-23, 2-24 e 2-25):

Para a direção radial:

$$
\begin{aligned}
& \rho\left(\frac{\partial v_{r}}{\partial t}+v_{r} \frac{\partial v_{r}}{\partial r}+\frac{v_{\theta}}{r} \frac{\partial v_{r}}{\partial \theta}-\frac{v_{\theta}^{2}}{r}+v_{z} \frac{\partial v_{r}}{\partial z}\right)=-\frac{\partial p}{\partial r}+\rho g_{r}+ \\
& +\mu\left(\frac{\partial^{2} v_{r}}{\partial r^{2}}+\frac{1}{r} \frac{\partial v_{r}}{\partial r}-\frac{v_{r}}{r^{2}}+\frac{1}{r^{2}} \frac{\partial^{2} v_{r}}{\partial \theta^{2}}-\frac{2}{r^{2}} \frac{\partial v_{\theta}}{\partial \theta}+\frac{\partial^{2} v_{r}}{\partial z^{2}}\right) .
\end{aligned}
$$

Para a direção circunferencial:

$$
\begin{aligned}
& \rho\left(\frac{\partial v_{\theta}}{\partial t}+v_{r} \frac{\partial v_{\theta}}{\partial r}+\frac{v_{\theta}}{r} \frac{\partial v_{\theta}}{\partial \theta}+\frac{v_{r} v_{\theta}}{r}+v_{z} \frac{\partial v_{\theta}}{\partial z}\right)=-\frac{1}{r} \frac{\partial p}{\partial \theta}+\rho g_{\theta}+ \\
& +\mu\left(\frac{\partial^{2} v_{\theta}}{\partial r^{2}}+\frac{1}{r} \frac{\partial v_{\theta}}{\partial r}-\frac{v_{\theta}}{r^{2}}+\frac{1}{r^{2}} \frac{\partial^{2} v_{\theta}}{\partial \theta^{2}}+\frac{2}{r^{2}} \frac{\partial v_{r}}{\partial \theta}+\frac{\partial^{2} v_{\theta}}{\partial z^{2}}\right) .
\end{aligned}
$$


Para a direção axial:

$$
\begin{aligned}
& \rho\left(\frac{\partial v_{z}}{\partial t}+v_{r} \frac{\partial v_{z}}{\partial r}+\frac{v_{\theta}}{r} \frac{\partial v_{z}}{\partial \theta}++v_{z} \frac{\partial v_{z}}{\partial z}\right)=-\frac{\partial p}{\partial z}+\rho g_{z}+\mu\left(\frac{\partial^{2} v_{z}}{\partial r^{2}}+\right. \\
& \left.+\frac{1}{r} \frac{\partial v_{z}}{\partial r}+\frac{1}{r^{2}} \frac{\partial^{2} v_{z}}{\partial \theta^{2}}+\frac{\partial^{2} v_{z}}{\partial z^{2}}\right) .
\end{aligned}
$$

Os índices $\theta, r$ e $z$ são relativas às direções circunferencial, radial e axial, respectivamente, e $g$ é a aceleração da gravidade.

Na Figura 2.5, considera-se o escoamento em um tubo de raio $R$ e um perfil de velocidade, em vermelho, onde a velocidade na parede é nula e no centro do tubo é máxima.

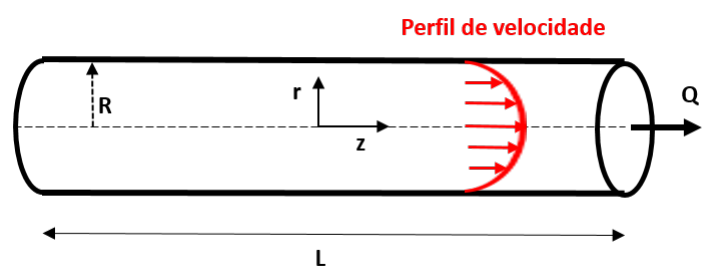

Figura 2.5: Esquema de escoamento em um tubo de raio $R$ mostrando o perfil de velocidade, em cor vermelha.

Com as seguintes premissas:

- Regime permanente e laminar;

- Efeitos gravitacionais desprezados;

$-v_{\theta}$ e $v_{r}=0$

- Simetria circunferencial: $v_{z}=v_{z}(r)$;

- Com a equação da continuidade (Equação 2-26) em coordenadas cilíndricas e as premissas anteriores, $\frac{\partial v_{z}}{\partial z}=0$.

$$
\frac{\partial v_{r}}{\partial r}+\frac{v_{r}}{r}+\frac{1}{r} \frac{v_{\theta}}{\theta}+\frac{v_{z}}{z}=0
$$


Logo temos:

Para direção radial:

$$
\frac{\partial p}{\partial r}=0
$$

Para direção circunferencial:

$$
\frac{\partial p}{\partial \theta}=0
$$

Para direção axial:

$$
\mu\left(\frac{\partial^{2} v_{z}}{\partial r^{2}}+\frac{1}{r} \frac{\partial v_{z}}{\partial r}\right)=\frac{\partial p}{\partial z}
$$

Com a condição de contorno de $v_{z}=0$ em $r=R$ e sabendo que a velocidade no centro deve ser finita, a velocidade é dada por:

$$
u(r)=-\frac{1}{4 \mu} \frac{d p}{d z}\left(R^{2}-r^{2}\right)
$$

A partir da equação da velocidade é possível calcular a vazão volumétrica para este escoamento, conhecida como equação de Hagen-Poiseuille:

$$
q=\int_{A} v_{z} d A=2 \pi \int_{0}^{R} v_{z} r d r=\frac{\pi R^{4}}{8 \mu}\left(-\frac{d p}{d z}\right)
$$

A Figura 2.6 representa uma garganta de poro com raio $R$ e com uma interface de fluido não-molhante e molhante. Considerando os efeitos capilares, podemos calcular a vazão volumétrica de cada fluido (Equações 2-32 e 2-33) a partir da Equação 2-31, assumindo que a vazão é constante ao longo da garganta. 


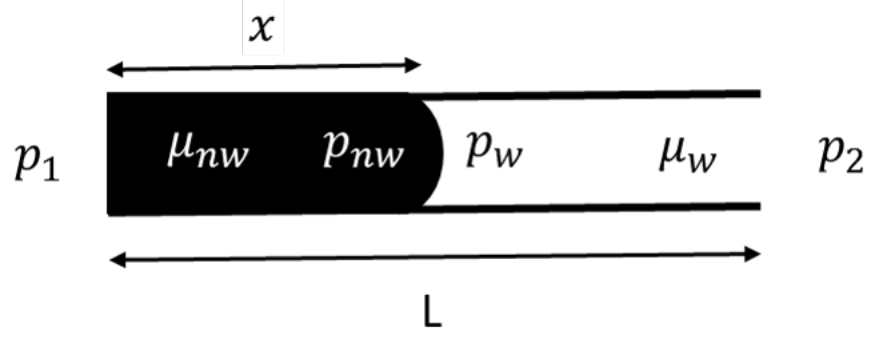

Figura 2.6: Representação de uma garganta de poro de raio $R$ e com uma interface de fluido não-molhante e molhante.

$$
\begin{gathered}
q=\frac{\pi R^{4}}{8 \mu_{n w}}\left(\frac{\Delta p_{n w}}{x}\right) . \\
q=\frac{\pi R^{4}}{8 \mu_{w}}\left(\frac{\Delta p_{w}}{L-x}\right) .
\end{gathered}
$$

A seguir, a Equação 2-34 é utilizada para calcular a variação total de pressão ao longo da garganta, onde $\Delta p_{n w}=p_{n w}-p_{1}, \Delta p_{w}=p_{2}-p_{w}$.

$$
\Delta p=\Delta p_{n w}+\Delta p_{w}-p_{n w}+p_{w}
$$

Como $p_{c}=p_{n w}-p_{w}$

$$
\Delta p=\Delta p_{n w}+\Delta p_{w}-p_{c}
$$

Substituindo as equações 2-32 e 2-33 em 2-35, temos que:

$$
\Delta p=\frac{8}{\pi R^{4}}\left[\mu_{n w} x+\mu_{w}(L-x)\right] q-p_{c}
$$

Logo, é possível se obter a equação de Washburn (Equação 2-37), onde a viscosidade efetiva é dada por $\mu_{e f f}=\mu_{n w} x / L+\mu_{w}(1-x / L)$.

$$
q=\frac{\pi R^{4}}{8 \mu_{e f f}}\left(\frac{\Delta p \pm p_{c}}{L}\right) .
$$




\subsection{4}

\section{Padrões de Escoamento}

O padrão do processo de deslocamento de um fluido em um meio poroso depende de dois números adimensionais: o número de capilaridade e a razão de viscosidade entre as fases.

O número de capilaridade, $\mathrm{Ca}$, representa a razão entre as forças viscosas e as forças capilares e é definido como:

$$
C a=\frac{q \mu_{i n j}}{A \sigma}
$$

onde $\mu_{i n j}$ é a viscosidade do fluido injetado, $q$ é a vazão volumétrica do fluido injetado, $A$ a área transversal ao fluxo e $\sigma$ a tensão interfacial.

A razão de viscosidade é definida como:

$$
M=\frac{\mu_{i n j}}{\mu_{\text {desl }}},
$$

onde $\mu_{i n j}$ é a viscosidade do fluido injetado e $\mu_{\text {desl }}$ é a viscosidade do fluido deslocado.

As três forças principais presentes no fluxo bifásico, considerando escoamento horizontal, são as forças viscosas devido ao fluido injetado, forças viscosas devido ao fluido que está sendo deslocado e forças capilares devido à interface entre fluido injetado e deslocado. Estas são responsáveis pelos diferentes padrões de escoamento observados tanto em experimentos quanto em modelos numéricos.

\subsubsection{1}

\section{Fingering Viscoso}

Neste padrão a principal força é devido a viscosidade do fluido deslocado, fazendo com que os efeitos capilares e a variação de pressão do fluido injetado sejam desprezíveis. A estrutura desses fingers são como raízes de árvores que se espalham por todo o meio poroso e não apresentam loops.

\subsubsection{2}

\section{Fingering Capilar}

O padrão de escoamento com formação de fingers capilares tem as forças capilares da interface entre o fluido injetado e o fluido deslocado como força principal. É caracterizado pelos números de capilaridade baixos nos quais as forças viscosas são desprezíveis. Diferentemente dos fingers viscosos, esses se 
espalham em todas as direções pelo meio poroso, e muitas vezes, se movendo em direção à borda de injeção. Observa-se a formação de loops fazendo com que o fluido deslocado fique imobilizado, o que resulta em uma saturação residual mais alta.

\subsubsection{3}

\section{Deslocamento Estável}

Neste padrão a força principal é devido à viscosidade do fluido injetado, fazendo com que os efeitos capilares e a variação de pressão do fluido deslocado sejam negligenciados. A estrutura do deslocamento é caracterizada por uma frente estável entre o fluido injetado e o fluido deslocado, remanescendo pequenos poros com o último.

\subsubsection{4}

\section{Diagrama de Fases}

O conceito de Diagrama de Fases descrevendo os diferentes padrões de escoamento foi introduzido por Lenormand et al. (14), em 1988. Este apresentava o resultados de diversas simulações e experimentos para números de capilaridades e razões de viscosidade diferentes. Com estes resultados, eles criaram um gráfico no qual o eixo $x$ representa $C a$ e o eixo $y$ representa $M$. Os diferentes padrões de escoamento foram analisados e definidos em regiões no gráfico (Figura 2.7). Além disto, neste estudo foi observado que a mudança na distribuição de tamanho de poros impacta nas fronteiras da região, mas o formato se mantém. De acordo com Aker et al. (9), o fato de o número de capilaridade não levar em conta a distribuição de tamanho de poros, uma análise cuidadosa se faz necessária antes que qualquer diagrama de fases seja desenhado. 


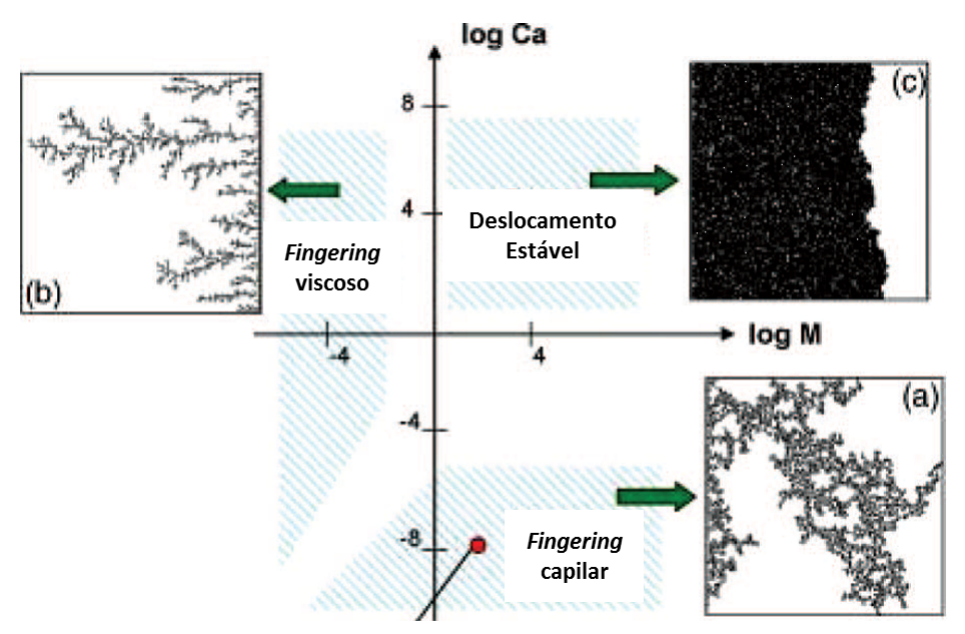

Figura 2.7: Diagrama de Fase do Lenormand mostrando os três diferentes padrões de fluxo para drenagem. Adaptado de Sinha e Wang, 2007 (2).

\subsection{5}

\section{Mecanismos de Deslocamento}

Com as observações através dos experimentos em microfluídica, os estudiosos definiram três mecanismos de deslocamento para o escoamento bifásico: deslocamento pistão, preenchimento de poros e snap-off ou quebra de gotas.

Quando a pressão do fluido injetado é alta o suficiente para que este invada o poro ou a garganta ocorre o deslocamento pistão. Em um deslocamento deste tipo, o fluido injetado empurra de forma uniforme o fluido deslocado, como uma espécie de pistão. Ou seja, a interface entre o fluido não-molhante e molhante é modelada como uma seção transversal à garganta.

Já o preenchimento de poros acontece quando fluido sai da garganta onde está contido, acessando o poro e criando novas interfaces. O preenchimento depende do tamanho do poro e do número de gargantas adjacentes conectadas a este. A Figura 2.8 mostra como o preenchimento pode ser modelado.

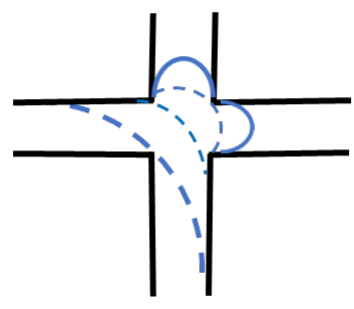

Figura 2.8: Desenho esquemático de como ocorre o preenchimento de poros quando o fluido sai de uma garganta. 
De acordo com Al-Gharbi e Blunt (3), o mecanismo de snap-off ou quebra de gotas é controlado pela fase molhante. Esta fase se acumula em camadas até que o fluido não-molhante não consiga mais ter contato com a parede e, assim, o fluido molhante acessa o centro da garganta, separando o não-molhante em duas gotas. Esta acumulação de fluido molhante em camadas é uma função do ângulo de contato e da relação entre o raio do poro e da garganta. Abaixo, na Figura 2.9, são mostrados o snap-off para drenagem e para embebição.

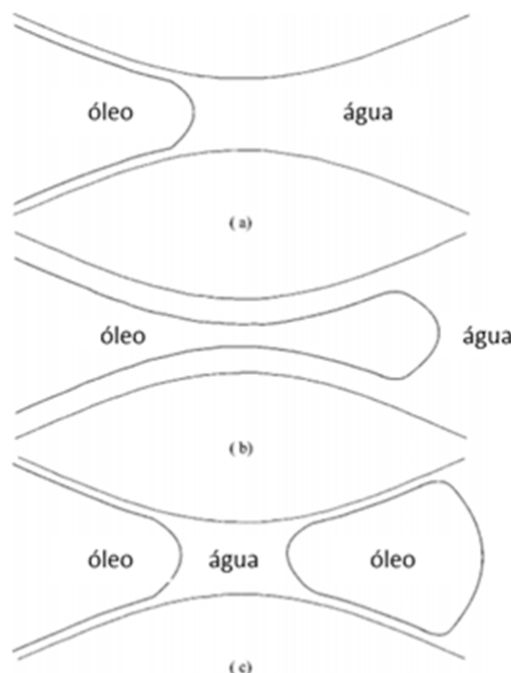

Snap-off na drenagem

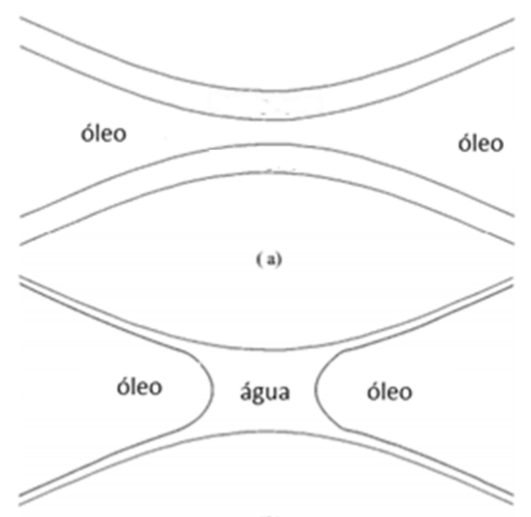

(b)

Snap-off na embebição

Figura 2.9: Desenho esquemático de como ocorre o snap-off para drenagem e para embebição.Para a drenagem: (a) o óleo como fluido não-molhante se aproxima da constrição da garganta; (b) a água como fluido molhante se acumula em camadas até que a pressão capilar caia e o óleo avance; (c) a água separa o óleo em duas gotas. Para embebição:(a) a água como fluido molhante se acumula em camadas na parede; (b)a água separa o óleo, fluido não-molhante, em duas gotas. Adaptado de Al-Gharbi e Blunt, 2005 (3).

\section{3}

\section{Modelos de Rede de Poros}

Diversos estudos relacionados ao comportamento do escoamento de fluidos em microestruturas têm sido desenvolvidos nas últimas décadas. Estes abrangem tanto experimentos a partir da visualização do escoamento em micromodelos como modelagem numérica de rede de poros e gargantas. Esta seção tem como objetivo descrever brevemente, em ordem cronológica, trabalhos realizados levando em conta as duas abordagens citadas anteriormente. 


\subsection{1}

\section{Visualização do Escoamento em Micromodelos}

De acordo com Karadimitriou e Hassanizadeh (15), micromodelos são redes de poros conectados para representação do meio poroso, tipicamente feitos de material transparente e com tamanho menores que $1 \mathrm{~mm}$ para se considerar os efeitos capilares em escoamento multifásico. Experimentos utilizando micromodelos são ferramentas fundamentais para observação do fluxo de fluidos e transporte de solutos em microescala. Diferentes padrões geométricos, métodos e materiais de fabricação são objetos de estudos em diversas áreas de pesquisa a fim de representar de forma melhor a física do escoamento em microporos.

Chatenever e Calhoun (16), em 1952, criaram um dos primeiros micromodelos composto de esferas de vidro empacotadas entre duas placas planas, também de vidro, sobre uma base de lucite. Este, chamado de "célula de observação", foi utilizado para estudo de diferentes regimes de escoamento imiscível de óleo e água. Posteriormente, Bonnet e Lenormand (17), em 1977, utilizaram resina transparente definindo uma geometria retangular para os canais. O fluido molhante era colorido e aparecia em cor preta nas fotografias do escoamento. Com este último tipo de micromodelo, Lenormand, Zarcone e Sarr (18), em 1983, observando as curvaturas das interfaces de fluidos e calculando a pressão capilar através da Lei de Young-Laplace, puderam analisar os mecanismos de deslocamento pistão e snap-off em escoamento bifásico.

Lenormand, Touboul e Zarcone (14), em 1988, conseguiram avançar nas análises tanto para drenagem quanto para embebição com diferentes fluidos. Com a variação do número de capilaridade e razão de viscosidade, três domínios de fluxo foram identificados: deslocamento estável, fingering capilar e fingering viscoso. Este experimento serviu para validar os resultados do simulador numérico desenvolvido por eles. Oren e Pinczewski (19), em 1996, estudaram o escoamento trifásico injetando gás como fluido não-molhante em micromodelo feito com vidro e saturado de óleo e água.

Com o amadurecimento de tecnologias para fabricação de micromodelos houve uma melhora na visualização do fluxo e no entendimento da distribuição dos fluidos no meio poroso. Berejnov, Djilali e Sinton (4), em 2008, criaram um microchip de cinco mil canais feito com polímero polidimetilsiloxano (Figura 2.10) onde puderam investigar o escoamento com efeito de diferentes molhabilidades através de variações do ângulo de contato. 


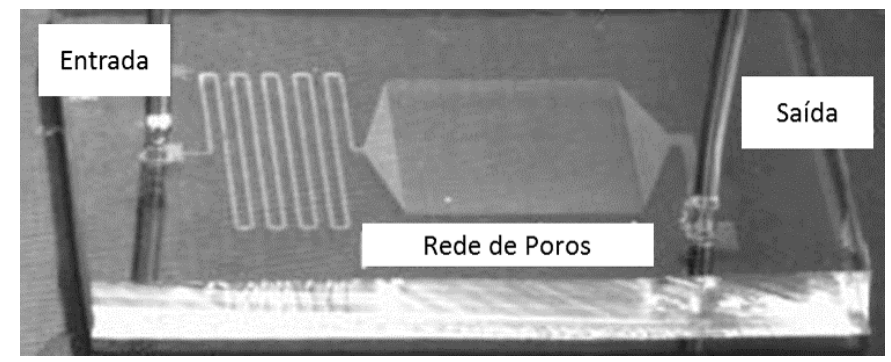

Figura 2.10: Micromodelo utilizado por Berejnov, Djilali e Sinton. Adaptado de Berejnov, Djilali e Sinton, 2008 (4).

Gunda et al. (5), em 2011, criaram o conceito Reservoir-on-a-Chip que consiste em um chip feito de silício e vidro representando um reservatório de petróleo, contendo todas as complexidades estruturais. Sendo assim, é possível correlacionar os resultados dos experimentos feitos no chip com os realizados nos testemunhos do reservatório. Abaixo, a Figura 2.11 mostra todo o processo de fabricação do chip que se inicia em extrair imagens da microestrutura de um testemunho. Em seguida, utiliza-se um software para analisar a imagem, reconstruindo todo espaço poroso em 3D. Com isto, algoritmos fazem a conversão deste modelo em poros e gargantas possibilitando assim, a fabricação dos chips como miniaturas do reservatório.

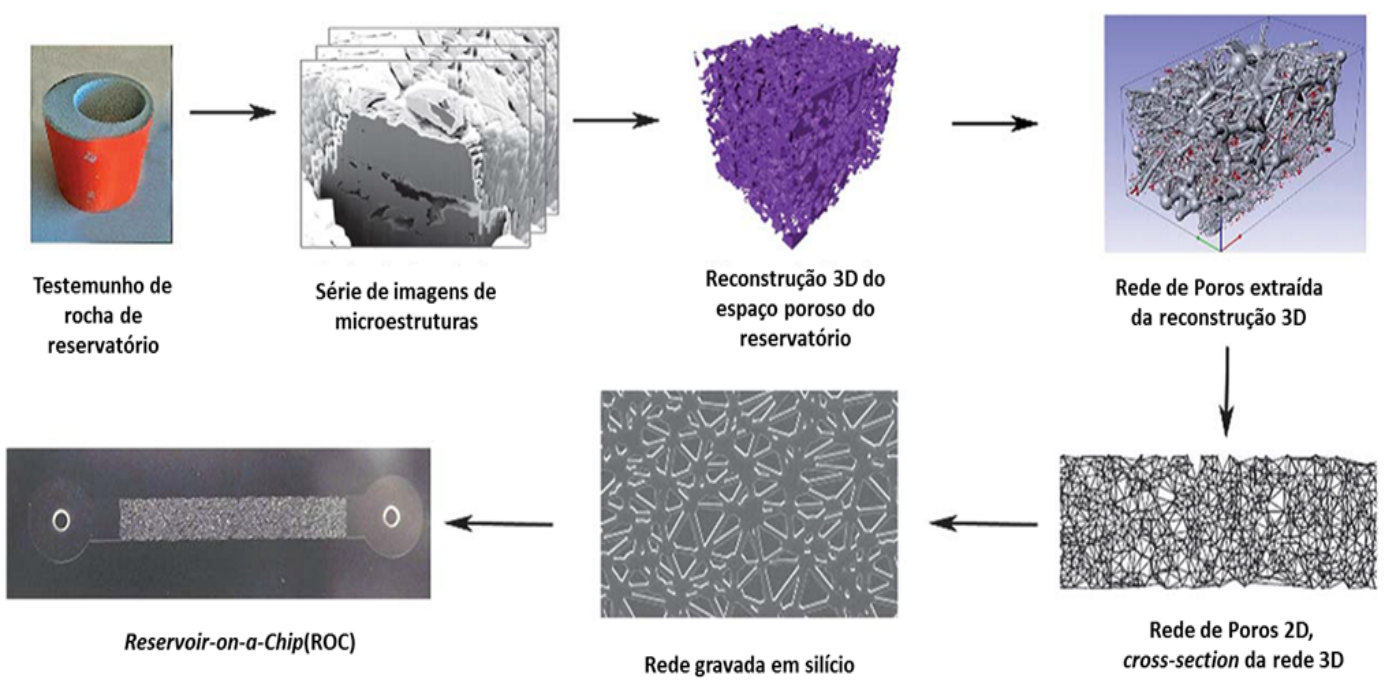

Figura 2.11: Mapa conceitual para construção do Reservoir-on-a-Chip. Adaptado de Gunda et al., 2011 (5).

Também, com a evolução da tecnologia dos micromodelos, estudos relacionados a métodos de recuperação avançados foram realizados. Por exemplo, 
Clarke et al. (20), em 2015, avaliaram a injeção de soluções poliméricas em micromodelos para melhorar o deslocamento de óleo.

\subsection{2}

\section{Modelos Numéricos de Rede de Poros}

Os trabalhos experimentais envolvendo micromodelos agregam grande valor para o estudo do escoamento de fluidos, porém são limitados tanto por conta da complexidade de alguns processos que dificultam medições quanto pelas incertezas dos resultados. Somados a estes problemas, ainda podem atingir tempos e custos elevados. Assim, os modelos numéricos de rede de poros como ferramentas complementares aos experimentos realizados em micromodelos, em algumas vezes, os substituem fornecendo um entendimento mais detalhado dos processos.

Modelos quasi-estáticos com diferentes distribuições de tamanhos de raio de gargantas cilíndricas com arranjos hexagonal, quadrado, hexagonal duplo e hexagonal triplo, conforme mostrado na Figura 2.12, foram propostos por Fatt (6), em 1956. Com isto foi possível analisar curvas de pressão capilar versus saturação de fluido molhante para os diferentes arranjos e estudar o impacto das diferentes distribuições dos tamanhos de raios na curva de pressão capilar.

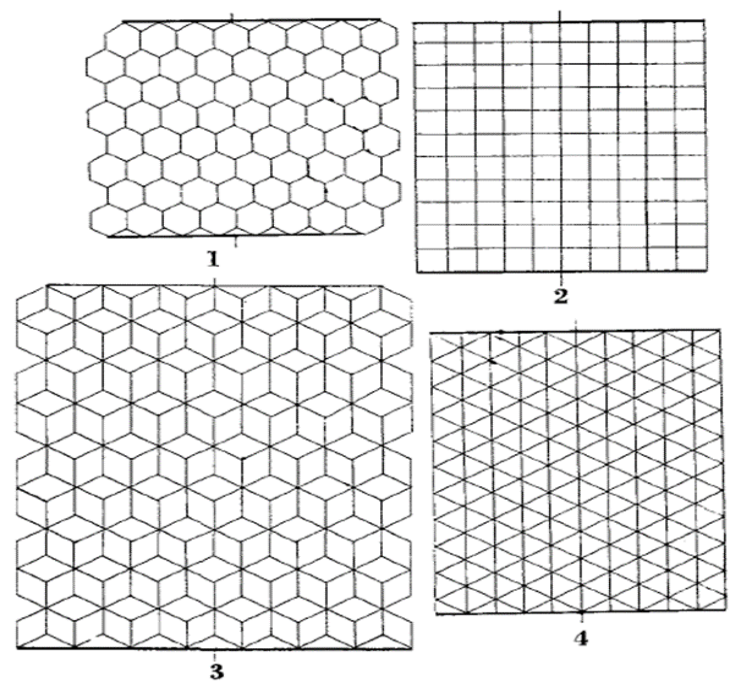

Figura 2.12: Arranjos de rede criados por Fatt(6): (1) Rede hexagonal; (2) Rede quadrada; (3) Rede hexagonal dupla; (4) Rede hexagonal tripla.

Quase trinta anos mais tarde, Koplik e Lasseter (7), em 1985, desenvolveram o primeiro modelo dinâmico de rede de gargantas de poros. Este apresentava poros esféricos de tamanho variável randomicamente, conectados por gargantas cilíndricas, também de raio variável. Eles investigaram as saturações 
residuais no processo de embebição para diferentes números de capilaridade. Além disto, apresentaram um histograma de quantidade bolhas de óleo aprisionado em função do tamanho destas para cada número de capilaridade. A Figura 2.13 mostra o escoamento da rede, considerando um número de capilaridade de $10^{-8}$, onde a água está em cor branca e o óleo em cor preta. O estudo foi limitado a uma rede pequena com centenas de poros devido à problemas computacionais no cálculo numérico relacionado ao capillary pinning. Capillary pinning é o termo utilizado para o evento de uma interface de fluido sair de uma garganta e voltar para mesma, podendo repetir este processo muitas vezes, fazendo com que os modelos fiquem estagnados neste ponto.

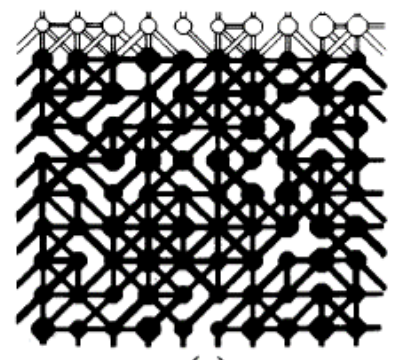

(a)

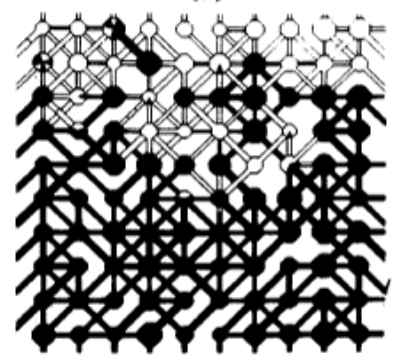

(c)

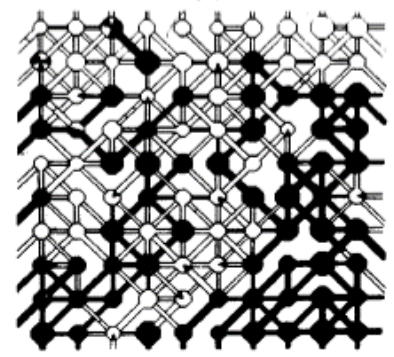

(e)

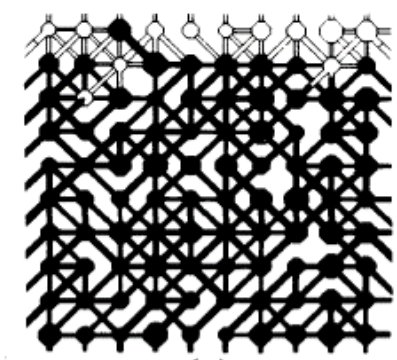

(b)

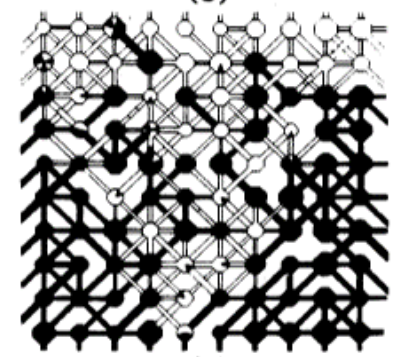

(d)

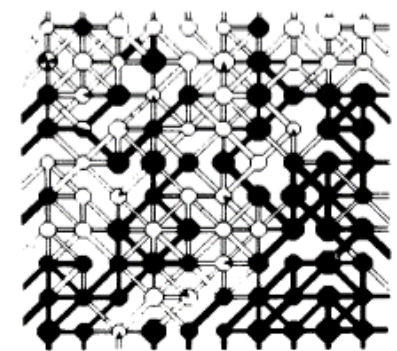

(f)

Figura 2.13: Fluxo de água considerando $C a=10^{-8}$, nos tempos 0, 6.33, 140, 227,432 e no estado final de regime permanente (7).

Dias e Payatakes (8), em 1986, utilizaram um modelo de rede quadrada desenvolvido por Payatakes, Ng e Flumerfelt (21) que contém células de tamanhos variados randomicamente em formato de tubo com constrição para estudo de embebição. Foram realizadas diversas análises quanto à saturação de óleo residual e a quantidade e tamanho de gânglios de óleo remanescentes 
variando número de capilaridade e razão de viscosidade. A Figura 2.14 mostra que a saturação de óleo residual tende a ser menor com o aumento do número de capilaridade e com a diminuição da razão de viscosidade.

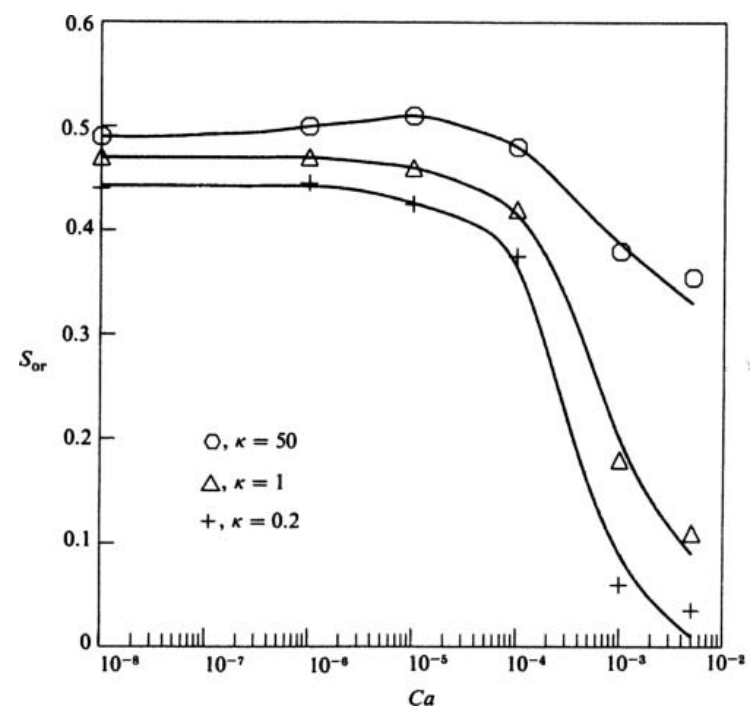

Figura 2.14: Gráfico de saturação de óleo residual versus número de capilaridade, Ca, para embebição em simulações de uma rede 15x30, para valores de razão de viscosidade de 50, 1 e 0.2 (8).

Citados na abordagem experimental descrita na subseção anterior, Lenormand, Touboul e Zarcone (14), em 1988, criaram um modelo bidimensional com poros esféricos e gargantas cilíndricas. O modelo apresentava uma solução não-linear com uma técnica de relaxação ao contrário de resolver uma sequência de equações lineares, como foi feito por Koplik e Lasseter (7) e Dias e Payatakes (8). Isto os permitiu fazer os testes de drenagem em rede de 100x100 para diferentes números de capilaridade e razão de viscosidade gerando o conhecido Diagrama de Fases do Lenormand, Figura 2.7.

Aker et al. (9), em 1996, desenvolveram um simulador bifásico em tubos bidimensionais levando em conta a dinâmica da pressão capilar no processo de drenagem. Com intuito de conseguir uma melhor representação do meio poroso com poros e gargantas de raios de curvatura variáveis e, assumindo molhabilidade perfeita, eles criaram o seguinte modelo para a pressão capilar:

$$
p_{c}=\frac{2 \sigma}{r}\left[1-\cos \left(2 \pi \frac{x}{d}\right)\right]
$$

onde $p_{c}$ é a pressão capilar, $\sigma$ é tensão interfacial entre os dois fluidos, $r$ é o raio de curvatura, $x$ é a posição da interface e $d$ é o comprimento total do tubo. Essas interfaces de fluidos podem se mover para frente ou para 
trás, invadindo ou não o poro. Se a interface se posiciona no início do tubo $(x=0)$ com uma vazão negativa ou no final do tubo $(x=d)$ com uma vazão positiva, o poro correspondente é preenchido e novas interfaces são criadas nas gargantas conectadas a este poro. A Figura 2.15 ilustra o preenchimento de uma garganta e a criação das novas interfaces em cada garganta conectada ao poro que foi preenchido. Cada nova interface é posicionada à uma distância $\delta$ que corresponde de 1 a $5 \%$ do comprimento total da garganta.

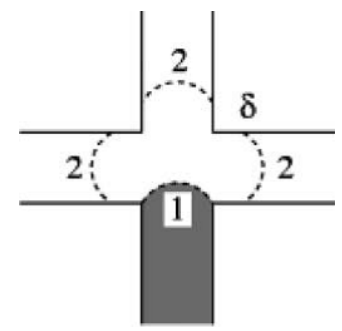

Figura 2.15: Fluido não molhante alcançando o final de uma garganta e três novas interfaces são posicionadas à uma distância $\delta$ do início da garganta (9).

Com a variação do número de capilaridade e razão de viscosidade, os três padrões de escoamento foram observados: fingering viscoso, fingering capilar e deslocamento estável, como pode ser visto na Figura 2.16.

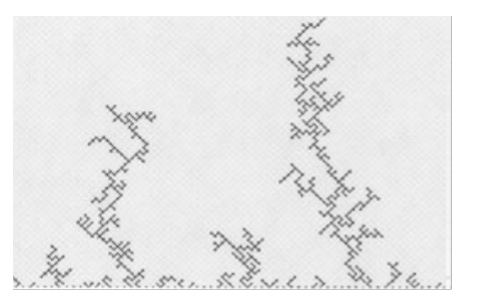

Malha 60x80, Fingering Viscoso $\mathrm{Ca}=4.6 \times 10^{-3}$ e $\mathrm{M}=1.1 \times 10^{-3}$

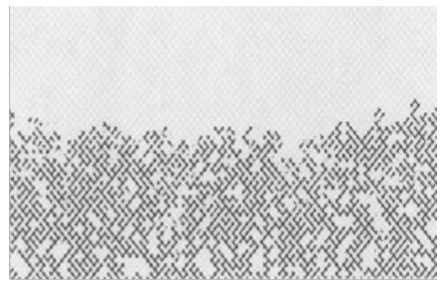

Malha 40x60, Deslocamento Estáve $\mathrm{Ca}=4.6 \times 10^{-3} \mathrm{e} \mathrm{M}=1.1 \times 10^{2}$

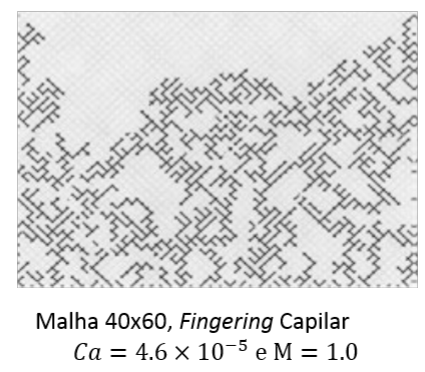

Figura 2.16: Padrões de Escoamento com a variação do número de capilaridade $(C a)$ e razão de viscosidade $(M)$. (Modificada de Aker et al. (9))

Ngueyn et al. (10), em 2004, desenvolveram um modelo dinâmico para estudo dos efeitos da vazão de injeção nos padrões de escoamento em des- 
locamento pistão e snap-off na embebição. Para isto, foram utilizadas três realizações distintas de tamanhos de poros e gargantas de seção transversal quadrada. Este trabalho conclui que a competição entre o deslocamento pistão e o snap-off são dependentes da vazão. Para vazões baixas $\left(C a<10^{-7}\right)$, o tempo de deslocamento seria grande o suficiente para formar filmes mais espessos na rede contribuindo para o snap-off e, por consequência, aumentando a saturação de óleo residual. Para vazões mais altas $\left(C a<10^{-3}\right)$, o tempo de deslocamento seria insuficiente para o espessamento destes filmes, sendo o escoamento dominado pelo deslocamento pistão. E para vazões intermediárias $\left(10^{-6}<C a<10^{-3}\right)$, os dois padrões de escoamento são observados. A Figura 2.17 mostra os padrões de escoamento do fluido molhante, em azul, para os números de capilaridade especificados anteriormente.

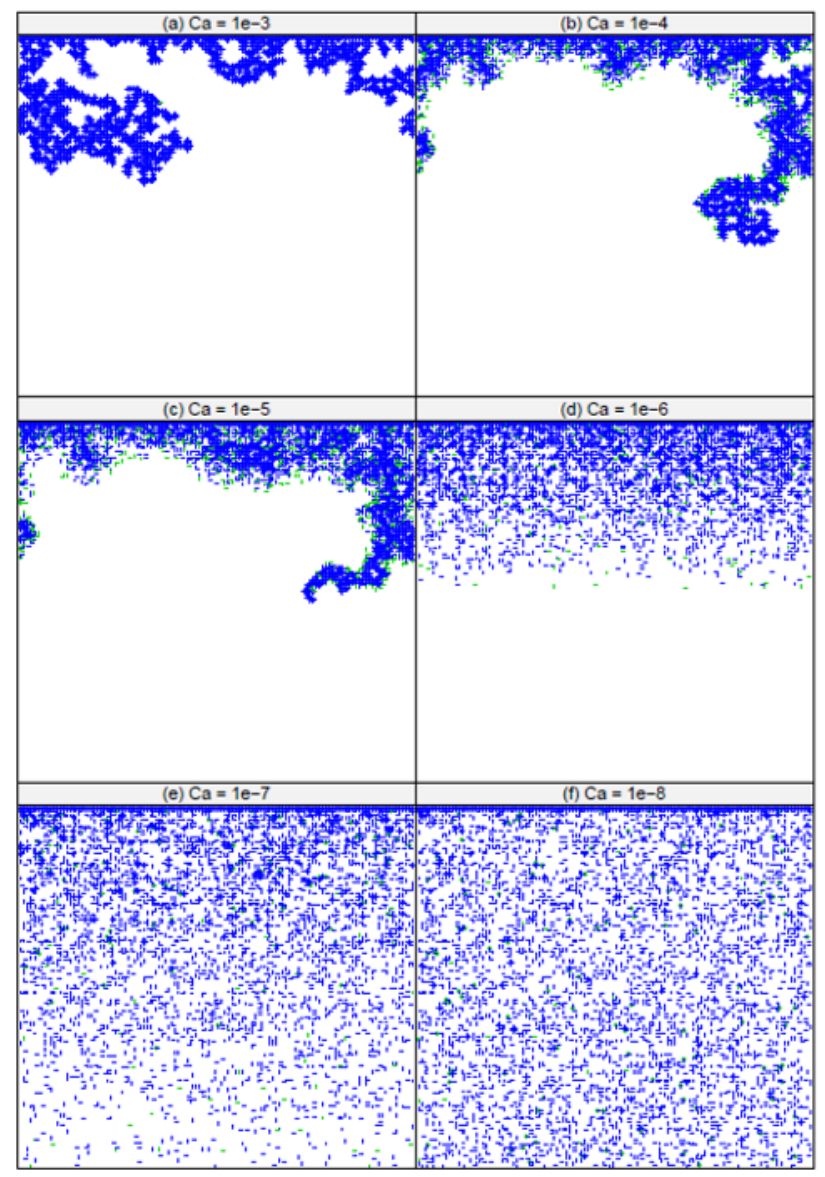

Figura 2.17: Padrões de escoamento para diferentes vazões de injeção, implicando em diferentes números de capilaridade para uma rede 2D (10).

Outro modelo dinâmico de rede para simular escoamento bifásico no meio poroso, levando em conta o snap-off, foi criado por Al-Gharbi e Blunt (3), em 2005. Diferentemente do anterior, este possui poros e gargantas com 
seção transversal triangular e com raio inscrito variando sinusoidalmente. Foram estudados os efeitos da variação de número de capilaridade e razão de viscosidade para o deslocamento por drenagem. A razão de viscosidade definida por eles é diferente da maioria dos pesquisadores, sendo a razão de viscosidade entre o fluido defensor e o invasor. Para números de capilaridade mais baixos $\left(C a \leq 10^{-5}\right)$, o fluido não molhante tende a invadir os poros maiores onde a pressão capilar é mais baixa, sendo equivalente à modelagem quasi-estática. Com o aumento do número de capilaridade, poros e gargantas de todos os tamanhos são invadidos e o deslocamento é menos ramificado. Para número de capilaridade altos e razão de viscosidade menores que 1, o deslocamento possui uma frente estável com muitas quebras de gotas. Com o aumento da razão de viscosidade, ocorrem mais fingers de fluido não molhante, fazendo com que o fluido molhante não tenha tempo suficiente para se acumular e o snap-off ocorre.

Quanto a estudos sobre os efeitos da molhabilidade na recuperação de óleo com injeção de água usando modelo de rede de poros, destaca-se o trabalho de Zhao, Blunt e Yao (22), em 2010. A modelagem foi baseada no imageamento Micro-CT de diferentes tipos de rochas e validada com dados experimentais de um arenito Berea de molhabilidade mista. Os resultados mostraram que em um meio com molhabilidade uniforme, a saturação de óleo diminui quando se torna menos molhável à água e, a recuperação é máxima, quando é molhável à óleo com um ângulo de contato acima de 100 graus. Este efeito, como já foi explicado anteriormente, se deve ao fato de a água tender a escoar pelas camadas molhantes preenchendo os elementos mais constritos causando a quebra de gotas, fazendo com que o óleo fique aprisionado nos poros maiores. Em meios de molhabilidade mista, a fração de óleo como fluido molhante tem um papel fundamental para recuperação do óleo. Quanto menor a fração de água como molhante, maior a recuperação.

Mais recentemente, Wang et al. (23), em 2015, desenvolveram um modelo de rede para escoamento bifásico de embebição levando em conta o deslocamento pistão, espessamento da camada molhante e snap-off. Diferentemente de Ngueyn et al. (10), que considerou a fronteira de saída como impermeável ao fluido molhante provocando um maior espessamento da camada molhante, uma fronteira de saída permeável foi adotada. Esta permitiu o escoamento tanto do fluido molhante quanto o do não molhante, tornando a modelagem mais realista. Como resultado, eles observaram que com o aumento da vazão para um ângulo de contato igual a zero, o snap-off é inibido. Assim, o fluido deslocado com permeabilidades relativas favoráveis permite a diminuição saturação de óleo residual. 


\section{3 \\ Metodologia}

O simulador de rede de poros abordado nesta dissertação foi desenvolvido no software Matlab e permite análises sobre o escoamento bifásico de fluidos tanto para o processo de drenagem quanto para o de embebição, considerando o deslocamento pistão.

Este capítulo descreve a metodologia empregada e se inicia com uma explicação sobre como um meio poroso é transformado em um modelo de rede. A solução para um modelo simples, considerando escoamento monofásico, é mostrada. Após esta etapa, são apresentadas as características geométricas do microchip analisado e como o modelo proposto representa esta geometria e as conexões, através de nós e capilares. O simulador foi desenvolvido de forma a suportar qualquer geometria do espaço poroso, sendo necessário fazer a transformação do mesmo em nós e capilares, além de incluir as informações geométricas. Ao final, descrevemos a modelagem numérica e diagramas de fluxo utilizados para o escoamento bifásico e mudanças na molhabilidade.

\section{1}

\section{Modelagem de Rede de Poros}

A modelagem de rede de poros é uma forma de representar um meio poroso seguindo propriedades geométricas e de conectividade do meio em questão. A Figura 3.1 mostra um exemplo simples de como fazemos esta transformação das características do meio para um modelo de rede de poros. 


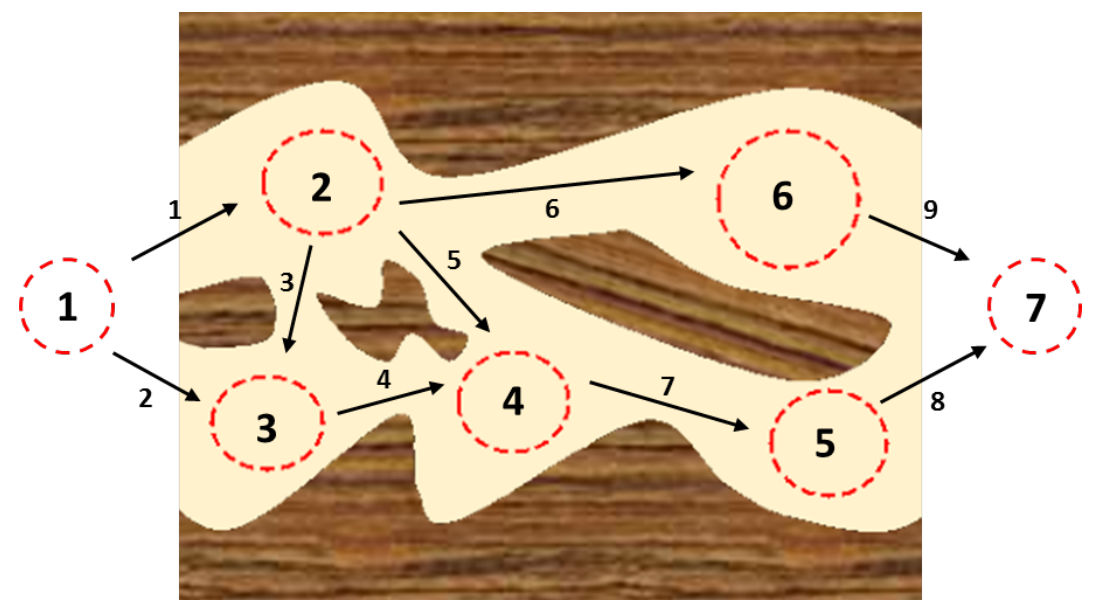

Figura 3.1: Modelo de Rede de Poros e Gargantas. Os poros estão representados como os círculos vermelhos tracejados e suas numerações se encontram no centro deste círculo. As gargantas são as setas pretas com suas numerações correspondentes. A ponta da seta indica o sentido de conexão da garganta que conecta dois poros. Os poros 1 e 7 são a entrada e a saída do escoamento respectivamente.

No modelo de rede, os poros são definidos por nós e suas conexões por capilares ou gargantas. No exemplo da Figura 3.1, temos 7 nós e 9 capilares. Para o entendimento da solução do modelo, mostramos inicialmente uma simplificação do problema, tratando como escoamento monofásico. Consideramos uma vazão de entrada imposta e uma pressão de saída conhecida. Através do cálculo de vazões nos capilares e conservação de massa nos nós, calculamos a pressão em cada nó como resultado de um sistema linear.

A vazão dos capilares é uma função linear da diferença de pressões entre os nós conectados pelo capilar:

$$
q_{k}=G_{k}\left(P_{n}-P_{m}\right)
$$

onde $n, m$ e $k$ são índices que indicam o nó de entrada do capilar, o nó de saída do capilar e o capilar, respectivamente. $G_{k}$ é a condutância do capilar.

No caso de um capilar de seção reta circular, a vazão é definida pela equação de Hagen-Poiseuille, Equação 2-31. Logo, podemos extrair a condutância, G, como:

$$
G_{k}=\frac{\pi R_{k}^{4}}{8 \mu_{k} L_{k}}
$$


onde $R$ é o raio do capilar, $\mu$ a viscosidade do fluido e $L$ o comprimento do k-ésimo capilar.

Para representar a conectividade da rede, definimos a matriz de incidência $C_{n \times m}$, onde $n$ é o número de nós e $m$ é o número de capilares, como:

$$
C_{n \times m}=\left\{\begin{aligned}
0, & \text { se o capilar } m \text { não está conectado ao nó } n \\
+1, & \text { se o capilar } m \text { sai do nó } n \\
-1, & \text { se o capilar } m \text { entra no nó } n .
\end{aligned}\right.
$$

Assim, para a rede do exemplo composta de 7 nós e 9 capilares, temos:

$$
C=\left[\begin{array}{rrrrrrrrr}
1 & 1 & 0 & 0 & 0 & 0 & 0 & 0 & 0 \\
-1 & 0 & 1 & 0 & 1 & 1 & 0 & 0 & 0 \\
0 & -1 & -1 & 1 & 0 & 0 & 0 & 0 & 0 \\
0 & 0 & 0 & -1 & -1 & 0 & 1 & 0 & 0 \\
0 & 0 & 0 & 0 & 0 & 0 & -1 & 1 & 0 \\
0 & 0 & 0 & 0 & 0 & -1 & 0 & 0 & 1 \\
0 & 0 & 0 & 0 & 0 & 0 & 0 & -1 & -1
\end{array}\right]_{7 \times 9}
$$

Dado uma matriz $P_{n \times 1}$ que representa as pressões em cada nó. Para calcular a diferença de pressão em cada capilar, temos que:

$$
C^{T} P=\left[\begin{array}{rrrrrrr}
1 & -1 & 0 & 0 & 0 & 0 & 0 \\
1 & 0 & -1 & 0 & 0 & 0 & 0 \\
0 & 1 & -1 & 0 & 0 & 0 & 0 \\
0 & 0 & 1 & -1 & 0 & 0 & 0 \\
0 & 1 & 0 & -1 & 0 & 0 & 0 \\
0 & 1 & 0 & 0 & 0 & -1 & 0 \\
0 & 0 & 0 & 1 & -1 & 0 & 0 \\
0 & 0 & 0 & 0 & 1 & 0 & -1 \\
0 & 0 & 0 & 0 & 0 & 1 & -1
\end{array}\right]_{9 \times 7} \times\left[\begin{array}{c}
P_{1} \\
P_{2} \\
P_{3} \\
P_{4} \\
P_{5} \\
P_{6} \\
P_{7}
\end{array}\right]_{7 \times 1}=\left[\begin{array}{c}
P_{1}-P_{2} \\
P_{1}-P_{3} \\
P_{2}-P_{3} \\
P_{3}-P_{4} \\
P_{2}-P_{4} \\
P_{2}-P_{6} \\
P_{4}-P_{5} \\
P_{5}-P_{7} \\
P_{6}-P_{7}
\end{array}\right]_{9 \times 1}=\Delta P_{9 \times 1}
$$

onde $C^{T}$ é a transposta da matriz de incidência.

Definimos $G_{m \times m}$ uma matriz diagonal com os valores das condutâncias de cada capilar e, através da Equação 3-1, calculamos a vazão nos capilares:

$$
q=G C^{T} P=G \Delta P
$$

Aplicando a lei de conservação de massa em cada nó da rede e considerando $q<0$ para vazão do capilar que entra no nó e $q>0$ para vazão do capilar que sai do nó, temos: 


$$
C q=0
$$

Desconsiderando as condições das bordas e substituindo a Equação 3-5 na Equação 3-6, obtemos o sistema linear escrito na forma matricial:

$$
C G C^{T} P=0 .
$$

Generalizando e tratando as condições dos extremos de acordo com a situação a ser estudada, escrevemos $A P=b$ na qual $A=C G C^{T}$.

\subsection{1}

\section{Especificações do Microchip e o Modelo de Poros}

O microchip foi construído pela Dolomite Microfluidics como uma representação de um meio poroso para estudos experimentais de escoamento. Sua fabrição em vidro transparente possibilita uma boa visualização do fluxo por microscópios, conforme mostrado na Figura 3.2.

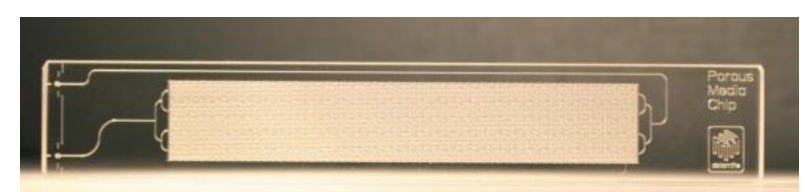

Figura 3.2: Microchip desenvolvido pela Dolomite Microfluidics (11)

O dispositivo é composto de microcanais constritos interconectados modelando gargantas e poros. O corpo do microchip contém uma área porosa de 10 x $60 \mathrm{~mm}$ e, em suas extremidades, conjuntos de canais controlam a vazão de entrada e saída de fluidos (Figura 3.3). 


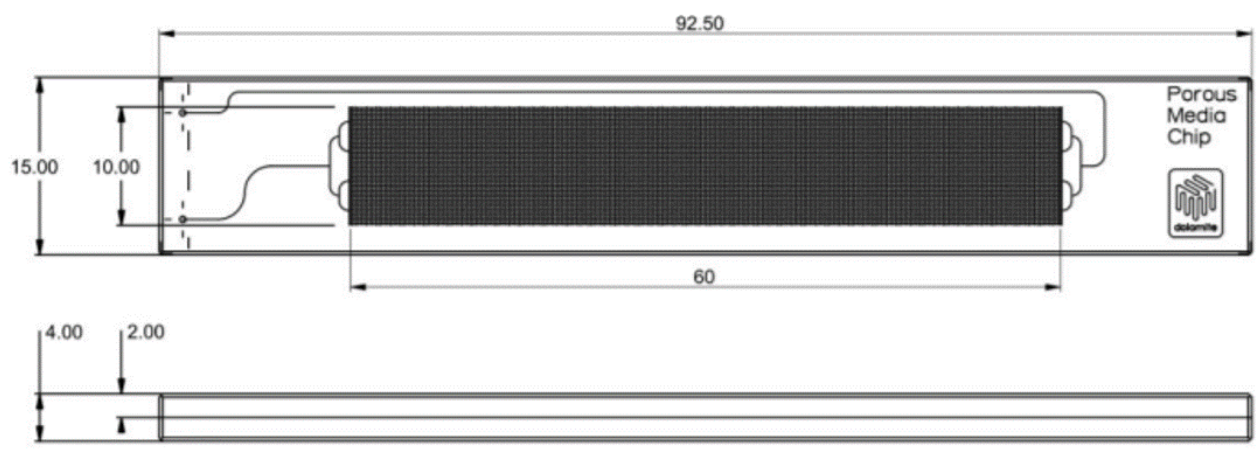

Figura 3.3: Dimensões do microchip desenvolvido pela Dolomite Microfluidics (11)

Todos os canais possuem seção transversal elíptica com altura de $100 \mu \mathrm{m}$ e largura de $110 \mu \mathrm{m}$. Além disto, a área porosa é dividida em malhas de $8 \times 8$, com dimensão $2 \times 2 \mathrm{~mm}$, que se repetem 150 vezes no chip. Segundo o fabricante, o padrão de constrições dos canais na malha é definido aleatoriamente. A foto tirada do microscópio (Figura 3.4a) indica a constrição de cada canal deste grid. Os canais em vermelho possuem constrição de $63 \mu m$, os de cor verde com $85 \mu m$ e os azuis não possuem constrição (Figura 3.4b). A distância entre dois canais é de $250 \mu m$. 
(a)

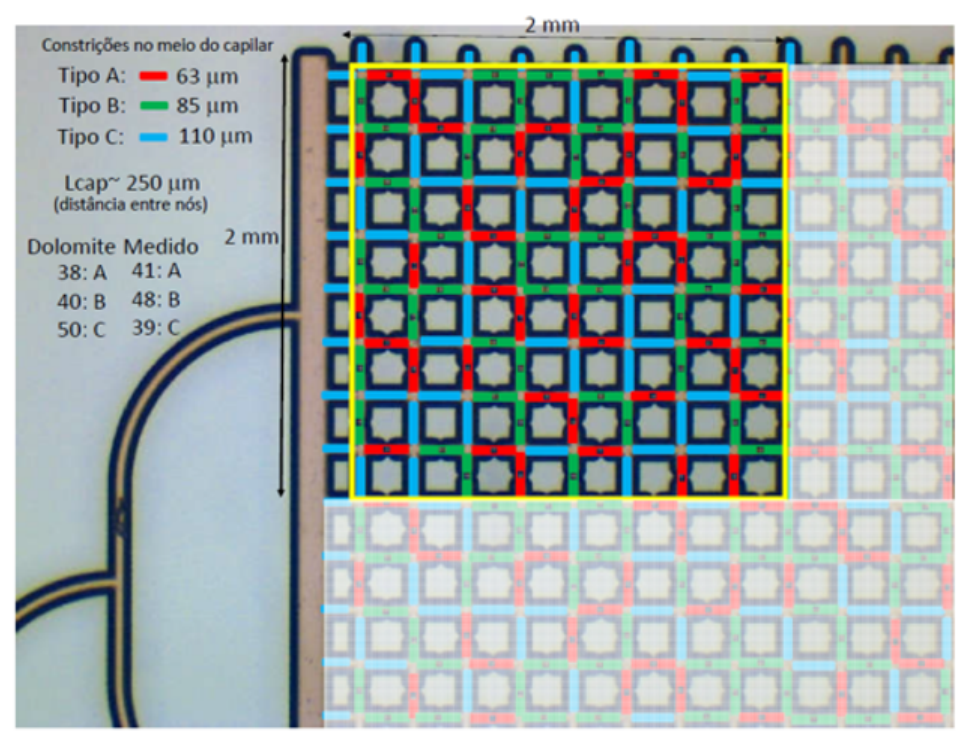

(b)
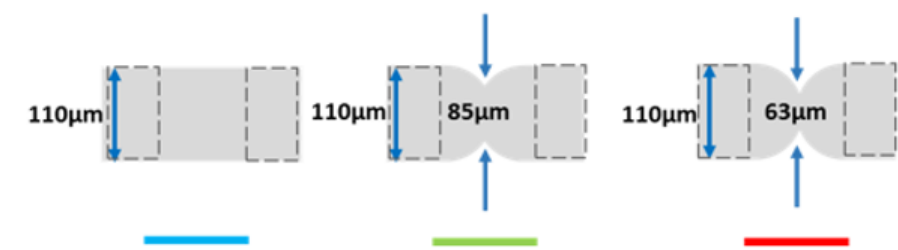

Figura 3.4: (a) Imagem do microchip tirada do microscópio. Destacado pelo quadrado amarelo, o padrão de grid de 8 x 8 que se repete pela área porosa. (b) Os canais em vermelho possuem constrição de $63 \mu m$, os de cor verde com $85 \mu m$ e os azuis não possuem constrição.

A representação do microchip em modelo de poros é mostrada na Figura 3.5. Os círculos em azul representam os poros e os capilares são as retas em cor cinza. A numeração dos nós estão em preto e a dos capilares em vermelho. Esta numeração é utilizada em uma matriz que chamamos de CapilarInOut, $m \times 2$, na qual as colunas indicam o nó de entrada e o nó de saída de cada capilar. Neste modelo temos uma malha $240 \times 40$ somando um total de 9603 capilares. 


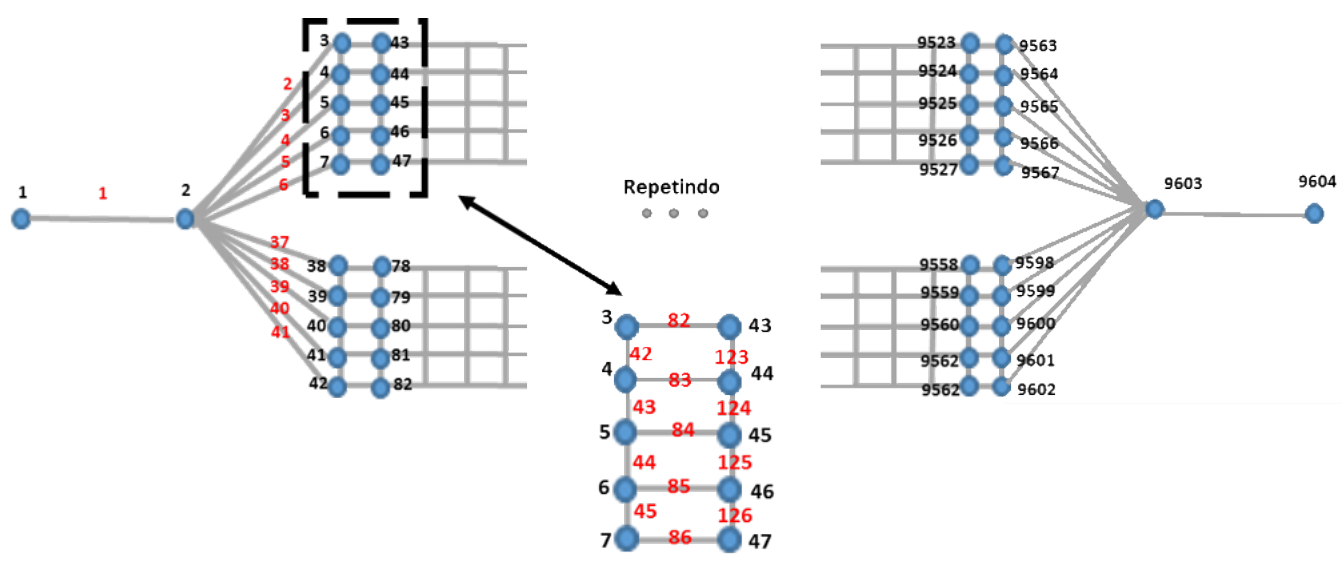

Figura 3.5: Representação do microchip através do modelo de rede

Para representação geométrica do microchip utilizamos a fotografia do microscópio (Figura 3.4), criamos uma matriz $8 \times 8$ com os valores dos raios de constrição dos capilares na horizontal e a outra $8 \times 8$ com os valores dos raios de constrição na vertical. Assim, extraímos o padrão do chip e, através do algoritmo CapilarRadius, obtivemos os raios de constrição para todos os capilares, conforme mostrado na Figura 3.6. A distância entre dois poros, L, é de $250 \mu m$ e os poros são considerados sem volume. 


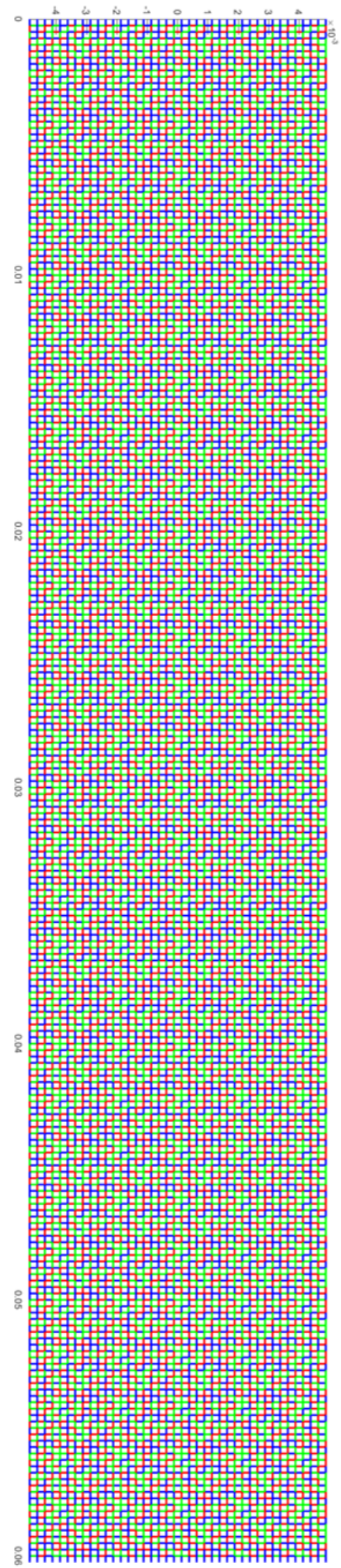

Figura 3.6: Imagem do modelo de rede construído através da repetição do grid padrão obtido pela fotografia do microscópio. Os canais em vermelho possuem constrição de $63 \mu m$, os de cor verde com $85 \mu m$ e os azuis não possuem constrição. 


\subsection{2}

\section{Modelagem Numérica}

Este estudo trata o escoamento de dois fluidos imiscíveis e de viscosidades diferentes. O modelo de rede é preenchido inicialmente com um fluido 1, óleo, sendo deslocado pela injeção de um fluido 2, a água. Diferentemente do escoamento monofásico, visto na Subseção 3.1, no fluxo bifásico os efeitos capilares apresentam grande relevância para o entendimento dos padrões de escoamento desenvolvidos pelos fluidos.

O simulador segue uma modelagem dinâmica na qual a vazão de injeção constante é imposta e a pressão de saída é zero. Com isto, as pressões entre os nós, pressões capilares e as condutâncias são calculadas a cada passo tempo e, através da conservação de massa, temos as vazões em cada capilar. Estas são utilizadas para o cálculo do deslocamento das interfaces de fluidos ao longo da rede. Conhecendo o posicionamento das interfaces, obtemos a saturação em cada capilar.

O mecanismo de deslocamento utilizado é o deslocamento pistão, não sendo capaz de simular a presença simultânea das fases em uma mesma seção transversal. Além disto, o fluxo ocorre somente em capilares, sendo o volume dos nós desconsiderados para análise. Os nós são saturados imediatamente após uma interface alcançar uns dos extremos do capilar.

O processo de drenagem e embebição é controlado pela ângulo de contato, $\theta$, entre o fluido que satura inicialmente o modelo de rede e a parede do capilar. Se for drenagem, processo em que o fluido não-molhante desloca o molhante, consideramos $\theta=0$, perfeitamente molhante. Para embebição, o fluido molhante desloca o não-molhante, $\theta=\pi$, perfeitamente não-molhante.

Na Figura 3.7, mostramos um fluxograma para uma visão geral dos processos envolvidos na simulação do escoamento no modelo de rede. 


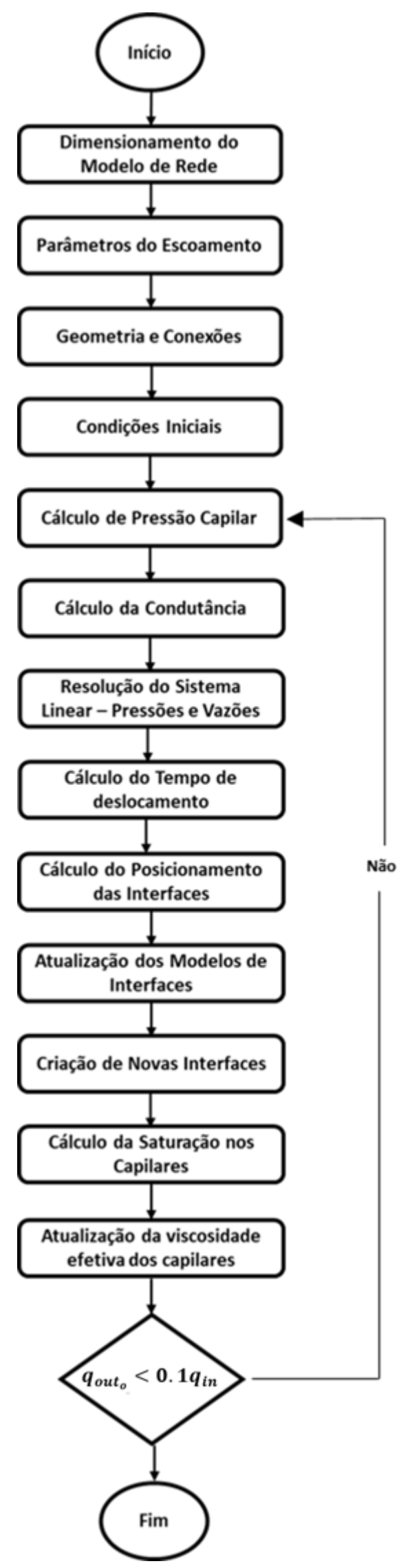

Figura 3.7: Fluxograma da Simulação de Rede de Poros 
O simulador permite a criação de até três interfaces nos capilares. A seguir, na Figura 3.8, são mostrados os diferentes modelos de interfaces possíveis. A letra $\mathrm{O}$ e $\mathrm{W}$ indicam a presença da fase óleo e água, respectivamente. Ninterfaces é o número de interfaces do capilar e InterfaceModel indica o modelo de interface para cada interface presente no capilar. Os índices de 1 a 3 são referências às 3 interfaces.
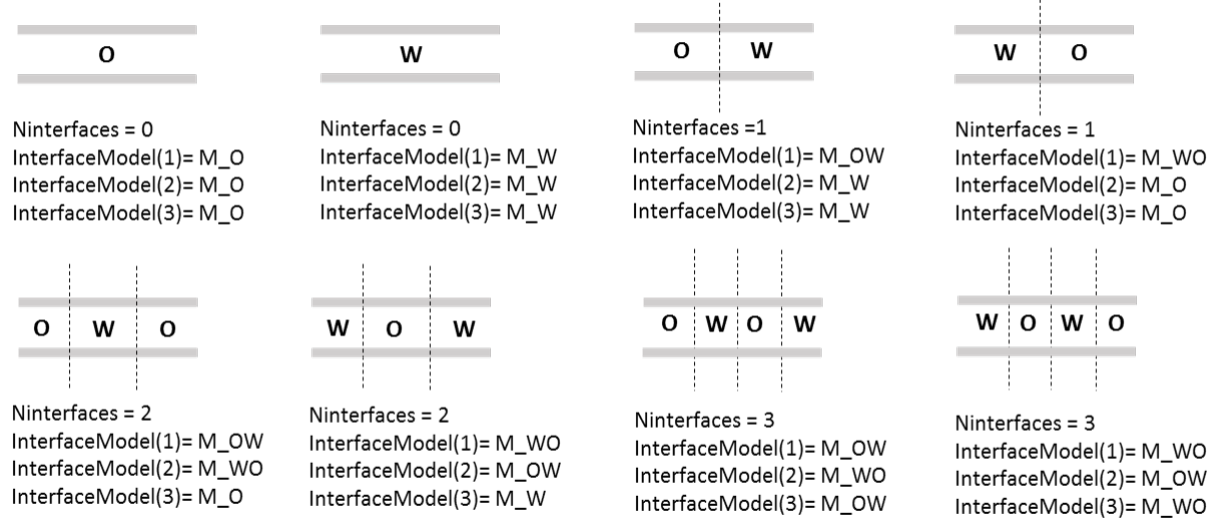

Figura 3.8: Modelos de Interfaces. A letra $\mathrm{O}$ e W indicam a presença da fase óleo e água, respectivamente. Ninter faces é o número de interfaces do capilar e InterfaceModel indica o modelo de interface para cada interface presente no capilar. Os índices de 1 a 3 são referências às 3 interfaces.

\subsubsection{1}

\section{Dimensionamento do Modelo de Rede e Parâmetros do Escoamento}

Para o dimensionamento do modelo de rede de poros definimos os seguintes parâmetros (Tabela 3.1):

Tabela 3.1: Parâmetros para o dimensionamento da rede de poros

\begin{tabular}{|c|c|c|}
\hline Parâmetro & Definição & Valor \\
\hline$N_{x}$ & Número de nós na direção horizotal & $240 \times$ escala \\
\hline$N_{y}$ & Número de nós na direção vertical & $40 \times$ escala \\
\hline$L$ & Comprimento do capilar & $250 \times 10^{-6} m$ \\
\hline$L_{x}$ & Dimensão horizontal total & $L \times\left(N_{x}+1\right)$ \\
\hline$L_{y}$ & Dimensão vertical total & $4 \times\left(N_{y}-1\right)$ \\
\hline$N_{n o ́}$ & Número de nós & $4+N_{x} \times N_{y}$ \\
\hline$N_{c a p}$ & Número de capilares & $2+\left(N_{y}-1\right) \times N_{x}+\left(N_{x}+1\right) \times N_{y}$ \\
\hline$S$ & Área transversal & $L_{y} \times 1 \times 10^{-4}$ \\
\hline
\end{tabular}

A escala, que varia de 0.1 a 1 , permite simular um percentual da área total do microchip. A tensão interfacial $(\sigma)$, viscosidades dos fluidos $\left(\mu_{w}\right.$ e $\left.\mu_{o}\right)$ 
e número de capilaridade $(C a)$ são os parâmetros do escoamento definidos pelo usuário do simulador. A vazão imposta é calculada como $q_{i n}=\sigma \times S \times C a / \mu_{w}$.

\subsubsection{2}

\section{Geometria , Conexões e Condições Iniciais}

Como dito na Subseção 3.1.1, os raios da constrição dos capilares para todo o modelo de rede foi construído a partir de uma matriz $8 \times 8$ representando um grid padrão.

Como a seção reta do capilar é elíptica, calculamos um raio circular equivalente a fim de aplicar a equação de Hagen-Poiseuille. Para os capilares sem constrição, o raio equivalente é dado utilizando conceito de raio hidráulico:

$$
R_{h}=\frac{2 A}{P}
$$

onde $R_{h}$ é o raio hidráulico, $A$ e $P$ são a área e o perímetro da elipse, respectivamente.

O raio dos capilares com constrição varia ao longo do comprimento $L$. Assim, propomos o cálculo de um raio hidráulico equivalente. Considerando escoamento desenvolvido e com raio variando ao longo do tubo, temos que:

$$
\int q d z=\int \frac{\pi R(z)^{4}}{8 \mu} \frac{d p}{d z} d z
$$

Resolvendo a integral, obtemos que $\Delta p=\frac{8 \mu q L}{\pi R_{m}^{4}}$ onde $R_{h e}$ é o raio hidráulico equivalente. Para um raio constante, $\Delta p=\frac{8 \mu q}{\pi} \int \frac{d z}{R^{4}}$. Igualando as duas expressões para $\Delta p$, obtemos:

$$
R_{h e}=\left(\frac{L}{\int_{0}^{L} \frac{d z}{R^{4}}}\right)^{1 / 4} .
$$

Na Figura 3.9 podemos observar que o capilar possui um determinado comprimento em que o raio não é afetado pela constrição, $R=R_{h}$ e um outro em que é afetado. Assim, resolvemos a integral $\int_{0}^{L} \frac{d z}{R^{4}}$, somando a integral relacionada ao comprimento onde o raio não é afetado à integral relacionada ao comprimento onde o raio é afetado. Esta última é solucionada através de 
um processo numérico dividindo o comprimento afetado pela constrição, $L_{\text {const }}$, em intervalos de comprimento $d z$.

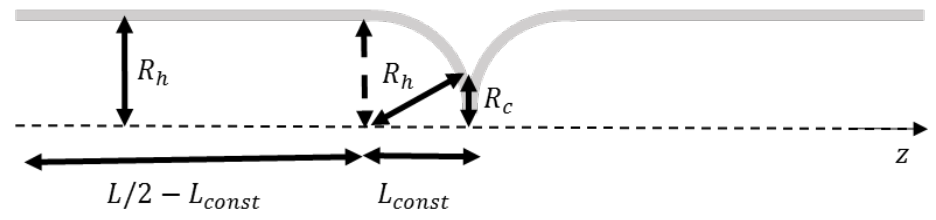

Figura 3.9: Representação de um capilar com constrição. Podemos observar o comprimento em que o raio do capilar não é afetado pela constrição, $L / 2-L_{\text {const }}$, e o comprimento em que é afetado, $L_{\text {const }}$. $R_{c}$ é o raio da constrição.

As coordenadas $x$ e $y$ de cada nó da rede são definidas sendo a origem de $x$ em $L_{x}=0$ e a origem de $y$ em $L_{y} / 2$, positivo em direção à parte superior do modelo de rede e negativo em direção à parte inferior (Figura 3.6).

Para representação da conexão de capilares aos nós, definimos a matriz de incidência conforme descrito na Subseção 3.1:

$C_{n \times m}=\left\{\begin{aligned} 0, & \text { se o capilar } m \text { não está conectado ao nó } n \\ +1, & \text { se o capilar } m \text { sai do nó } n \\ -1, & \text { se o capilar } m \text { entra no nó } n\end{aligned}\right.$

As condições iniciais do modelo de poros são:

- Nós e capilares são totalmente saturados com óleo, sendo a saturação de água igual a zero;

- Ninterfaces, número de interfaces, igual a zero;

- InterfaceModel, modelo de interface, igual a M_O;

- $x$ indica o posicionamento das interfaces nos capilares. Abaixo, na Figura 3.10, mostramos o posicionamento inicial das três interfaces tanto para os capilares na horizontal quanto para vertical:

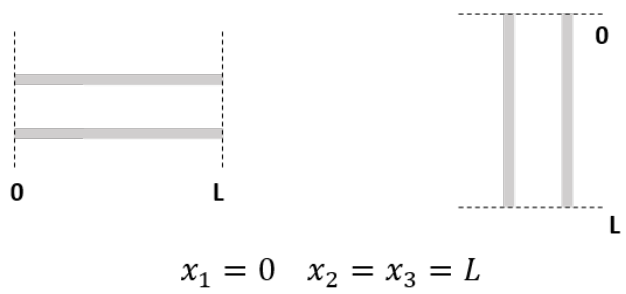

Figura 3.10: Posicionamento das interfaces. $x$ indica o posicionamento das interfaces nos capilares. Os índices de 1 a 3 são referências às 3 interfaces. 
- Nó de entrada saturado de água;

- Primeiro capilar com Ninterfaces $=1$, InterfaceModel $(1)=M \_W O$ e $x_{1}=L-d n$, sendo $d n=L \times 0.01$;

- A saturação do primeiro capilar é igual a $x_{1} / L$;

- A viscosidades efetiva dos capilares é definida como:

$$
\mu_{e f f}=S a t_{c a p} \times \mu_{w}+\left(1-S a t_{c a p}\right) \times \mu_{o}
$$

onde $\mu_{\text {eff }}$ é a viscosidade efetiva e $S a t_{c a p}$ é a saturação do capilar, sendo 0 para totalmente saturado de óleo e 1 para totalmente saturado de água.

\subsubsection{3}

\section{Cálculo da Pressão Capilar e Condutância}

O modelo de pressão capilar sugerido por Aker et al. (9), em 1996, define a pressão capilar em função do posicionamento da interface, com a pressão capilar máxima de módulo $4 \sigma / R$ no centro do capilar, e nos extremos, nula. Se considerássemos este modelo, o valor de pressão capilar máximo, mesmo para o raio sem constrição, excederia o valor máximo real nos capilares do microchip. Assim, propomos o seguinte modelo de pressão capilar:

$$
P_{\text {cap }}=\frac{2 \sigma}{R_{c}} \sin \left(\frac{\pi x}{L}\right)
$$

onde $P_{\text {cap }}$ é a pressão capilar e $R_{c}$ o raio da constrição.

Na Figura 3-12, mostramos a curva da pressão capilar variando com a posição da interface. No centro do capilar, seu módulo apresenta o valor de $2 \sigma / R_{c}, \operatorname{com} R_{c}=42.5 \times 10^{-6} \mathrm{~m}$.

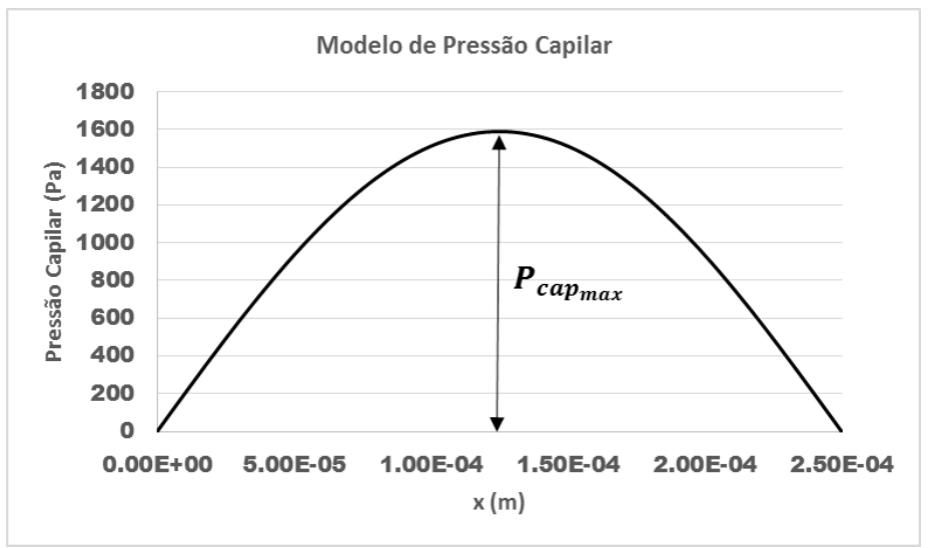

Figura 3.11: Curva da pressão capilar variando com a posição da interface, sendo o módulo no centro do capilar igual a $2 \sigma / R_{c}$ e $R_{c}=42.5 \times 10^{-6} \mathrm{~m}$ 
O sinal da pressão capilar depende do modelo de interface. Se a interface for fluido molhante/fluido não-molhante, a pressão capilar é positiva, se for o contrário, fluido não-molhante/fluido molhante, é negativa. Para o cálculo da pressão capilar total, somamos as pressões capilares de cada interface, $P_{\text {cap } p_{\text {total }}}=P_{c a p_{1}}+P_{c a p_{2}}+P_{c a p_{3}}$. A Figura 3.12 mostra dois exemplos de cálculo de pressão capilar total, considerando o óleo como fluido molhante.

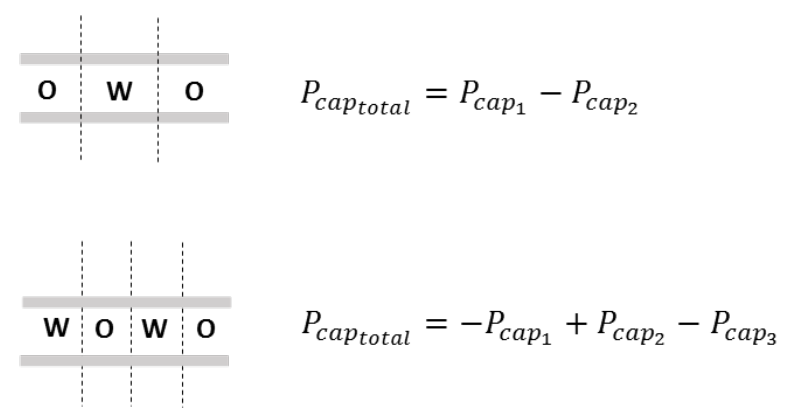

Figura 3.12: Cálculo de pressão capilar total considerando diferentes números de interfaces e óleo como fluido molhante.

A condutância, G, é definida por:

$$
G=\frac{\pi R_{h e}^{4}}{8 \mu_{e f f} L}
$$

\subsubsection{4}

\section{Cálculo de Pressões e Vazões}

Diferentemente do cálculo de vazão que descrevemos para o fluxo monofásico na Subseção 3.1, no escoamento bifásico utilizamos a Equação de Washburn para incorporar os efeitos capilares (Equação 2-37). Na forma matricial, temos que:

$$
q=G \Delta P=G C^{T} P+G P_{\text {cap }} .
$$

Substituindo a Equação 3-14 na equação de conservação de massa, Equação 3-6, incluímos os efeitos capilares no cálculo de vazão dos nós. Observando a Equação 3-15, podemos notar que esta representa o sistema linear $A P=b$ descrito na Subseção 3.1.

$$
C G C^{T} P=-C G P_{\text {cap }}
$$


Aplicando a condição inicial de vazão imposta igual a $q_{i n}$, temos que o primeiro elemento da matriz b é igual a $-C G P_{c a p}+q_{i n}$. Para garantir uma pressão de saída igual a 0 , modificamos a última linha da matriz $\mathrm{A}$, impondo valor zero para todos os elementos exceto para o elemento relativo ao último nó, que tem valor 1. Também, colocamos a última linha da matriz b, relativa ao último nó, com valor 0 . Resolvendo o sistema, obtemos as pressão em cada nó do modelo. Conhecidas as pressões em cada nó, pressão capilar, matriz de incidência e a condutância, utilizamos a Equação 3-14 para o cálculo das vazões em cada capilar.

\subsubsection{5}

\section{Cálculo do Tempo de Deslocamento e Posicionamento das Interfaces}

Uma melhor escolha do passo de tempo determinado para cada iteração no simulador permite tratar problemas de convergência nas soluções do escoamento. De acordo com Aker et al. (9), a distância máxima de deslocamento de uma interface seria de $1 \%$ para garantir uma boa convergência e estabilidade numérica. A Figura 3.13 mostra a pressão em função do tempo para diferentes valores de percentuais de deslocamento, mostrando suavidade quando o deslocamento máximo é de $1 \%$.

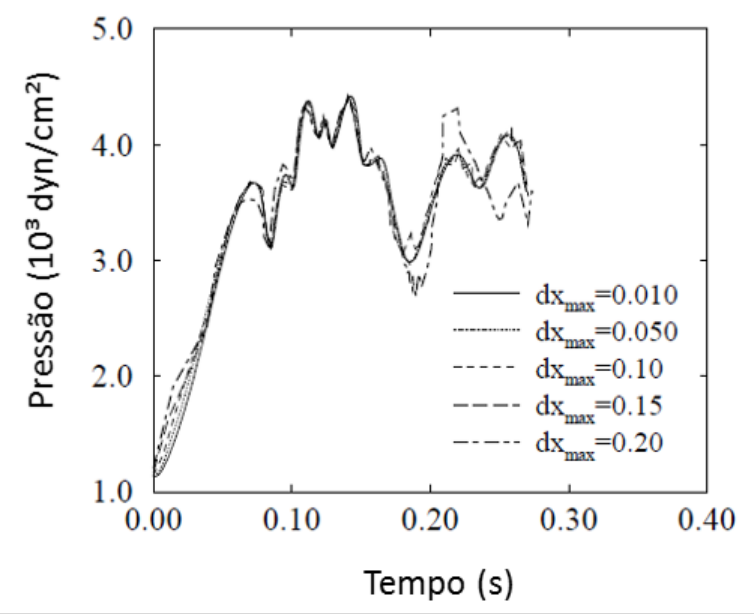

Figura 3.13: Pressão em função do tempo para diferentes valores de percentuais de deslocamento, mostrando suavidade quando o deslocamento máximo é de 1\%. Adaptado de Aker, 1996 (9). 
Neste trabalho calculamos a distância entre as posições das interfaces e os extremos dos capilares, $D s_{\text {cap }}$, considerando o sentido da velocidade. Com isto, calculamos o tempo de deslocamento em cada capilar, $D t_{c a p}$, que é dado por:

$$
D t_{c a p}=\frac{\min \left(D s_{c a p}, 0.01 L\right) A}{q}
$$

onde $A$ não é a área considerando o raio hidráulico usado na equação de Hagen-Poiseuille. $A$ é a área transversal do capilar mais próxima da realidade. Para isto, dividimos o capilar em dois intervalos de interesse, como feito na Subseção 3.1.2.2: em comprimento afetado e não afetado pela constrição. Para o comprimento não afetado, a área da elipse é calculada utilizando os raios da seção transversal elíptica informada pelo fabricante do microchip. Para o cálculo da área da elipse no comprimento afetado pela constrição, utilizamos o raio da elipse não afetado pela constrição, $50 \mu m$, e o raio hidráulico equivalente calculado na Subseção 3.1.2.2.

Após o cálculo do tempo de deslocamento em cada capilar, o passo de tempo, $D t$, considerado na iteração será:

$$
D t=\min \left(D t_{c a p} \neq 0\right)
$$

Devido às instabilidades geradas pelos baixas velocidades de escoamento avaliadas neste trabalho, quando uma interface precisa se deslocar a uma distância menor que $d n$ para completar um capilar, reduzimos este deslocamento em 10\% dentro de uma tolerância mínima. Em vista disto, a interface se deslocará de forma mais suave próxima aos extremos que, nos casos de números de capilaridade baixos, se apresentam como zonas instáveis.

De acordo com o modelo de pressão capilar proposto, na região central do capilar pode ocorrer tanto um aumento quanto uma redução da pressão, gerando também instabilidades e, por vezes, invertendo os sentidos das velocidades. Assim, checamos quando ocorre a inversão dos sentidos das velocidades nas interações consecutivas e reduzimos em $50 \%$ o deslocamento necessário da interface. Isto permite tanto um melhor equilíbrio da pressão capilar na região central como também evita problemas de capillary pinning nos extremos do capilar. 
Uma vez que o passo de tempo é calculado, todas as interfaces se movem e as novas posições são calculadas:

$$
x(i)=x(i-1)+\frac{q}{A \times D t},
$$

onde i é a iteração.

\subsubsection{6}

\section{Atualização dos Modelos de Interfaces e Criação de Novas Interfaces}

Após o reposicionamento das interfaces, algumas destas podem alcançar um dos extremos dos capilares. Por isto, tanto o modelo de interfaces quanto o número de interfaces devem ser atualizados. A Figura 3.14 mostra três exemplos de atualizações realizadas:

(1) $\quad \vec{v}>0$

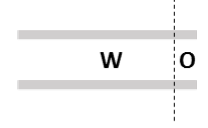

$$
\begin{aligned}
& \text { Ninterfaces }=1 \\
& \text { InterfaceModel(1)= Model_WO } \\
& \text { InterfaceModel }(2)=\text { Model_O } \\
& \text { InterfaceModel }(3)=\text { Model_O }
\end{aligned}
$$

(2) $\quad \vec{v}<0$

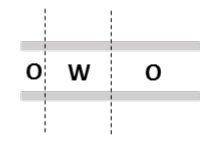

Ninterfaces $=2$ InterfaceModel $(1)=$ Model_OW InterfaceModel $(2)=$ Model_WO InterfaceModel(3)= Model_O

(3) $\quad \vec{v}>0$

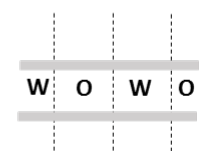

Ninterfaces $=3$

InterfaceModel $(1)=$ Model_WO InterfaceModel $(2)=$ Model_OW InterfaceModel(3)= ModeI_WO

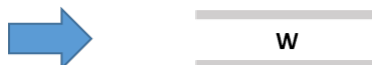

Ninterfaces $=0$

InterfaceModel(1) = Model $W$ InterfaceModel(2)= Model_W InterfaceModel(3)= Model_W
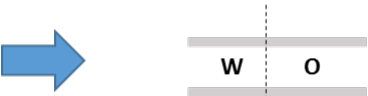

Ninterfaces $=1$

InterfaceModel( 1$)=$ Model Wo InterfaceModel $(2)=$ Model_O InterfaceModel $(3)=$ Model_o

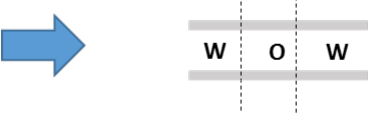

Ninterfaces $=2$

InterfaceModel(1)= Model_WO InterfaceModel(2)= ModeI_OW InterfaceModel(3)= Model_W

Figura 3.14: Exemplos de atualizações de número e modelos de interfaces em casos em que as interfaces completam o capilar. (1)Para velocidade positiva, ou seja, o capilar completando para direita, reduzimos o número de interface de 1 para 0. (2)Para velocidade negativa, ou seja, o capilar completando para esquerda, reduzimos o número de interface de 2 para 1. (3)Para velocidade positiva, reduzimos o número de interface de 3 para 2. Após as reduções, fazemos as atualizações dos modelos das interfaces. 
Por não considerarmos volume nos nós, assim que um capilar é preenchido, checamos se este foi completado em 0 ou em L e o nó correspondente é automaticamente preenchido.

Quando um nó é preenchido, a informação de quais outros capilares estão conectados a este nó é obtida através da matriz de incidência. Os capilares que entram no nó possuem valor -1 e os que saem do nó possuem valor +1 . Sabendo disto, criamos novas interfaces de comprimento $d n$ nestes capilares, respeitando estes sentidos.

Na Figura 3.15, descrevemos os casos de criação de novas interfaces para os capilares que saem do nó.

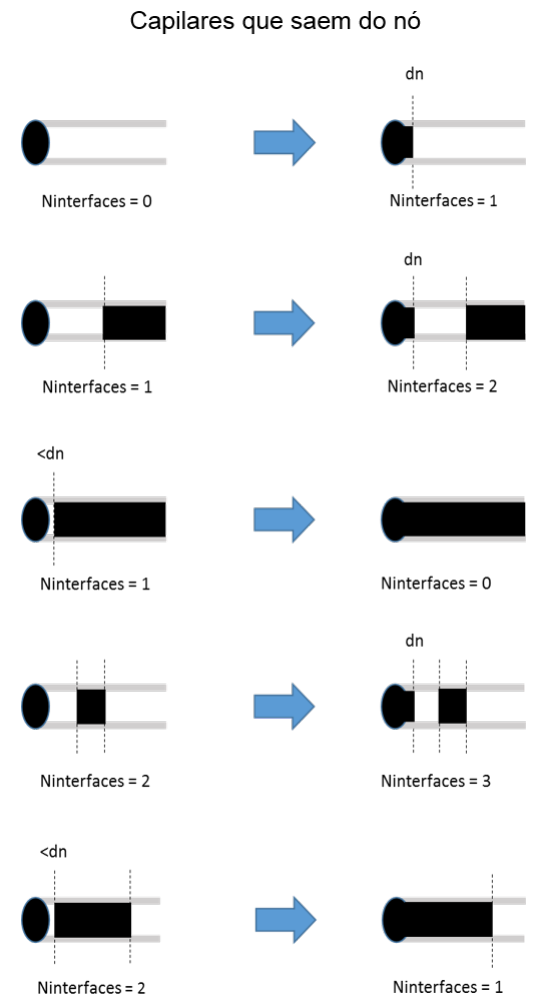

Figura 3.15: Regras para criação de novas interfaces para os capilares que saem do nó. À esquerda, apresentamos os capilares no momento em que os nós, representados pelo círculo, foram preenchidos com um fluido em preto. $\mathrm{O}$ número de interfaces está indicado abaixo de cada capilar. À direita, mostramos a criação de uma nova interface de comprimento $d n$. Quando a primeira interface está a uma distância do nó menor que $d n$, ocorre a redução do número de interfaces. 
Na Figura 3.16, apresentamos os casos de criação de novas interfaces para os capilares que entram no nó.

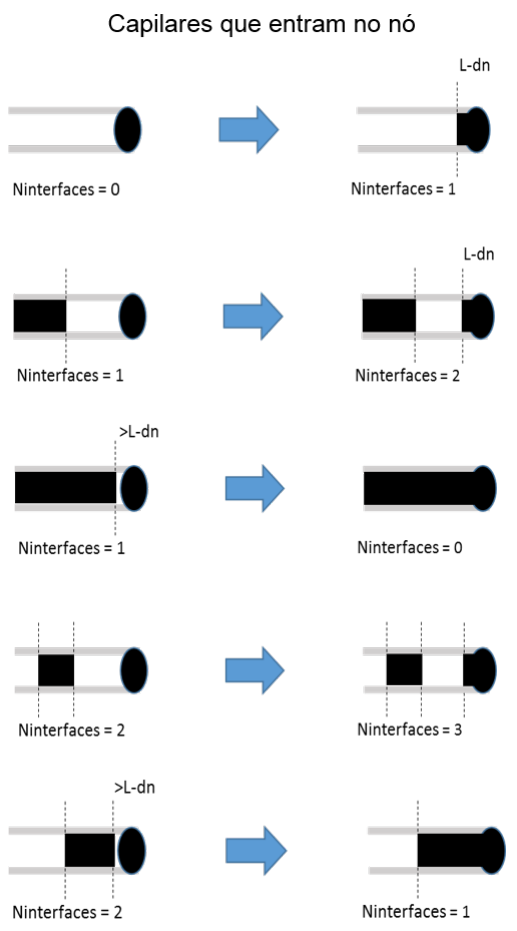

Figura 3.16: Regras para criação de novas interfaces para os capilares que entram no nó. À esquerda, apresentamos os capilares no momento em que os nós, representados pelo círculo, foram preenchidos com um fluido em preto. O número de interfaces está indicado abaixo de cada capilar. À direita, mostramos a criação de uma nova interface de comprimento $d n$. Quando a última interface está a uma distância do nó maior que $L-d n$, propomos uma redução do número de interfaces.

Aker et al. (9) propuseram a ocorrência de até 2 interfaces de fluidos em um capilar. Assim, quando um nó é preenchido e cria-se uma interface em um capilar que já contém duas interfaces, ocorre uma redução de 3 para 1 interface, conforme mostrado na Figura 3.17. 


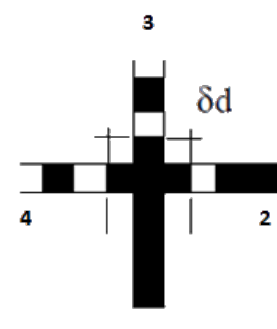

(a)

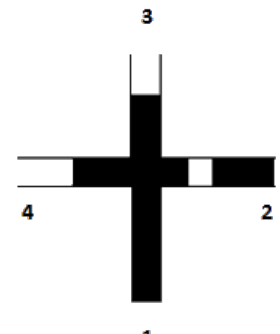

(b)

Figura 3.17: Modelo proposto por Aker et al. (9) no qual um capilar pode conter no máximo 2 interfaces. (a) O capilar 1 é preenchido e 3 novas interfaces de comprimento $\delta d$ são acrescentadas aos outros capilares. Observa-se que os capilares 3 e 4 já possuíam 2 interfaces e foi acrescentada uma terceira. (b) A redução de 3 para 1 interface ocorre. (Modificada de Aker et al. (9))

Ao analisar esta redução de interfaces juntamente ao modelo de pressão capilar sugerido por Aker et. al, percebemos que este não conserva o estado da pressão capilar, podendo causar certas instabilidades no modelo. A Figura 3.18 mostra como esta redução afeta o estado de pressão. 


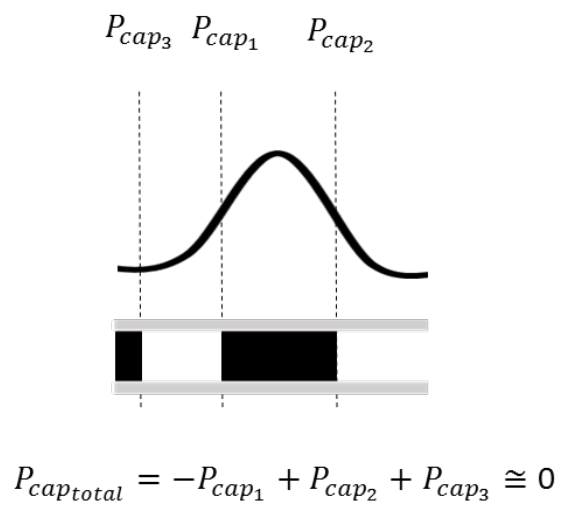

(a)

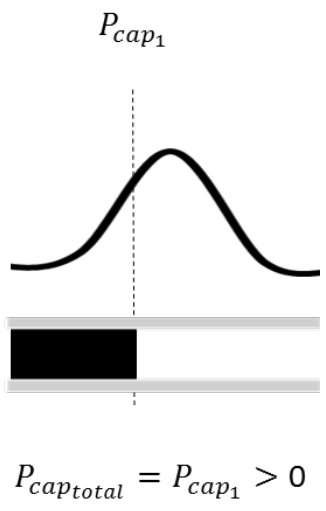

(b)

Figura 3.18: Análise da redução de interfaces juntamente ao modelo de pressão capilar sugerido por Aker et. al (9), descrito na Subseção 2.3.2. (a) O capilar possui um volume de fluido molhante representado na cor preta. Este volume está centralizado no capilar, obtendo valores de pressão capilar praticamente iguais. Devido aos diferentes modelos de interfaces, estas pressões se anulam. A terceira interface criada, também de cor preta, possui um volume ínfimo não impactando na resultante $P_{\text {cap } p_{\text {total }}}$. (b) Quando se reduz de 3 interfaces para 1 , juntam-se os dois volumes e desloca-se o volume resultante para o início do capilar. Assim, a resultante $P_{\text {cap } p_{\text {total }}}$ é positiva, modificando consideravelmente o estado original de pressões.

A extensão para um modelo de 3 interfaces permite contornar este desequilíbrio da pressão capilar e, ao mesmo tempo, manter a conservação de massa. Assim, propomos a redução de 4 para 2 interfaces.

Para os capilares que saem do nó, checamos se a primeira interface está a uma distância do nó menor que $d n$. Para os capilares que entram no nó, checamos se a última interface está a uma distância do nó maior que $L-d n$. Na ocorrência destes dois casos, a redução é realizada como anteriormente (Figura 3.19): 


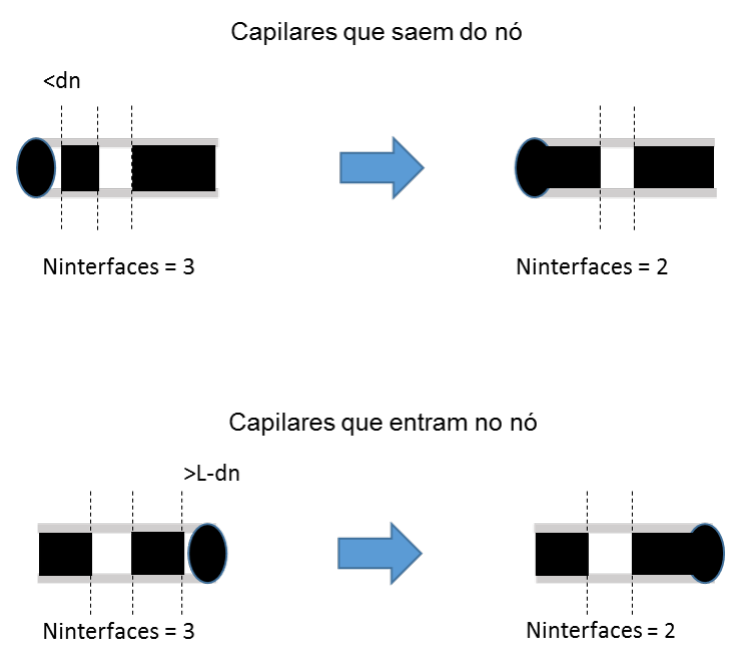

Figura 3.19: Criação de novas interfaces para os capilares com três interfaces, respeitando a matriz de incidência. À esquerda, apresentamos os capilares no momento em que os nós, representados pelo círculo, foram preenchidos com um fluido em preto. O número de interfaces está indicado abaixo de cada capilar. À direita, mostramos a criação de uma nova interface de comprimento $d n$. Para os capilares que saem do nó, checamos se a primeira interface está a uma distância do nó menor que $d n$. Para os capilares que entram no nó, checamos se a última interface está a uma distância do nó maior que $L-d n$. Na ocorrência destes dois casos, propomos a redução de 3 para 2 interfaces.

Os casos diferentes dos dois descritos acima contemplam capilares que contêm 3 interfaces e a entrada de uma quarta impacta na redução para 2 interfaces. Na Figura 3.20, mostramos o mecanismo tanto para os capilares que saem do nó quanto para os que entram: 


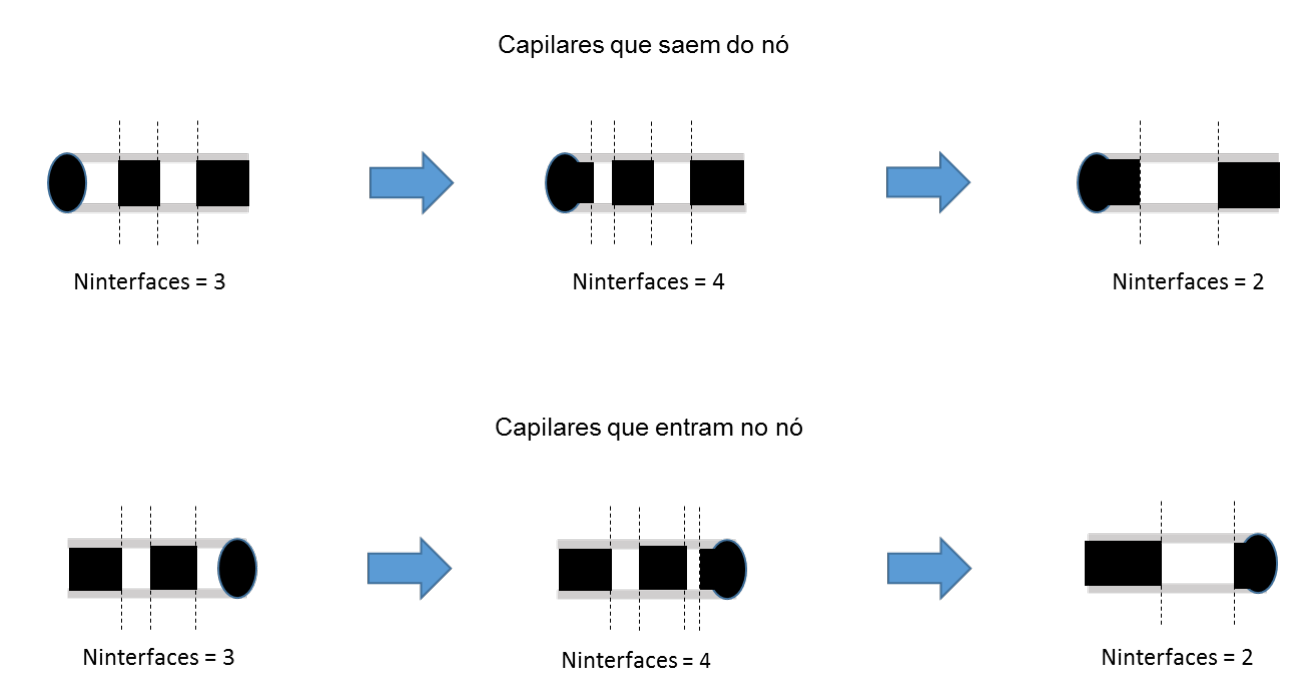

Figura 3.20: Criação interface respeitando a matriz de incidência. À esquerda, apresentamos os capilares no momento em que os nós, representados pelo círculo, foram preenchidos com um fluido em preto. O número de interfaces está indicado abaixo de cada capilar. No centro, apresentamos a criação de uma nova interface de comprimento $d n$, resultando em 4 interfaces. À direita observamos o estado do capilar após a redução para 2 interfaces.

Para a escolha do posicionamento das duas interfaces resultantes da redução, resolvemos um sistema de equações que trata tanto a conservação de massa no capilar quanto a manutenção do estado original da pressão capilar:

$$
\left\{\begin{array}{l}
x_{2}^{\prime}-x_{1}^{\prime}=d x \\
P_{c a p_{1}}^{\prime}+P_{c a p_{2}}^{\prime}=P_{c a p_{t o t a l}}
\end{array}\right.
$$

sendo $d x= \begin{cases}x_{1}+\left(x_{3}-x_{2}\right)-d n, & \text { se o sentido for positivo } \\ x_{2}-x_{1}+L-x_{3}-d n, & \text { se o sentido for negativo }\end{cases}$

$x_{1}, x_{2}$ e $x_{3}$ são as posições da interfaces antes da redução, $x_{1}^{\prime}$ e $x_{2}^{\prime}$ são as novas posições das interfaces após a redução, $P_{c a p_{1}}^{\prime}$ e $P_{c a p_{2}}^{\prime}$ são as pressões capilares relacionadas às novas interfaces e $P_{\text {cap total }}$ é a pressão capilar total antes da redução, com as três interfaces. 


\subsubsection{7}

\section{Cálculo de Saturação nos Capilares}

O cálculo de saturação de água, $S a t_{c a p}$, nos capilares é dado por:

$$
\text { Sat }_{c a p}= \begin{cases}\frac{x_{1}+\left(x_{3}-x_{2}\right)}{L}, & \text { interfaceModel }(1)=M \_W \text { ou } M \_W O ; \\ 1-\frac{x_{1}+\left(x_{3}-x_{2}\right)}{L}, & \text { interfaceModel }(1)=M \_O \text { ou } M \_O W .\end{cases}
$$

Após o cálculo de saturação nos capilares, atualizamos a viscosidade efetiva. Todo procedimento descrito desde a Subseção 3.1.2.3 é executado a cada iteração. A condição de parada da simulação é para uma vazão de óleo na saída menor que $10 \%$ da vazão de entrada, $q_{i n}$.

\subsubsection{8}

\section{Condições Iniciais, de Contorno e de Controle}

Nesta parte mostramos um resumo das condições iniciais, de contorno e de controle utilizadas na modelagem numérica do problema.

As condições iniciais são:

- Nós e capilares são totalmente saturados com óleo, $S a t_{c a p}=0$;

- Ninterfaces $=0$;

- InterfaceModel $=M \_O$;

$-x_{1}=0$ e $x_{2}=x_{3}=0$;

- Nó de entrada saturado de água;

- Primeiro capilar com Ninterfaces $=1$, InterfaceModel $(1)=M \_W O$ e $x_{1}=L-d n$, sendo $d n=L \times 0.01$;

- A saturação de água do primeiro capilar é igual a $x_{1} / L$;

$-\mu_{\text {eff }}=\operatorname{Sat}_{c a p} \times \mu_{w}+\left(1-\operatorname{Sat}_{c a p}\right) \times \mu_{o}$.

As condições de contorno são:

- Vazão imposta constante na entrada, calculada a partir do número de capilaridade;

- Pressão na saída igual a zero.

A condição de controle ou de parada:

- Vazão de óleo na saída menor que $10 \%$ da vazão de entrada, $q_{i n}$. 


\section{4}

\section{Resultados e Discussões}

Neste trabalho avaliamos diferentes padrões de escoamento e eficiências de deslocamento através da saturação de óleo remanescente, tanto para o processo de drenagem quanto para o de embebição. O meio poroso está inicialmente saturado com óleo e uma vazão de injeção de água é imposta. Nossas simulações contemplam números de capilaridade baixos e típicos de fluxo bifásico em reservatórios. Para uma primeira análise e validação do modelo, comparamos nossos resultados com experimentos realizados pelo Laboratório de Microhidrodinâmica e Escoamento em Meios Porosos da PUCRio (12). Estes experimentos de deslocamento do óleo foram feitos em dois microchips de mesma geometria fabricados pela Dolomite Microfluidics, um hidrofílico e o outro hidrofóbico. Esta geometria foi a mesma utilizada na modelagem numérica proposta. Após esta comparação, variamos a razão de viscosidade e número de capilaridade.

\section{1}

\section{Resultados para Drenagem}

\subsection{1}

\section{Comparação com o Experimento}

Para a primeira análise, mantemos fixa a razão de viscosidade e variamos o número de capilaridade, conforme foi realizado no experimento (12). A Tabela 4.1 mostra os parâmetros de entrada que foram utilizados tanto para o experimento quanto para o modelo numérico:

Tabela 4.1: Parâmetros de Entrada - Experimento (12) e Modelo Numérico

\begin{tabular}{|c|c|c|}
\hline Parâmetro & Valor & Unidade \\
\hline$\mu_{o}$ & 0.016 & Pa.s \\
\hline$\mu_{w}$ & 0.001 & Pa.s \\
\hline$\sigma$ & 0.03379 & $\mathrm{~N} / \mathrm{m}$ \\
\hline $\mathrm{M}$ & $1 / 16$ & \\
\hline $\mathrm{Ca}$ & $2.74 \times 10^{-7} \mathrm{a} 3.51 \times 10^{-5}$ & \\
\hline$\theta$ & 0 & \\
\hline
\end{tabular}


A seguir (Figuras 4.1, 4.4, 4.7 e 4.10) mostramos imagens do escoamento no chip a cada variação de aproximadamente $10 \%$ de saturação de água para os diferentes números de capilaridade.

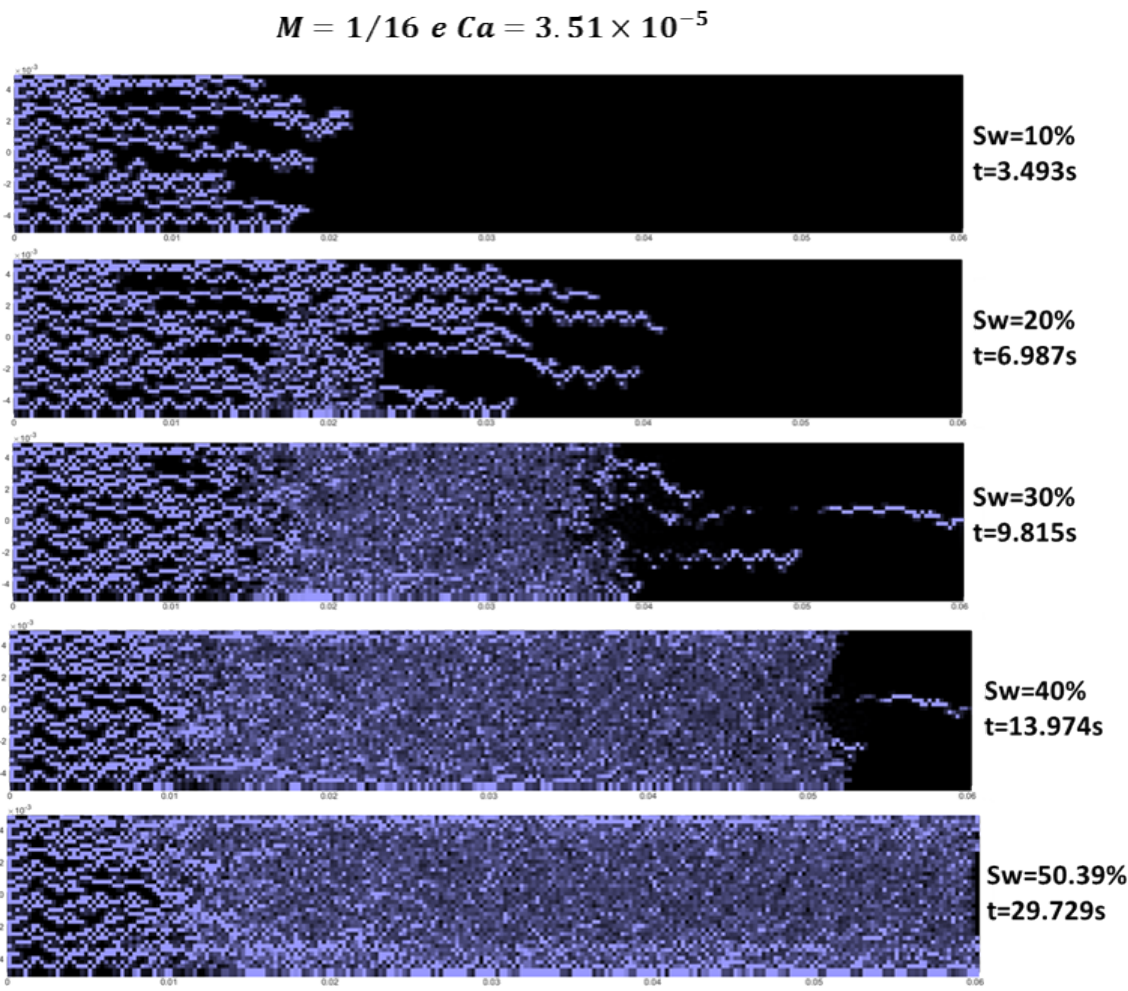

Figura 4.1: Escoamento por Drenagem, $M=1 / 16$ e $C a=3.51 \times 10^{-5}$. $\mathrm{A}$ direita da imagem mostramos as saturações de água no chip e os tempos correspondentes.

Podemos observar na Figura 4.1 que a diferença entre as viscosidades dos fluidos, sendo maior a do fluido deslocado, contribui para a formação de fingers viscosos. Para este número de capilaridade, com vazão mais alta, percebemos a criação de diversos fingers no início do fluxo, em 3.493s. Isto se deve ao fato da pressão de entrada ser alta o suficiente para garantir a injeção imposta.

$\mathrm{Na}$ imagem com saturação de água em torno de $20 \%$, notamos o início de uma zona de contato de fingers. Na saturação em torno de $30 \%$, esta zona cresce e se mantém até o fim do escoamento, como um deslocamento estável. Este deslocamento provoca um grande aumento da pressão de entrada, visto na Figura 4.2, em torno de 8.0s. Alguns volumes de óleo que circundavam os caminhos que inicialmente eram preferenciais à água, entram nestes caminhos criando novas interfaces água/óleo. O surgimento de pressão capilar no sentido contrário ao movimento, devido a estas novas interfaces, faz com que a pressão 
de entrada aumente para manutenção da vazão imposta. Observamos também, na Figura 4.2, alguns pontos com queda de pressão. Alguns fingers de água se tornaram mais espessos nessa zona, facilitando o fluxo da água através de uma maior permeabilidade relativa. Também, a pressão é aliviada no momento de breakthrough. Juntando todos estes fenômenos, a curva de pressão de entrada oscila em quase todo escoamento.

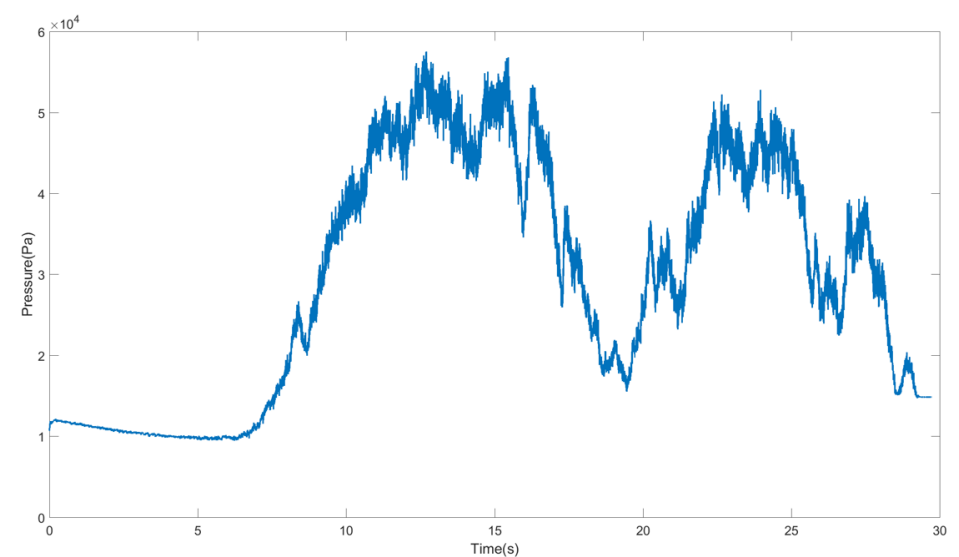

Figura 4.2: Pressão na Entrada x Tempo, $M=1 / 16$ e $C a=3.51 \times 10^{-5}$.

De acordo com a imagem do escoamento, Figura 4.1, o breakthrough ocorreu quando a saturação de água estava em torno de 30\%, em um tempo de preenchimento de 9.8s. Ao analisar a curva de saturação com o tempo, Figura 4.3 , notamos que a saturação de água cresce linearmente até aproximadamente 17.0s. Com isto, podemos concluir que em $9.8 \mathrm{~s}$ um pequeno volume de água chegou ao final do chip, porém não deve ser caracterizado como breakthrough. No laboratório, provavelmente, isto pode ocorrer e não ser percebido. Além disto, em 17.0s, ocorre a maior queda na curva de pressão, Figura 4.2. 


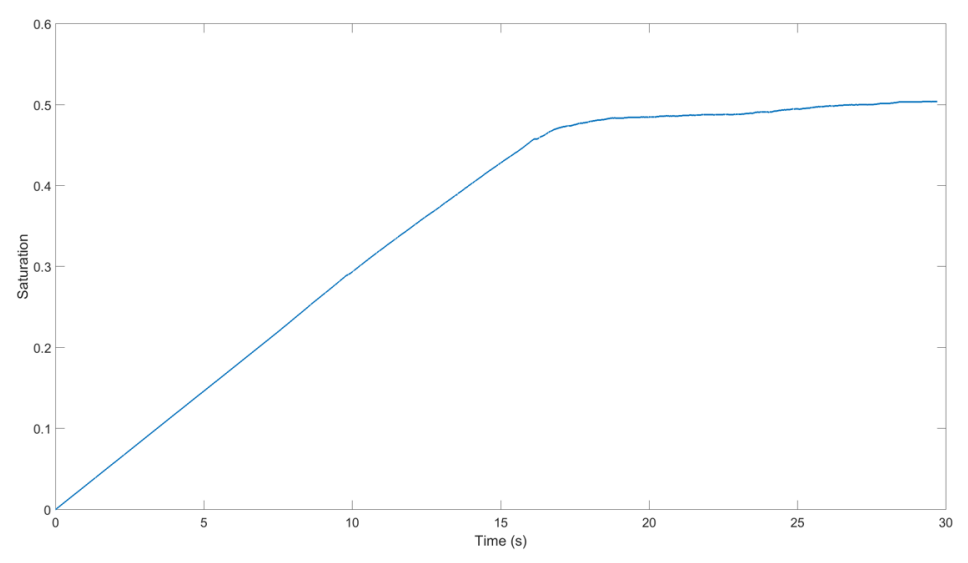

Figura 4.3: Saturação de Água x Tempo, $M=1 / 16$ e $C a=3.51 \times 10^{-5}$.

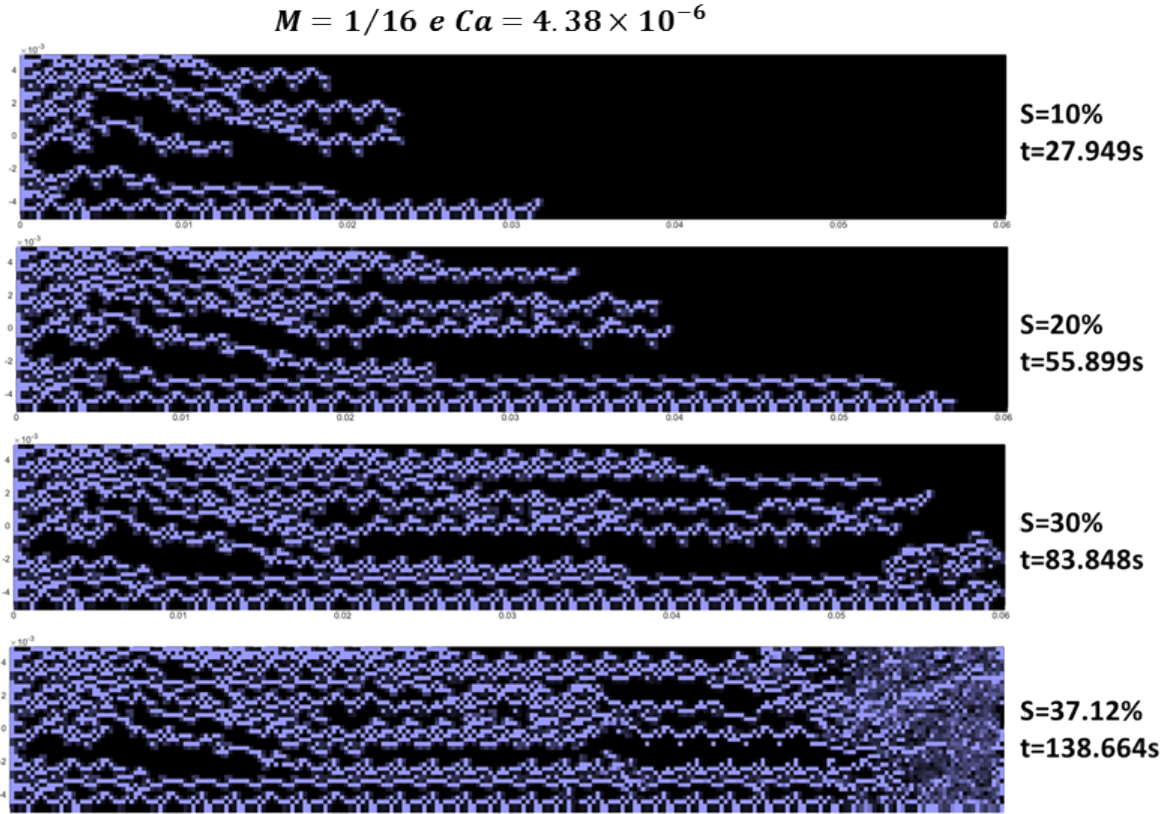

Figura 4.4: Escoamento por Drenagem, $M=1 / 16$ e $C a=4.38 \times 10^{-6}$. À direita da imagem mostramos as saturações de água no chip e os tempos correspondentes.

Na Figura 4.4, para um número de capilaridade mais baixo e, por consequência, vazão imposta menor, percebemos uma menor quantidade de fingers criados no início do escoamento, em 27.949s. Assim, a curva de pressão de entrada(Figura 4.5) se mantém quase constante, com poucas oscilações devido à pressão capilar. Ao seu final, percebemos um crescimento com a ocorrência do contato de fingers, conforme explicado anteriormente. 


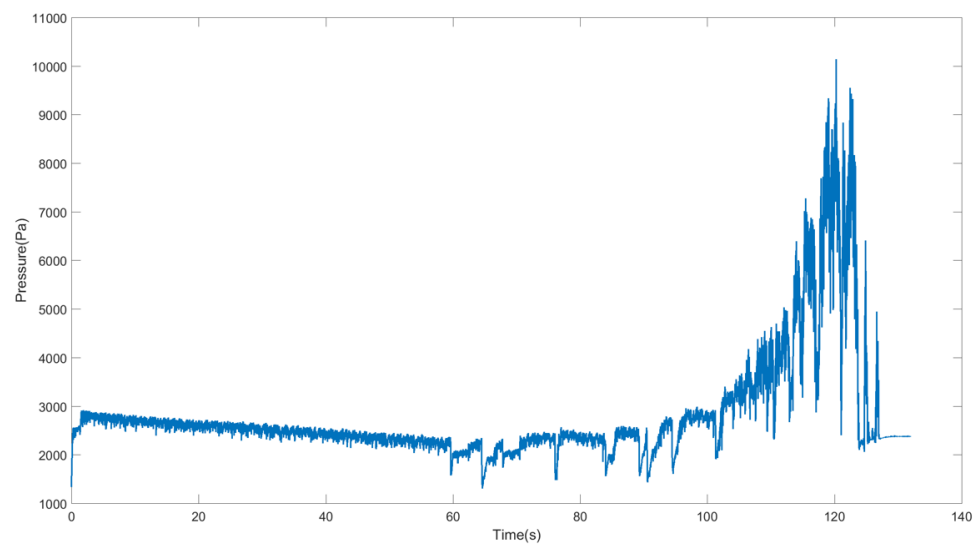

Figura 4.5: Pressão na Entrada x Tempo, $M=1 / 16$ e $C a=4.38 \times 10^{-6}$.

Por considerarmos a vazão imposta constante e fluidos incompressíveis, a saturação de água cresce linearmente (Figura 4.6) até o momento de breakthrough, em $60.0 \mathrm{~s}$. Na curva de pressão isto é refletido com a primeira queda observada (Figura 4.5).

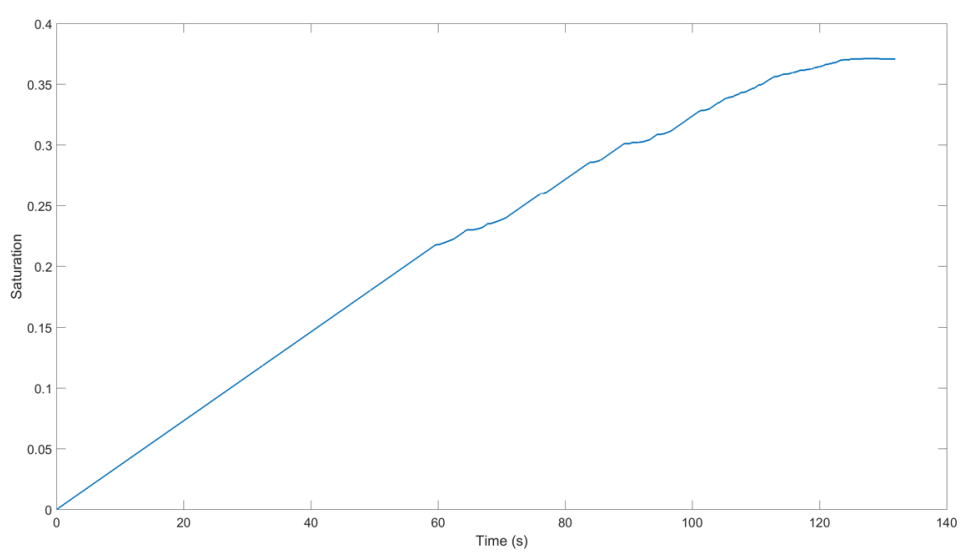

Figura 4.6: Saturação de Água x Tempo, $M=1 / 16$ e $C a=4.38 \times 10^{-6}$. 


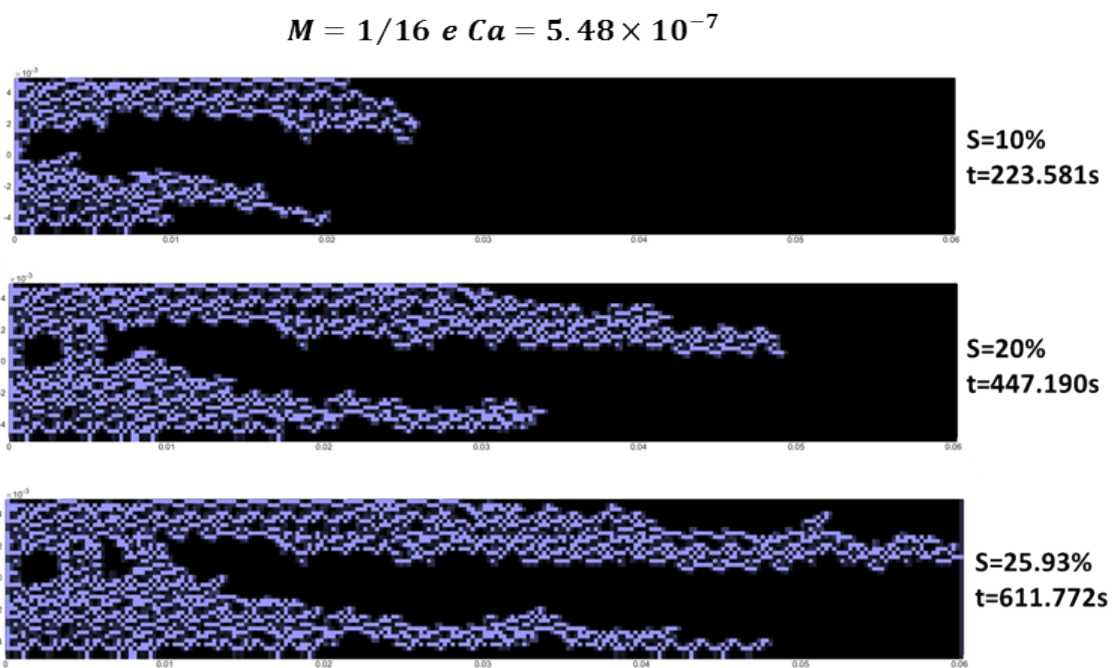

Figura 4.7: Escoamento por Drenagem, $M=1 / 16$ e $C a=5.48 \times 10^{-7}$. À direita da imagem mostramos as saturações de água no chip e os tempos correspondentes.

Para números de capilaridades ainda mais baixos (Figuras 4.7 e 4.10) percebemos a criação de poucos fingers e mais espessos. Estes se estendem rapidamente até a saída do chip devido ao aumento da permeabilidade relativa localizada. As curvas de pressão (Figuras 4.8 e 4.11) apresentam valores menores, comparadas às dos escoamentos analisados anteriormente, por conta de vazões impostas menores. Além disto, se mantêm constante em quase todo o escoamento com oscilações por instabilidade da pressão capilar.

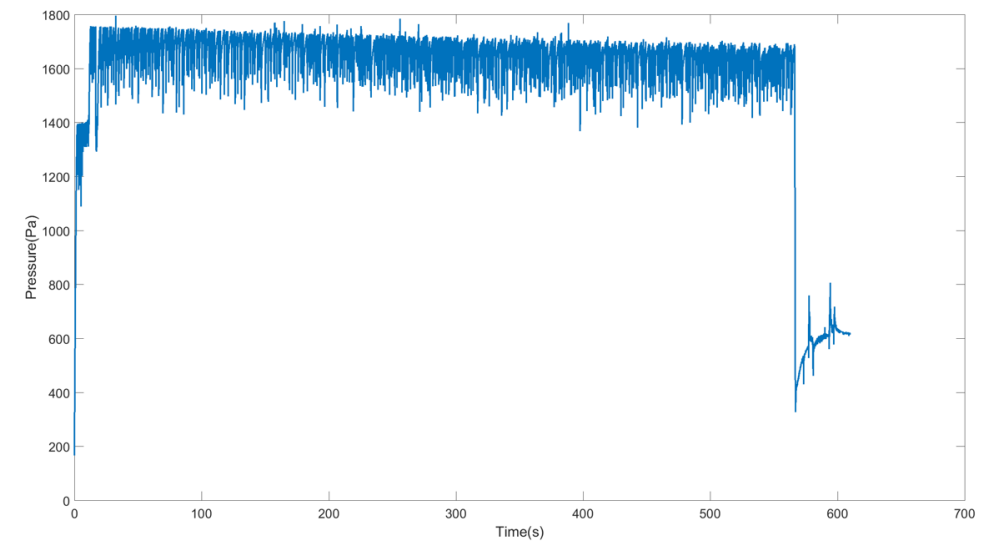

Figura 4.8: Pressão na Entrada x Tempo, $M=1 / 16$ e $C a=5.48 \times 10^{-7}$.

As Figuras 4.9 e 4.12 mostram os gráficos de saturação com o tempo para os escoamentos com números de capilaridade mais baixos. Percebemos 
que os escoamentos alcançam o regime permanente logo após o breakthrough, que pode ser notado também através da queda nas curvas de pressão (Figuras 4.8 e 4.11$)$.

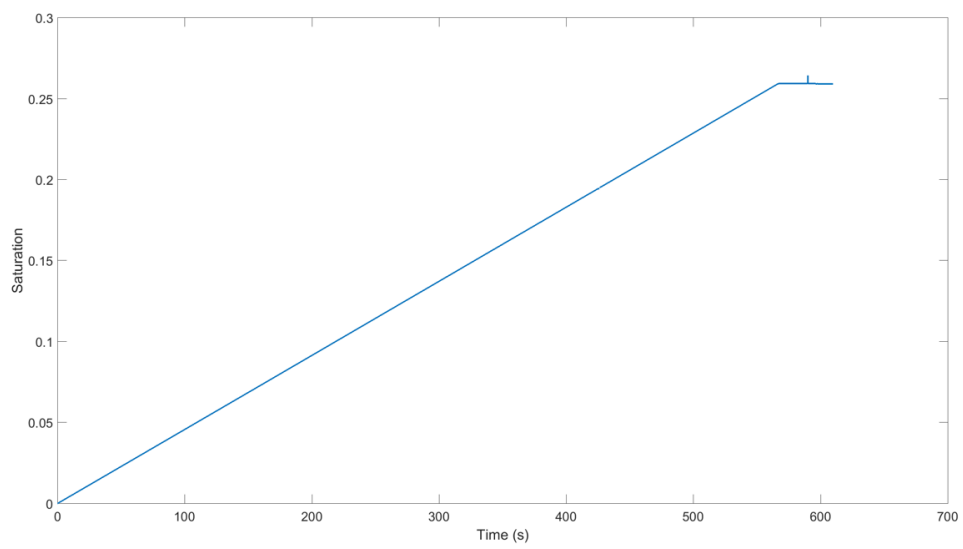

Figura 4.9: Saturação de Água x Tempo, $M=1 / 16$ e $C a=5.48 \times 10^{-7}$.

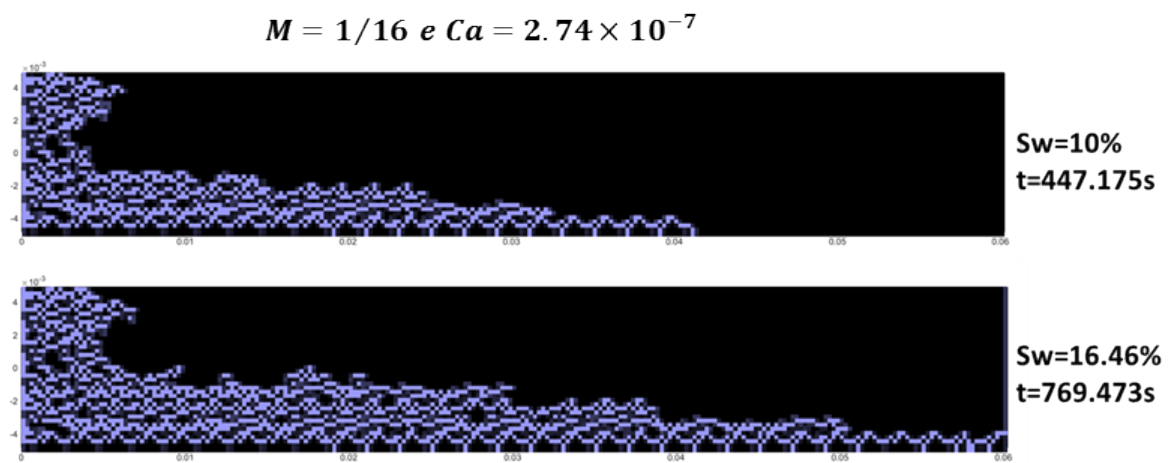

Figura 4.10: Escoamento por Drenagem, $M=1 / 16$ e $C a=2.74 \times 10^{-7}$. À direita da imagem mostramos as saturações de água no chip e os tempos correspondentes. 


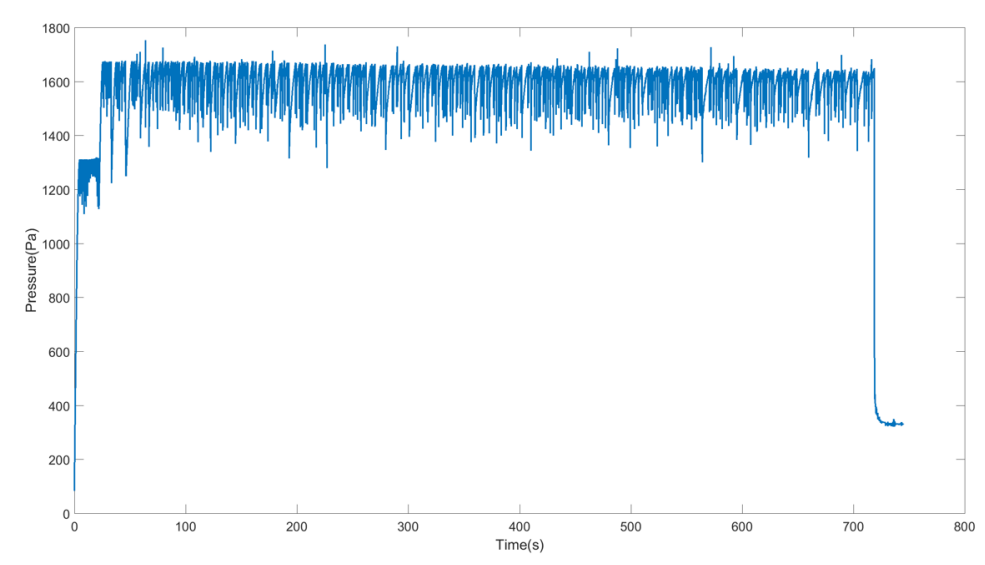

Figura 4.11: Pressão na Entrada x Tempo, $M=1 / 16$ e $C a=2.74 \times 10^{-7}$.

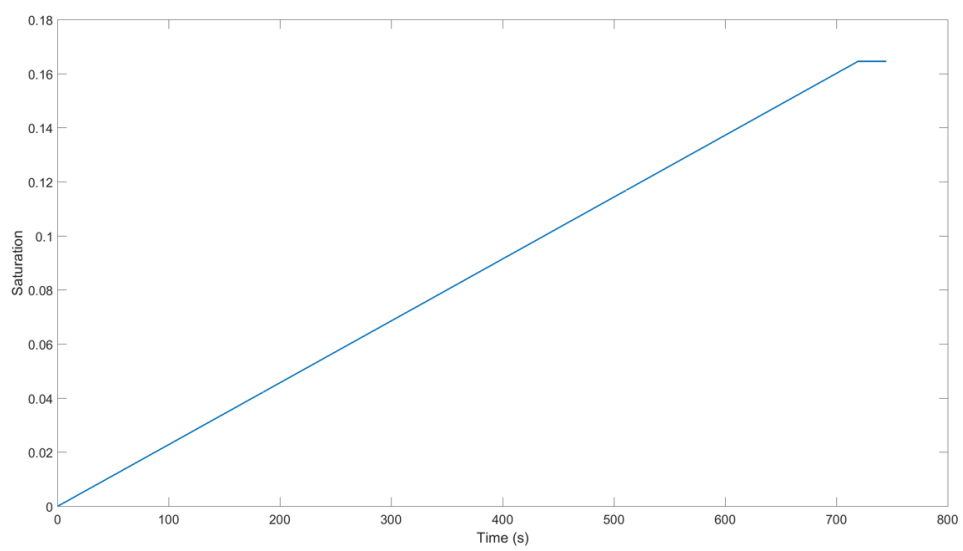

Figura 4.12: Saturação de Água x Tempo, $M=1 / 16$ e $C a=2.74 \times 10^{-7}$.

A Tabela 4.2 mostra as eficiências do deslocamento através da saturação de óleo remanescente, $S_{o r}$, para os diferentes números de capilaridades, tanto para o experimento quanto para o simulador.

Tabela 4.2: Eficiências de Deslocamento (Drenagem) - Experimento (12) e Simulador

\begin{tabular}{|c|c|c|}
\hline $\mathbf{C a}$ & $S_{\text {or }}$ (Experimento) & $S_{\text {or }}($ Simulador $)$ \\
\hline $2.74 \times 10^{-7}$ & $43.50 \%$ & $83.54 \%$ \\
\hline $5.48 \times 10^{-7}$ & $42.30 \%$ & $74.07 \%$ \\
\hline $4.38 \times 10^{-6}$ & $33.40 \%$ & $62.88 \%$ \\
\hline $3.51 \times 10^{-5}$ & $29.50 \%$ & $49.61 \%$ \\
\hline
\end{tabular}


A Figura 4.13 mostra o gráfico de $C a \times S_{\text {or }}$ para o experimento e para o modelo numérico. Podemos observar que a tendência da curva é similar. Com o aumento do número de capilaridade, o escoamento apresenta uma maior eficiência de deslocamento, menor saturação de óleo remanescente, visto também em resultados da literatura $(3,9,14)$.

As diferenças dos valores de $S_{\text {or }}$ entre o experimento e o simulador se devem ao fato de considerarmos o deslocamento pistão, não contemplando o mecanismo de snap-off para a recuperação de óleo. A presença de "quebra" de gotas foi notada durante o experimento, principalmente em números de capilaridades mais baixos. No snap-off, a camada molhante de óleo "quebra" o caminho de água provocando uma redução na permeabilidade relativa desta. Assim, o escoamento do óleo é melhorado resultando em uma $S_{o r}$ menor.

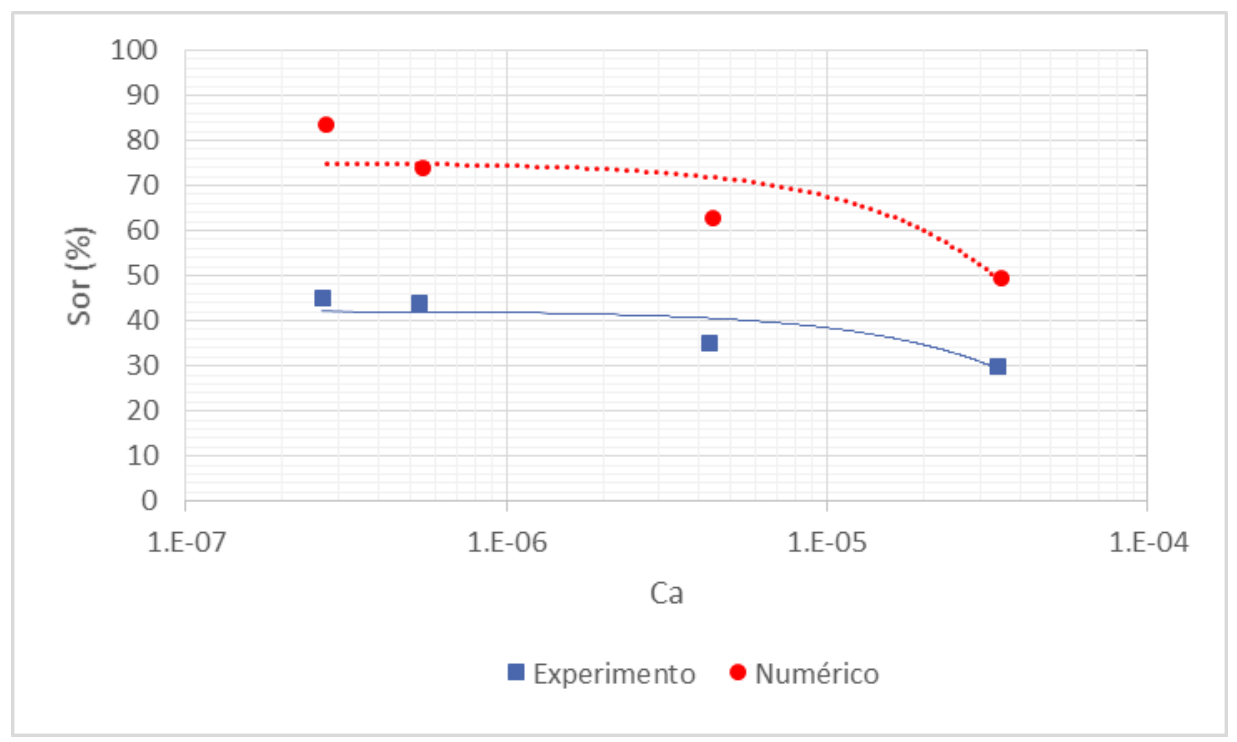

Figura 4.13: Comparação entre o Modelo Numérico e o Experimento através do gráfico de $C a \times S_{o r}$.

\subsection{2}

\section{Variação de Razão de Viscosidade}

A segunda análise do processo de drenagem trata da variação da razão de viscosidade para os mesmos números de capilaridade discutidos na Subseção 4.1.1. Avaliamos o escoamento com uma razão de viscosidade de $1 / 2$, maior que a analisada na Subseção 4.1.1. E, após isto, analisamos os resultados para uma razão de viscosidade menor, de 1/50. Para variação deste parâmetro, modificamos apenas a viscosidade do óleo.

As Figuras 4.14, 4.17, 4.20 e 4.23 mostram as imagens do escoamento para os diferentes números de capilaridade e razão de viscosidade de 1/2. 
Observamos que o escoamento é marcado por uma frente estável resultando em uma menor saturação de óleo remanescente (Figuras 4.16, 4.19, 4.22 e 4.25).

Para os diferentes números de capilaridades não houve grande variação do padrão do escoamento e da recuperação do óleo. Para os números de capilaridade mais altos, ainda se observa uma zona de contato de alguns fingers no final do fluxo, criando novas interfaces e provocando o aumento de pressão no tempo final (Figuras 4.15 e 4.18).

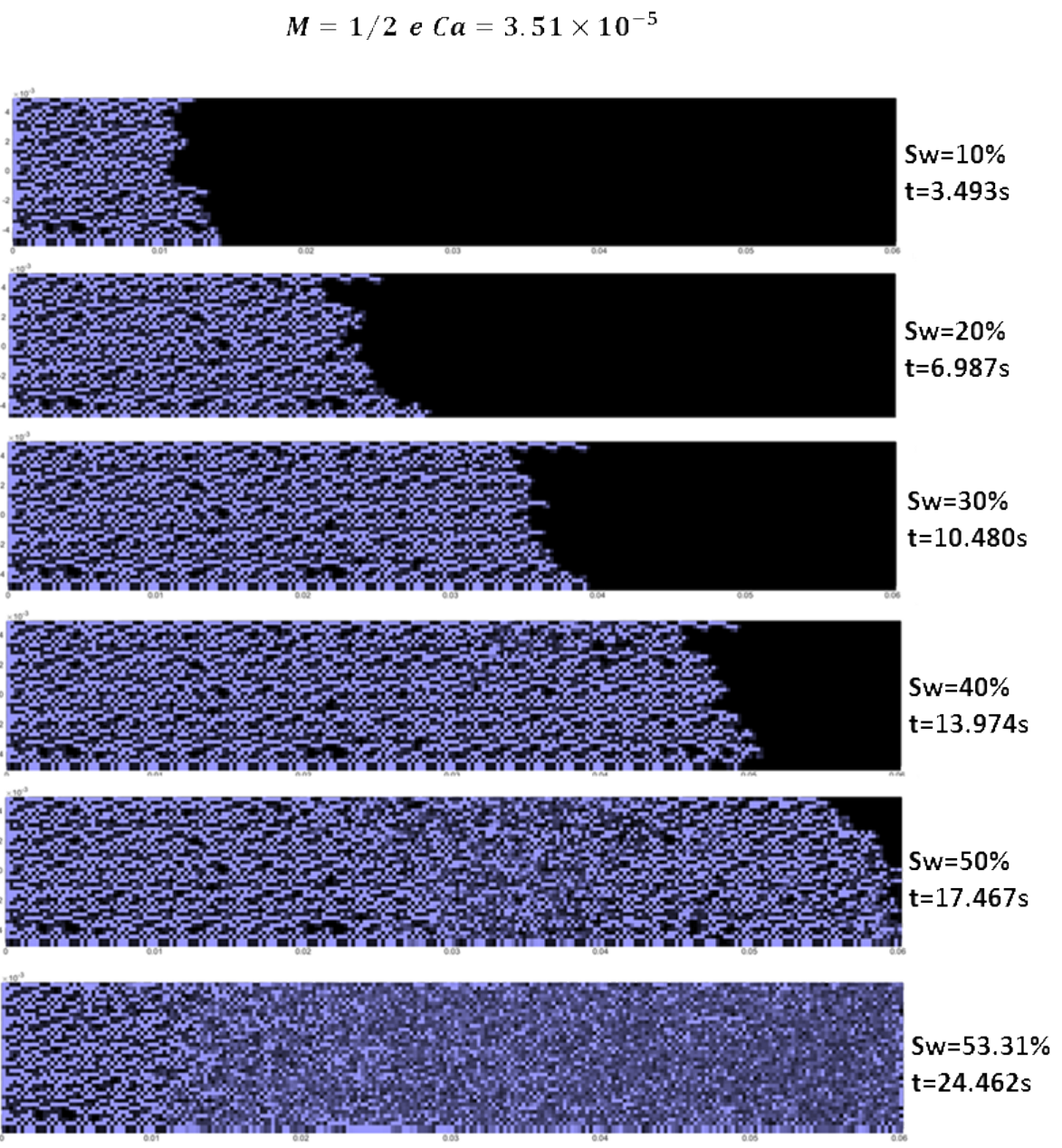

Figura 4.14: Escoamento por Drenagem, $M=1 / 2$ e $C a=3.51 \times 10^{-5}$. À direita da imagem mostramos as saturações de água no chip e os tempos correspondentes. 


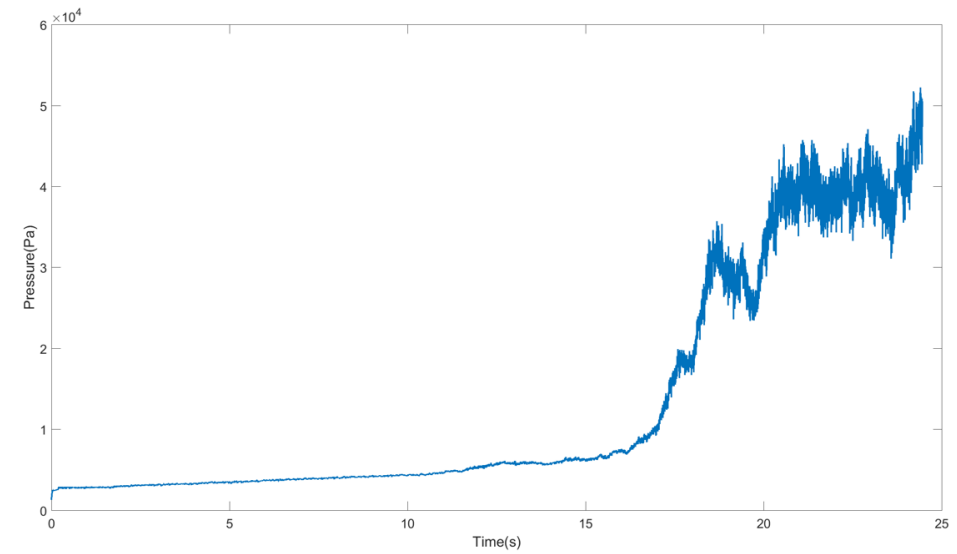

Figura 4.15: Pressão na Entrada x Tempo, $M=1 / 2$ e $C a=3.51 \times 10^{-5}$.

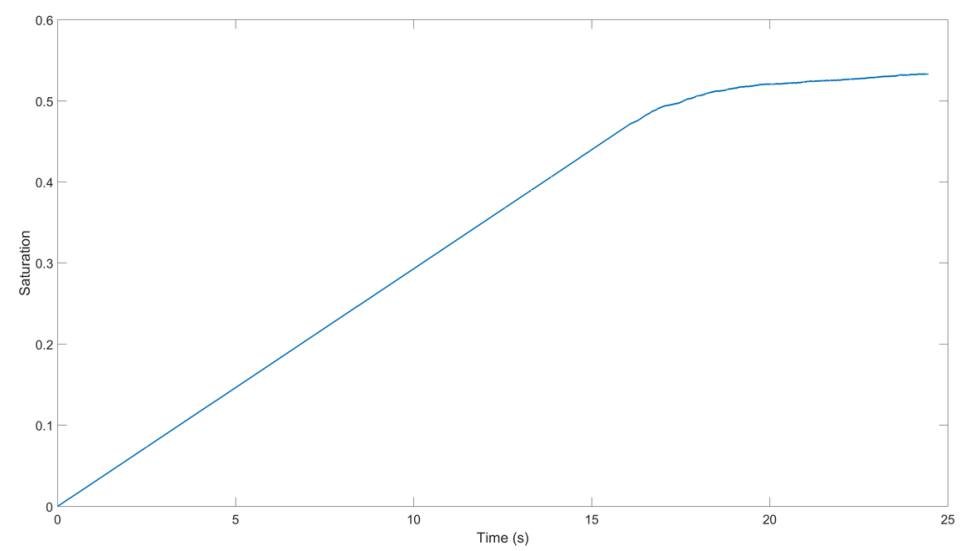

Figura 4.16: Saturação de Água x Tempo, $M=1 / 2$ e $C a=3.51 \times 10^{-5}$. 


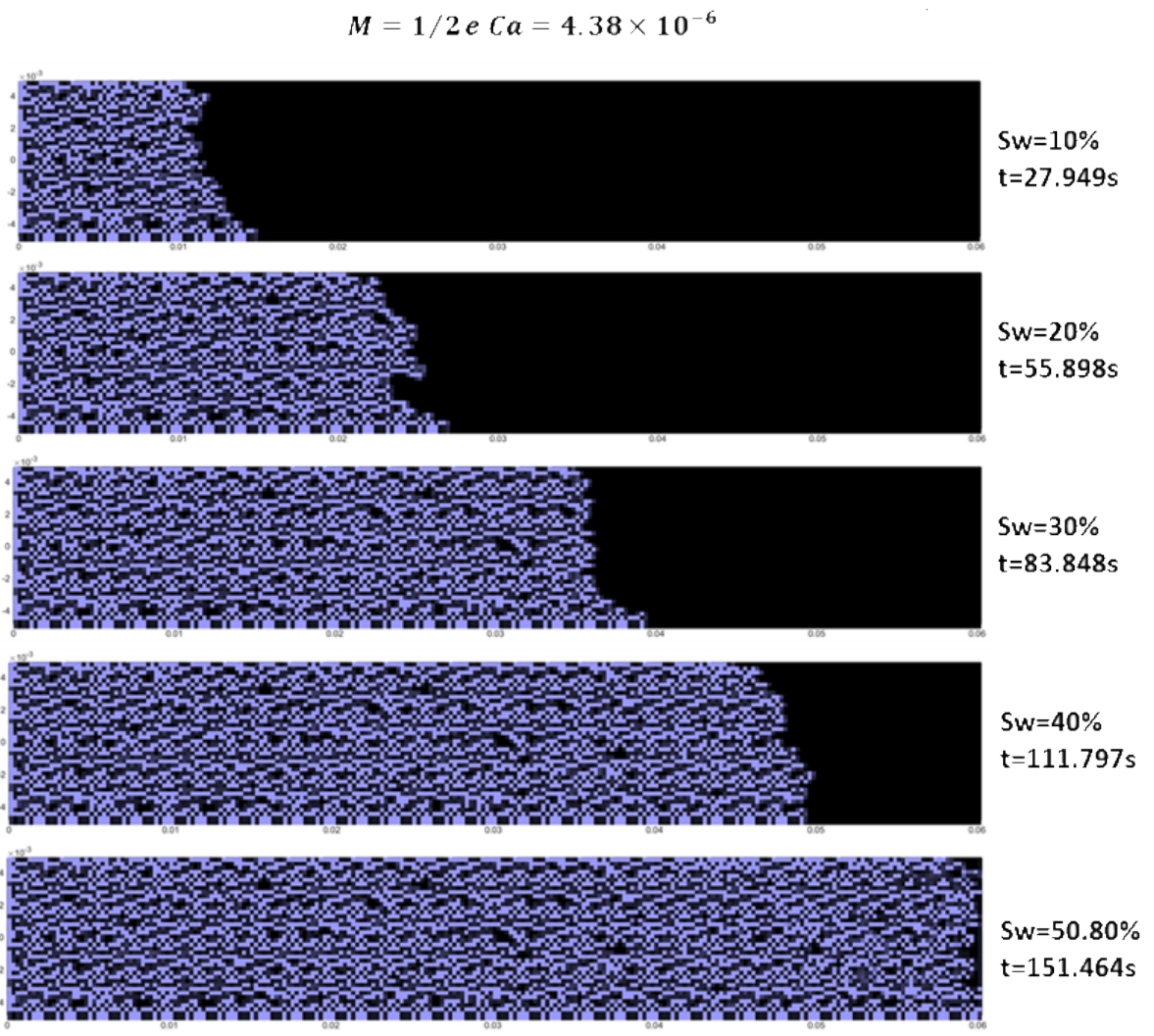

Figura 4.17: Escoamento por Drenagem, $M=1 / 2$ e $C a=4.38 \times 10^{-6}$. $\AA$ direita da imagem mostramos as saturações de água no chip e os tempos correspondentes.

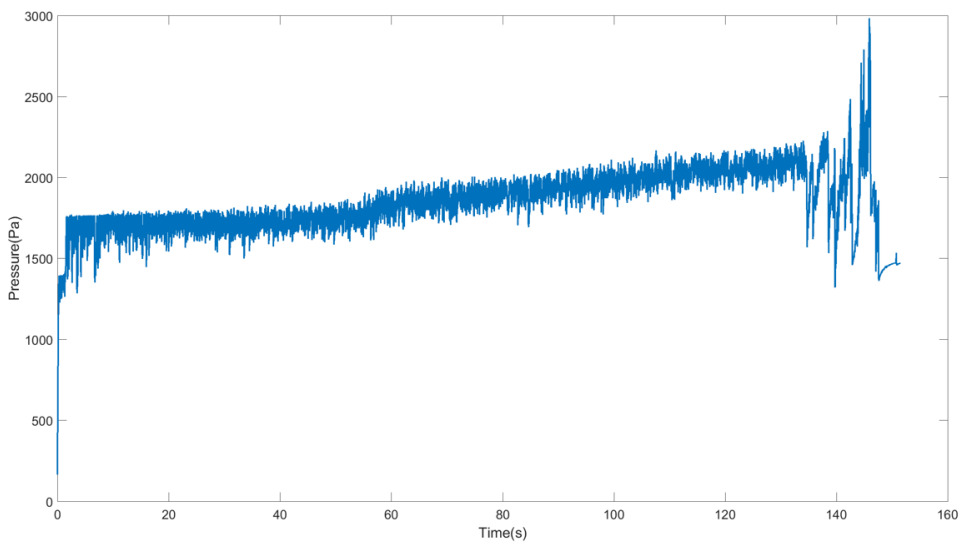

Figura 4.18: Pressão na Entrada x Tempo, $M=1 / 2$ e $C a=4.38 \times 10^{-6}$. 


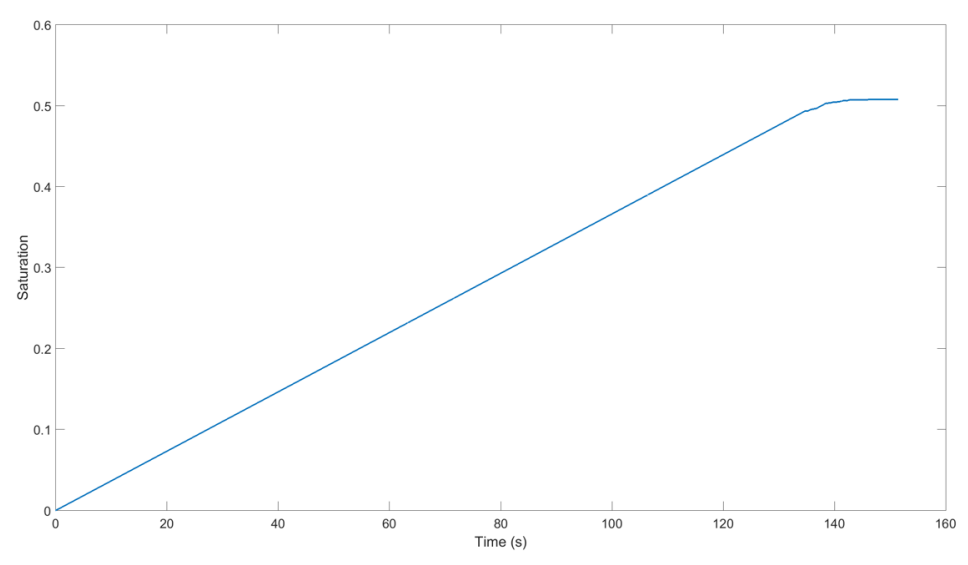

Figura 4.19: Saturação de Água x Tempo, $M=1 / 2$ e $C a=4.38 \times 10^{-6}$.

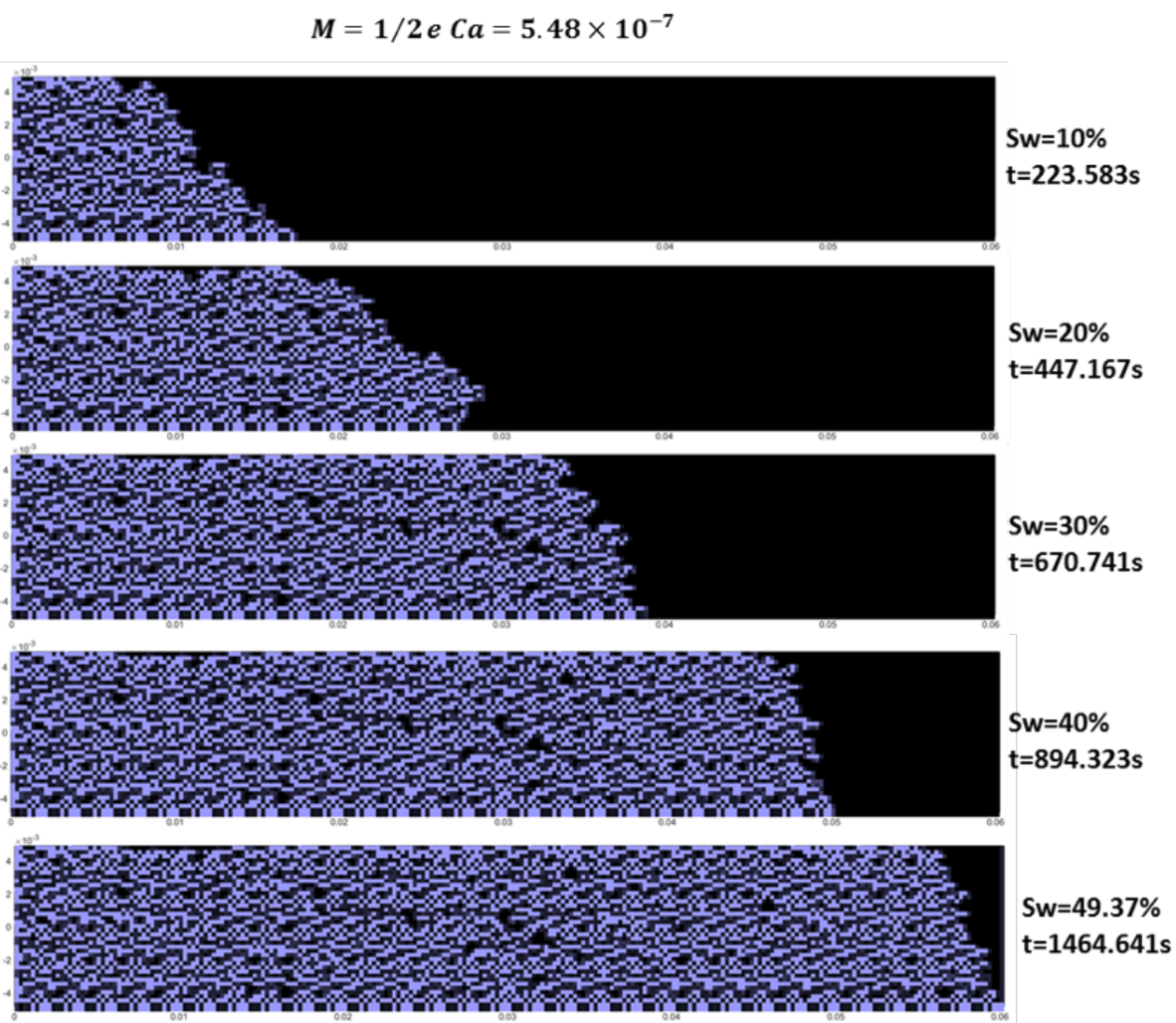

Figura 4.20: Escoamento por Drenagem, $M=1 / 2$ e $C a=5.48 \times 10^{-7}$. $\AA$ direita da imagem mostramos as saturações de água no chip e os tempos correspondentes. 


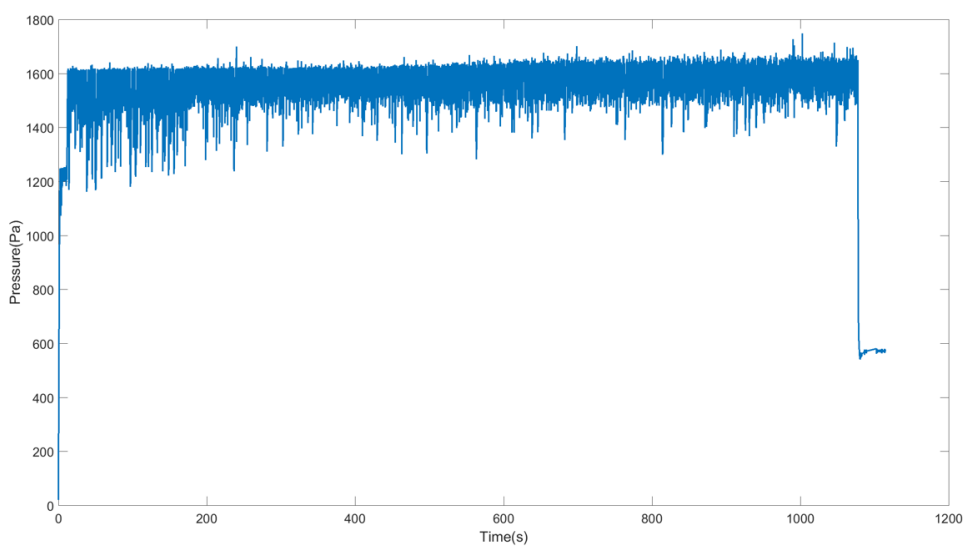

Figura 4.21: Pressão na Entrada x Tempo, $M=1 / 2$ e $C a=5.48 \times 10^{-7}$.

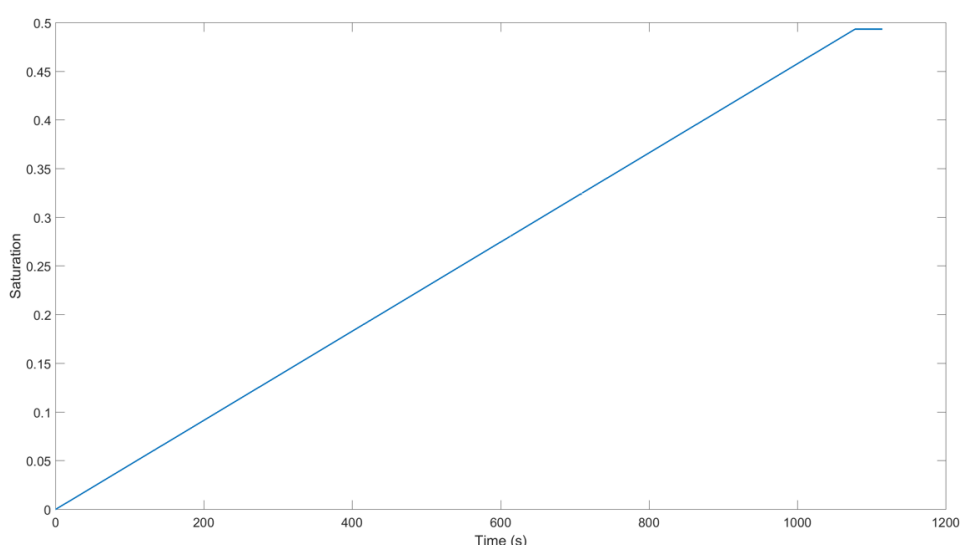

Figura 4.22: Saturação de Água x Tempo, $M=1 / 2$ e $C a=5.48 \times 10^{-7}$. 


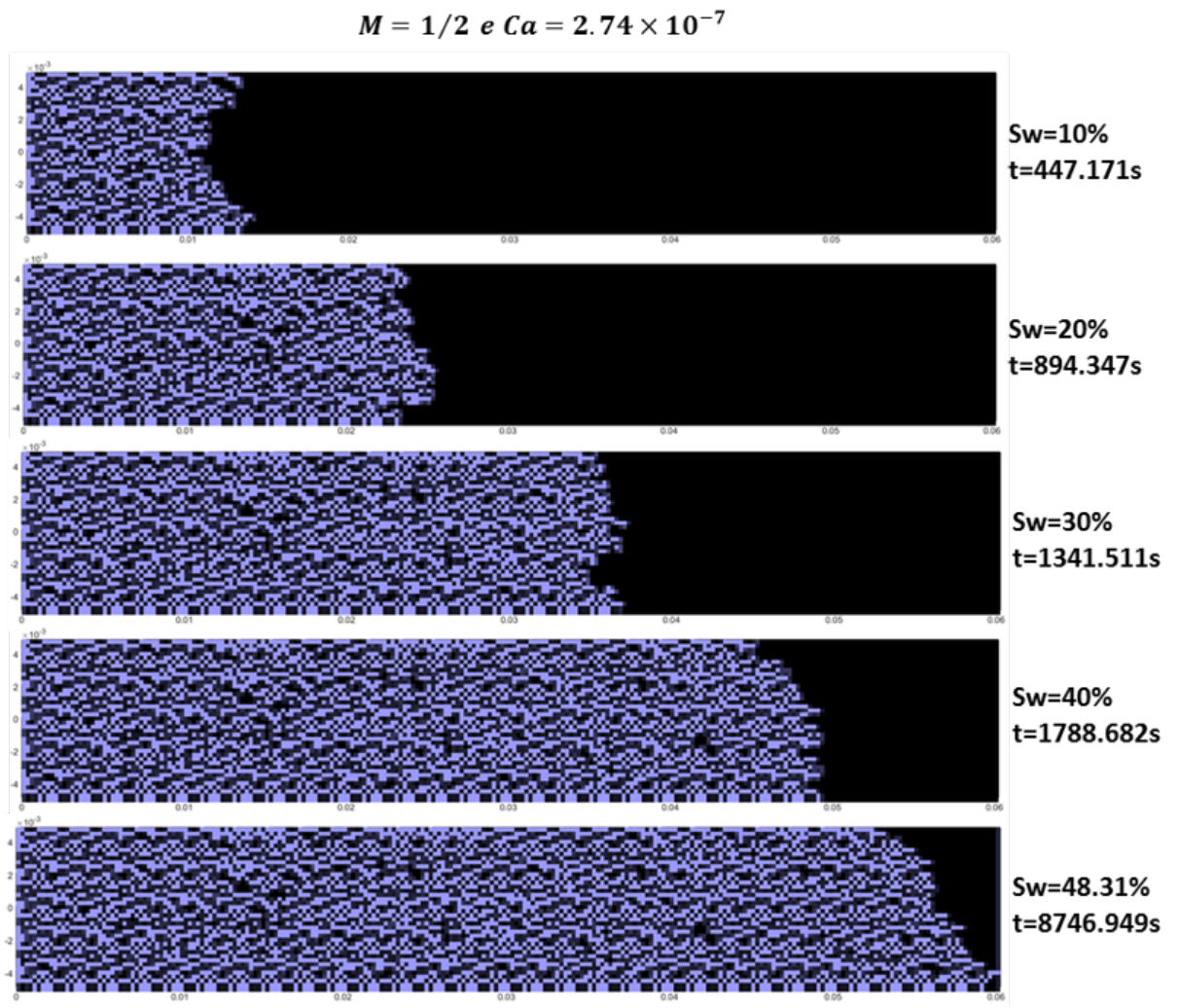

Figura 4.23: Escoamento por Drenagem, $M=1 / 2$ e $C a=2.74 \times 10^{-7}$. À direita da imagem mostramos as saturações de água no chip e os tempos correspondentes.

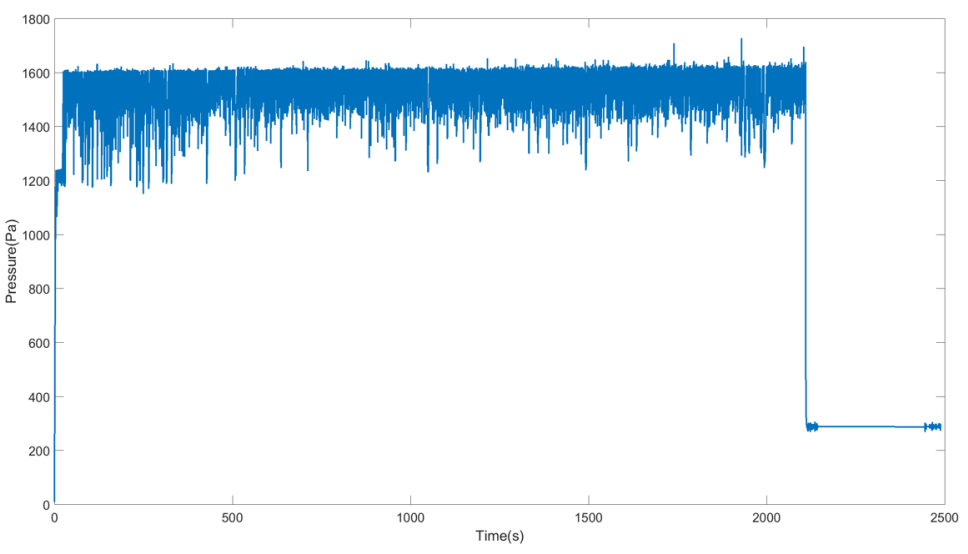

Figura 4.24: Pressão na Entrada x Tempo, $M=1 / 2$ e $C a=2.74 \times 10^{-7}$. 


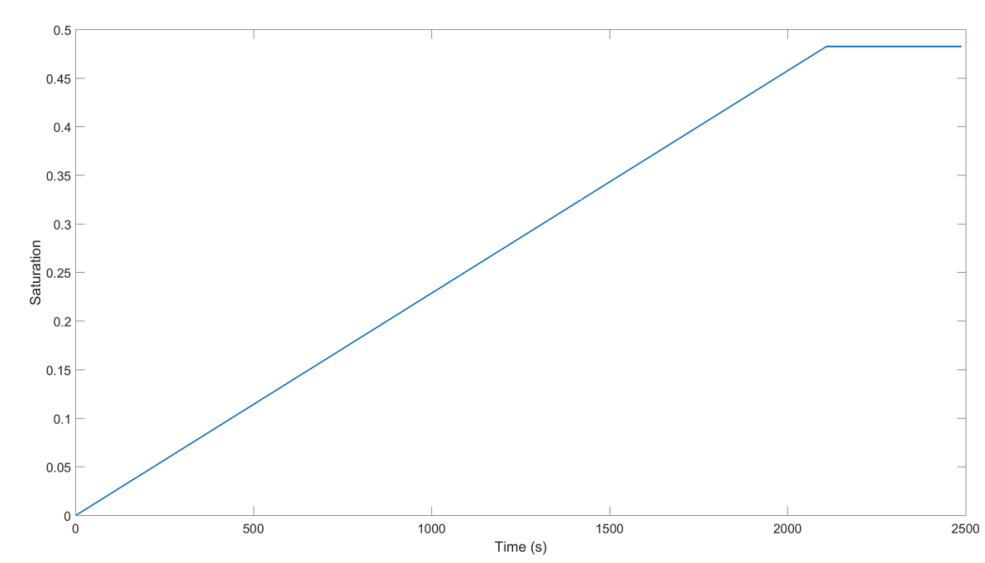

Figura 4.25: Saturação de Água x Tempo, $M=1 / 2$ e $C a=2.74 \times 10^{-7}$.

As Figuras 4.26, 4.29, 4.32 e 4.35 apresentam as imagens do escoamento para os diferentes números de capilaridade e razão de viscosidade de 1/50. O padrão de escoamento observado para os diferentes números de capilaridades é similar ao de razão de viscosidade de 1/16, analisado na Subseção 4.1.1, sendo marcado pelos fingers viscosos. Nesse caso, por conta da razão de viscosidade ser menos favorável, a pressão de entrada é maior comparada às simulações anteriores.

Para os números de capilaridades mais altos (Figuras 4.26 e 4.29), observamos uma zona de contato de fingers, causando o aumento de pressão na entrada (Figuras 4.27 e 4.30). Para os números de capilaridades mais baixos, a pressão permanece constante com as oscilações devido aos efeitos da pressão capilar, e diminuindo no momento de breakthrough (Figuras 4.33 e 4.36).

A saturação de água cresce linearmente até o momento do breakthrough, provando a conservação de massa (Figuras 4.28, 4.31, 4.34 e 4.37). 


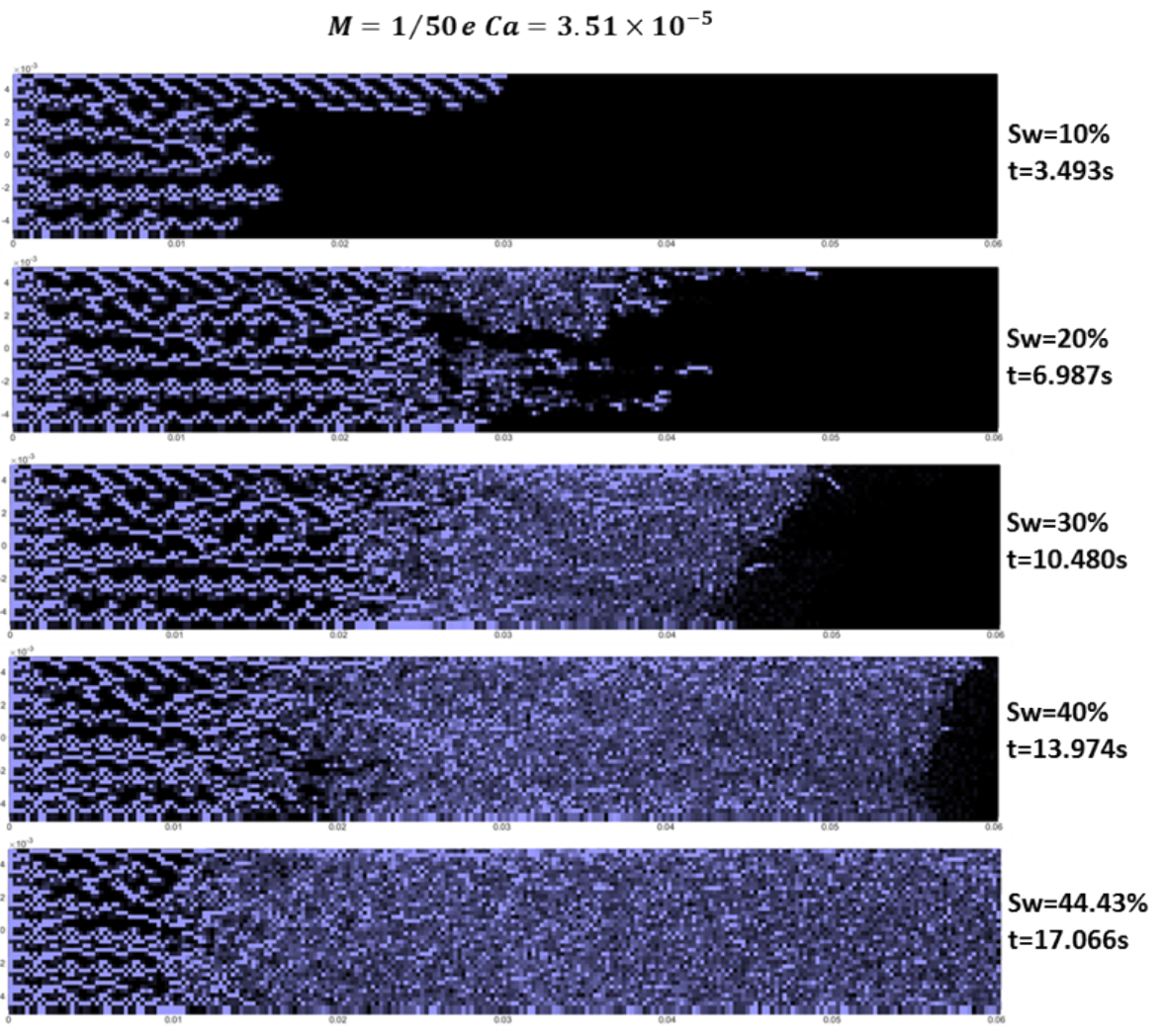

Figura 4.26: Escoamento por Drenagem, $M=1 / 50$ e $C a=3.51 \times 10^{-5}$. À direita da imagem mostramos as saturações de água no chip e os tempos correspondentes.

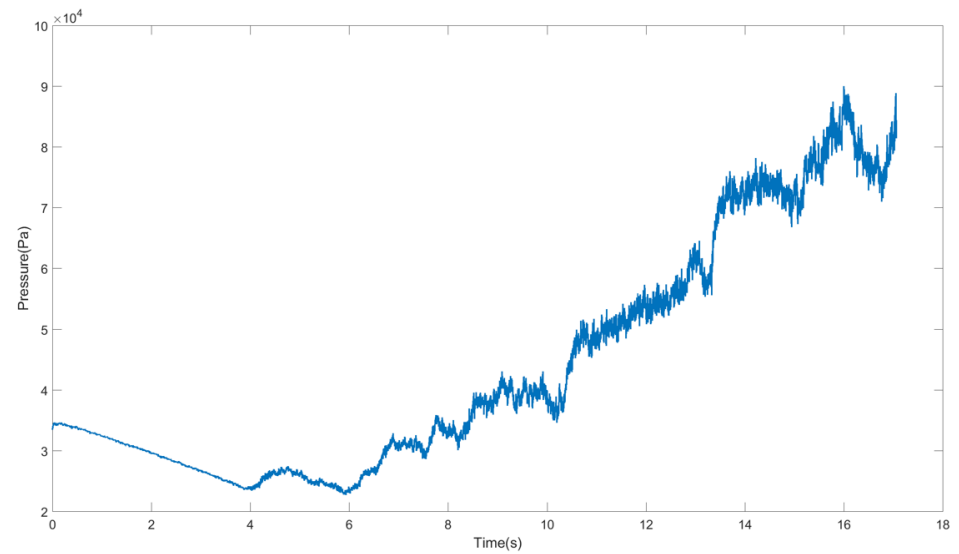

Figura 4.27: Pressão na Entrada x Tempo, $M=1 / 50$ e $C a=3.51 \times 10^{-5}$. 


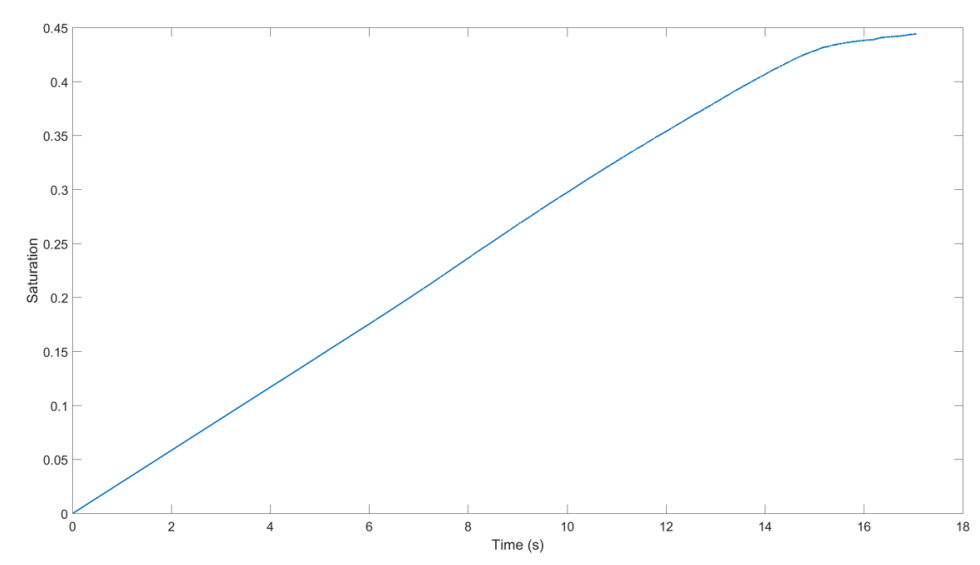

Figura 4.28: Saturação de Água x Tempo, $M=1 / 50$ e $C a=3.51 \times 10^{-5}$.

$$
M=1 / 50 \text { e } C a=4.38 \times 10^{-6}
$$

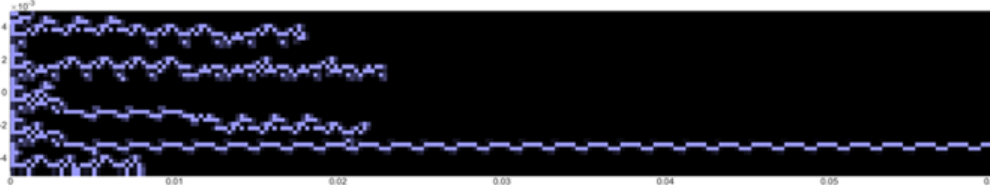

Sw $=8.45 \%$

$t=27.949 \mathrm{~s}$

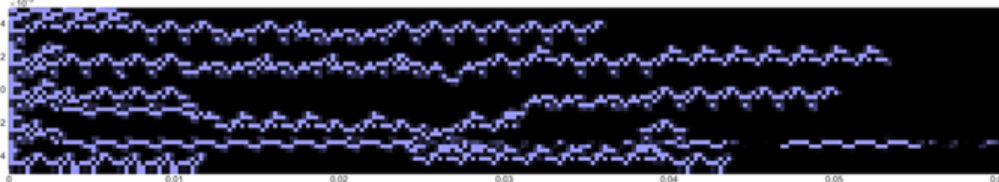

$\mathrm{Sw}=16.48 \%$

$t=55.898 \mathrm{~s}$

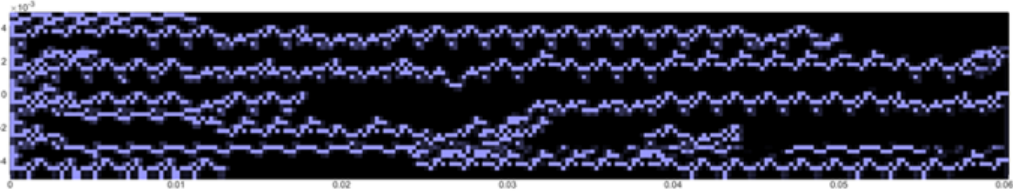

Sw $=20.81 \%$

$\mathrm{t}=83.847 \mathrm{~s}$

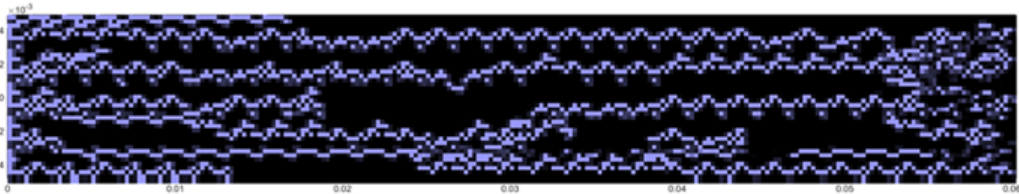

$\mathrm{Sw}=23.19 \%$

$\mathrm{t}=111.796 \mathrm{~s}$

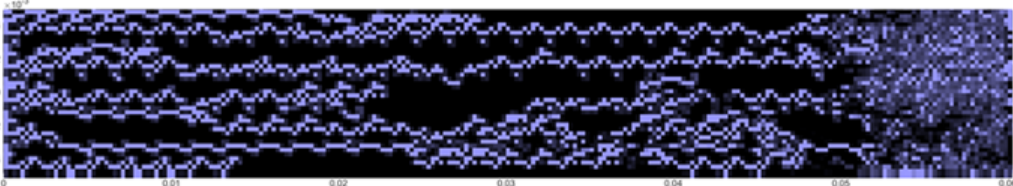

Sw $=28.17 \%$

$t=167.695 \mathrm{~s}$

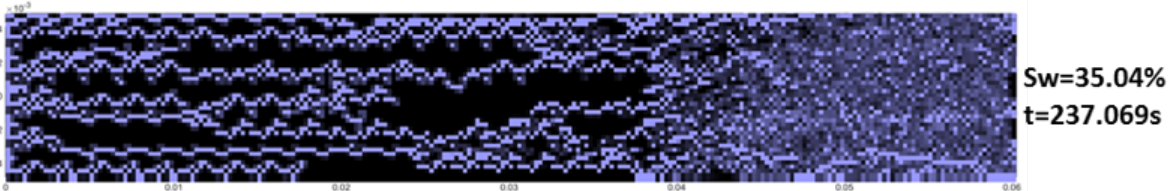

Figura 4.29: Escoamento por Drenagem, $M=1 / 50$ e $C a=4.38 \times 10^{-6}$. À direita da imagem mostramos as saturações de água no chip e os tempos correspondentes. 


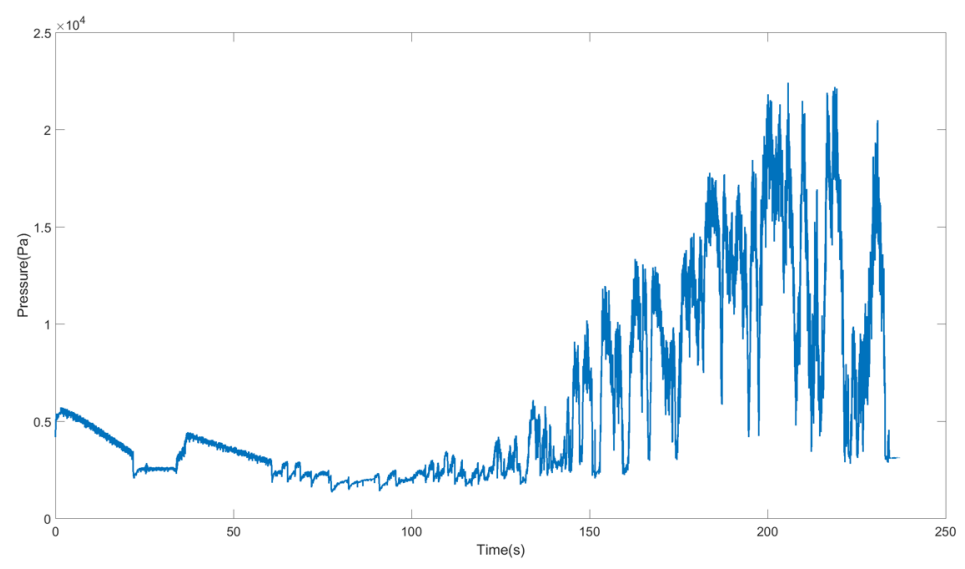

Figura 4.30: Pressão na Entrada x Tempo, $M=1 / 50$ e $C a=4.38 \times 10^{-6}$.

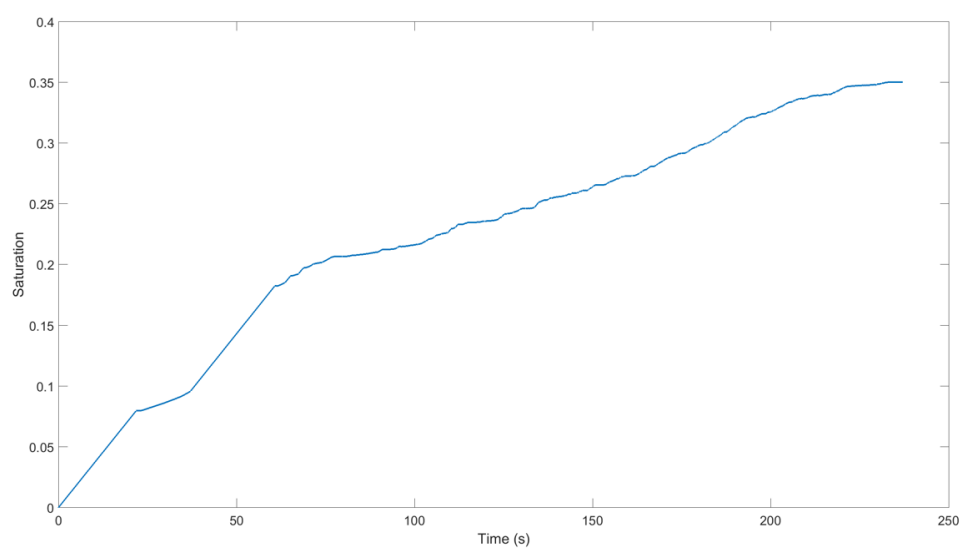

Figura 4.31: Saturação de Água x Tempo, $M=1 / 50$ e $C a=4.38 \times 10^{-6}$.

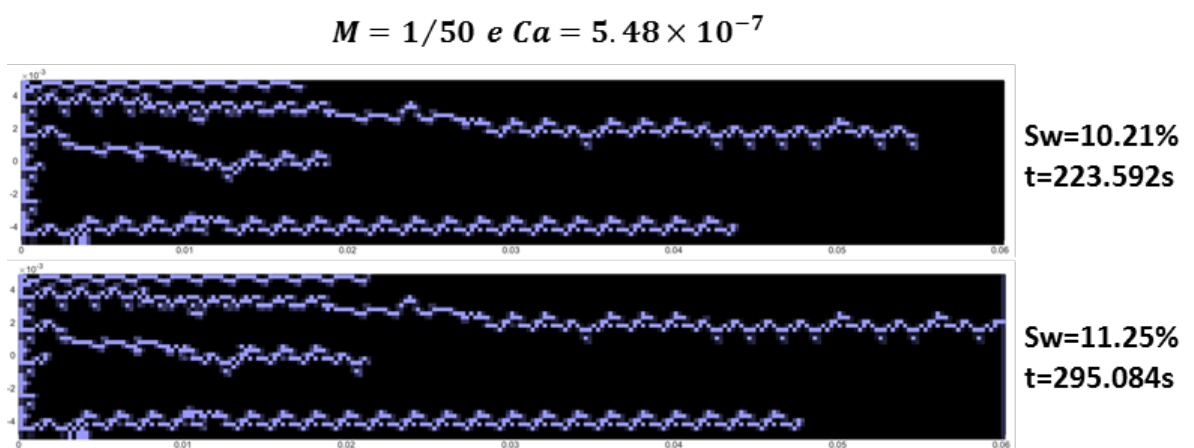

Figura 4.32: Escoamento por Drenagem, $M=1 / 50$ e $C a=5.48 \times 10^{-7}$. À direita da imagem mostramos as saturações de água no chip e os tempos correspondentes. 


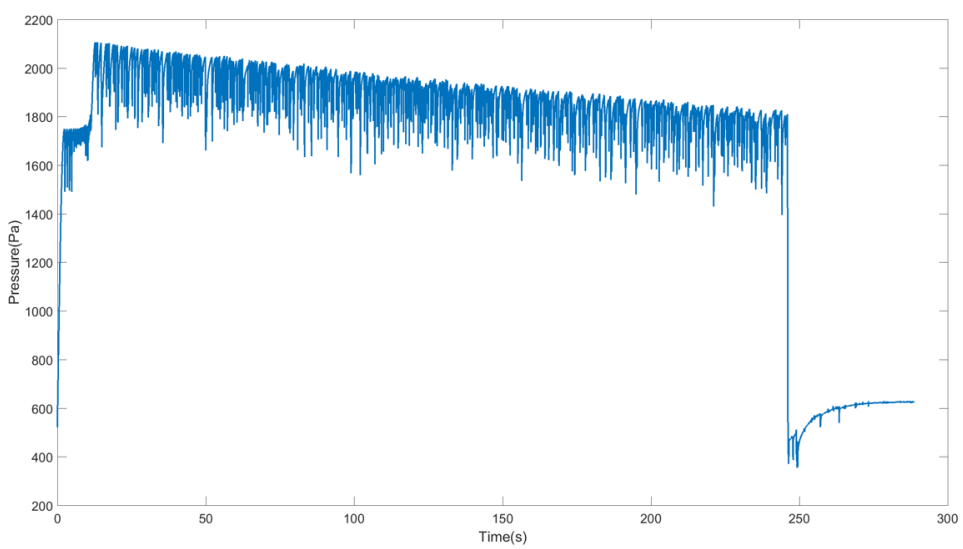

Figura 4.33: Pressão na Entrada x Tempo, $M=1 / 50$ e $C a=5.48 \times 10^{-7}$.

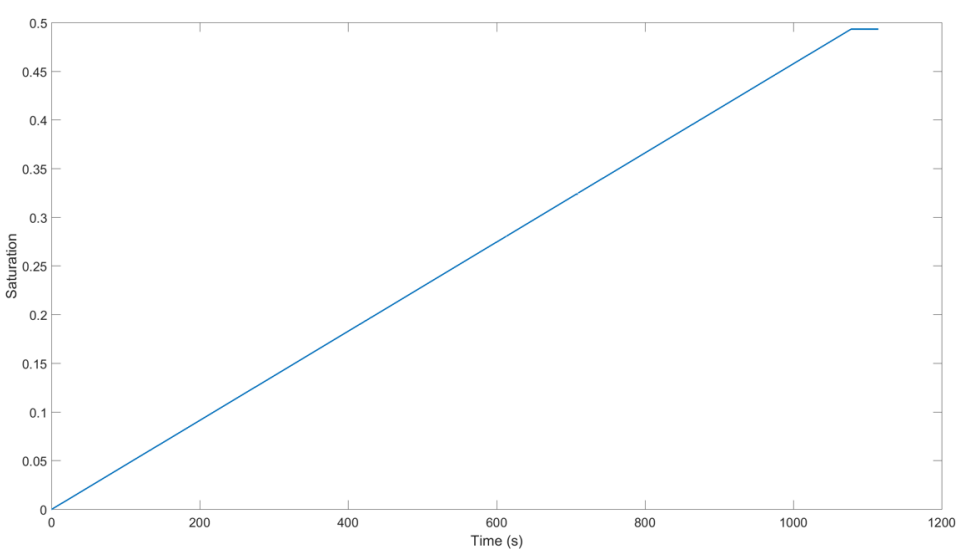

Figura 4.34: Saturação de Água x Tempo, $M=1 / 50$ e $C a=2.74 \times 10^{-7}$.

$$
M=1 / 50 \text { e Ca }=2.74 \times 10^{-7}
$$
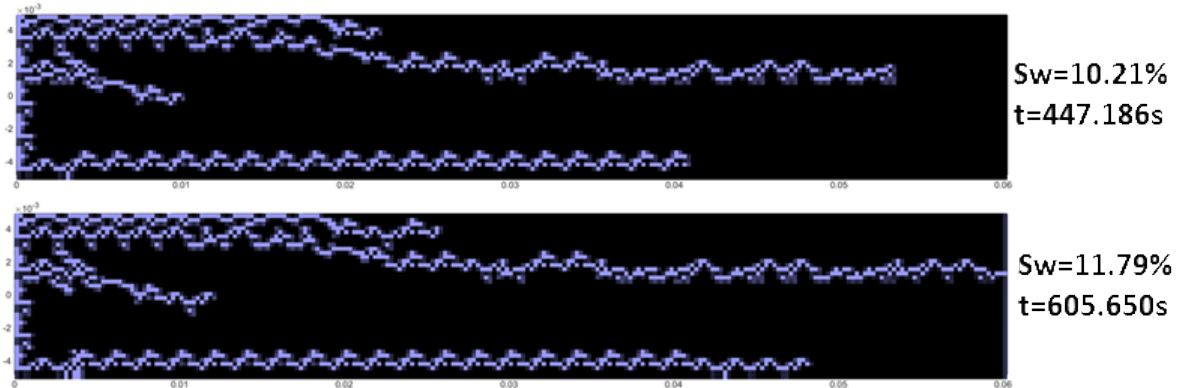

Figura 4.35: Escoamento por Drenagem, $M=1 / 50$ e $C a=2.74 \times 10^{-7}$. À direita da imagem mostramos as saturações de água no chip e os tempos correspondentes. 


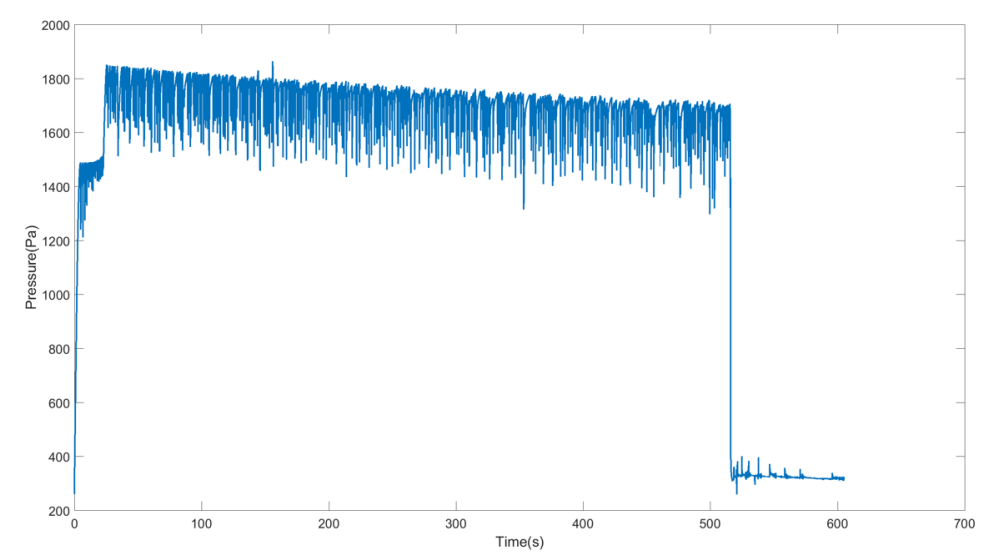

Figura 4.36: Pressão na Entrada x Tempo, $M=1 / 50$ e $C a=2.74 \times 10^{-7}$.

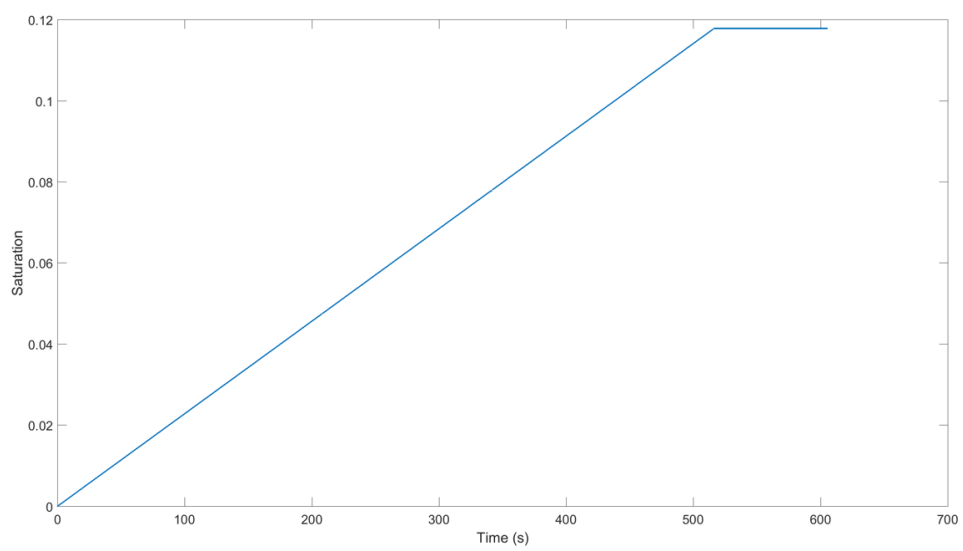

Figura 4.37: Saturação de Água x Tempo, $M=1 / 50$ e $C a=5.48 \times 10^{-7}$.

A Tabela 4.3 apresenta um resumo dos resultados das simulações para os diferentes números de capilaridade e razão de viscosidade:

Tabela 4.3: Eficiências de Deslocamento (Drenagem) - Simulador

\begin{tabular}{|c|c|c|c|c|}
\hline $\mathbf{C a}$ & Vazão $\left(\mathrm{m}^{3} / \mathrm{s}\right)$ & $S_{\text {or }}(\mathbf{M = 1} / \mathbf{5 0})$ & $S_{\text {or }}(\mathbf{M}=\mathbf{1} / \mathbf{1 6})$ & $S_{\text {or }}(\mathbf{M}=\mathbf{1 / 2})$ \\
\hline $2.74 \times 10^{-7}$ & $9.02 \times 10^{-12}$ & $88.21 \%$ & $83.54 \%$ & $51.69 \%$ \\
\hline $5.48 \times 10^{-7}$ & $1.80 \times 10^{-11}$ & $88.75 \%$ & $74.07 \%$ & $50.63 \%$ \\
\hline $4.38 \times 10^{-6}$ & $1.44 \times 10^{-10}$ & $64.96 \%$ & $62.88 \%$ & $49.20 \%$ \\
\hline $3.51 \times 10^{-5}$ & $1.15 \times 10^{-9}$ & $55.57 \%$ & $49.61 \%$ & $46.69 \%$ \\
\hline
\end{tabular}


Com o gráfico de $C a \times S_{\text {or }}$ (Figura 4.38), percebemos que quanto maior a razão de viscosidade, considerando razões de viscosidades menores que 1 , maior a eficiência de deslocamento do óleo. Observamos que o escoamento com razão de viscosidade igual a $1 / 50$, apresenta uma maior quantidade de fingers viscosos comparando ao de $1 / 16$. Porém, estes se direcionam rapidamente para a saída do chip, implicando em uma maior saturação de óleo remanescente. Como neste padrão de escoamento a principal força é devido a viscosidade do fluido deslocado, quando a razão de viscosidade aumenta, a frente é mais estável.

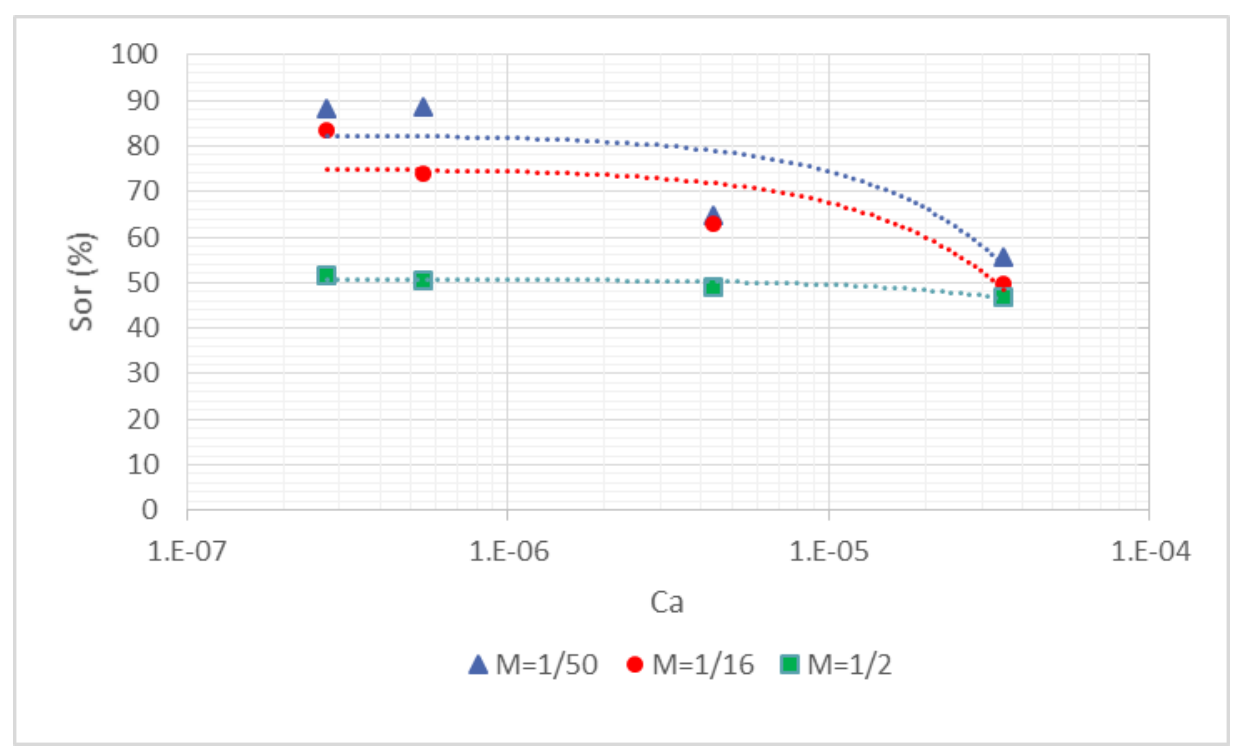

Figura 4.38: Gráfico de $C a \times S_{\text {or }}$ para $M=1 / 50, M=1 / 16$ e $M=1 / 2$.

\section{2}

\section{Resultados para Embebição}

De acordo com Joekar-Niasar e Hassanizadeh (24), quando as forças capilares são comparáveis às forças viscosas, esta competição provoca uma maior não-linearidade no campo das pressões. Isto ainda pode ser agravado quando o fluxo capilar é dominante. Em vista disto, ocorrem muitas oscilações de saturações em poros e capilares referidas como capillary pinning na literatura $(7,8,24)$.

Grande parte das simulações de escoamento por embebição analisadas neste trabalho foram marcadas por forças capilares, principalmente para baixos números de capilaridade. Devido aos longos tempos de simulações associados e instabilidades numéricas com o capillary pinning, consideramos a redução da escala do chip para $60 \%$. 


\subsection{1}

\section{Comparação com o Experimento}

Os mesmos procedimentos de análises do processo de drenagem foram realizados para embebição. Primeiramente, mantemos fixa a razão de viscosidade e variamos o número de capilaridade, conforme o experimento (12). A Tabela 4.4 mostra os parâmetros de entrada que foram utilizados tanto para o experimento quanto para o modelo numérico:

Tabela 4.4: Parâmetros de Entrada - Experimento (12) e Modelo Numérico

\begin{tabular}{|c|c|c|}
\hline Parâmetro & Valor & Unidade \\
\hline$\mu_{o}$ & 0.016 & Pa.s \\
\hline$\mu_{w}$ & 0.001 & Pa.s \\
\hline$\sigma$ & 0.03379 & $\mathrm{~N} / \mathrm{m}$ \\
\hline $\mathrm{M}$ & $1 / 16$ & \\
\hline $\mathrm{Ca}$ & $2.74 \times 10^{-7} \mathrm{a} 3.51 \times 10^{-5}$ & \\
\hline$\theta$ & $\pi$ & \\
\hline
\end{tabular}

As Figuras 4.39, 4.43 e 4.10 mostram as imagens do escoamento no chip a cada variação de aproximadamente $10 \%$ de saturação de água para os diferentes números de capilaridade. Podemos observar uma competição entre fingers viscosos e capilares para o número de capilaridade mais alto, onde a vazão imposta é maior. Para os números de capilaridades mais baixos, o padrão de fingering capilar é dominante.

As curvas de pressão de entrada com o tempo (Figuras 4.40, 4.44 e 4.11) possuem valores mais baixos comparadas às de drenagem. Isto ocorre devido ao fato de que na embebição, a pressão capilar está a favor do deslocamento, não necessitando de pressões tão altas na entrada como na drenagem. Também, as pressões de entrada diminuem com a redução do número de capilaridade por conta de vazões impostas cada vez menores.

A saturação cresce linearmente com o tempo até o momento de breakthrough, provando a conservação de massa (Figuras 4.42, 4.45 e 4.12). 


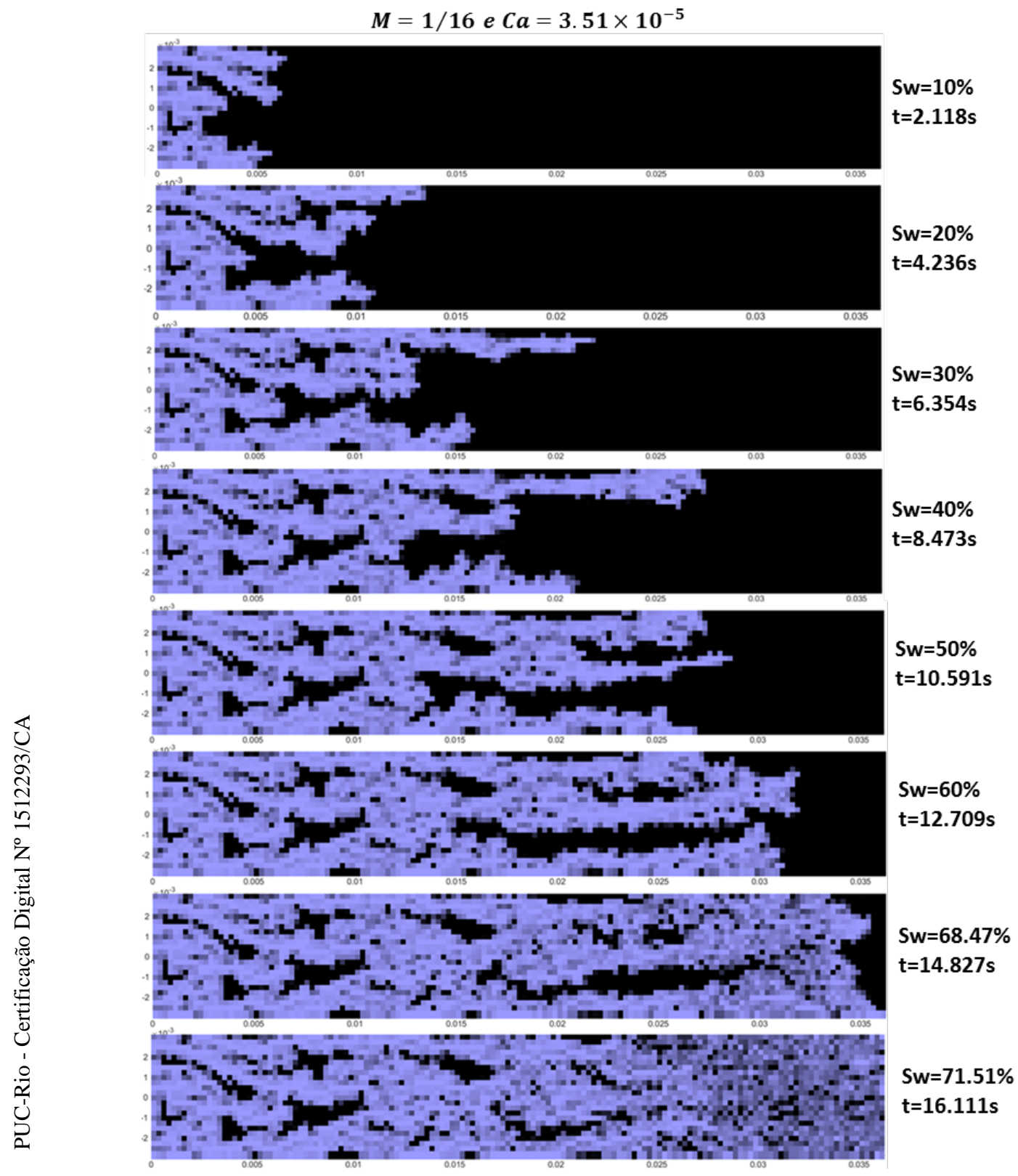

Figura 4.39: Escoamento por Embebição, $M=1 / 16$ e $C a=3.51 \times 10^{-5}$. À direita da imagem mostramos as saturações de água no chip e os tempos correspondentes. 


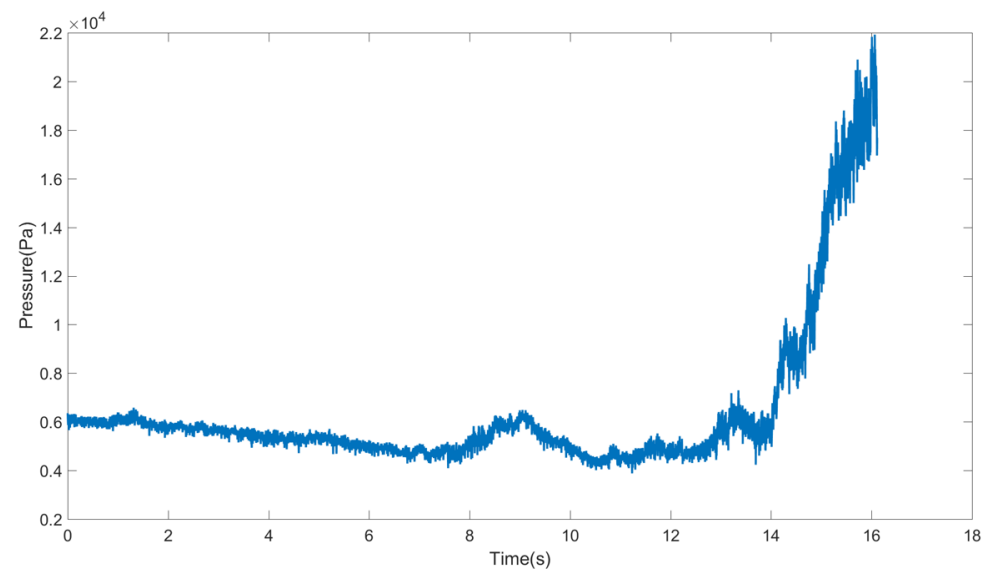

Figura 4.40: Pressão na Entrada x Tempo, $M=1 / 16$ e $C a=3.51 \times 10^{-5}$.

A curva de pressão de entrada com tempo, para o número de capilaridade de $3.51 \times 10^{-5}$ (Figura 4.40), apresenta crescimentos com o tempo. Isto ocorre porque alguns fingers modificam suas direções (8.473s, Figura 4.39), se unindo a outros. Uma vez que esta junção implica na formação de gânglios de óleos e, por consequência, pressões capilares em direção contrária ao movimento, o caminho preferencial do fluxo é em capilares com fluxo monofásico. Neste conjunto de capilares, por não haver pressão capilar na direção a favor do fluxo, a pressão de entrada aumenta para a manutenção da vazão imposta. A Figura 4.41 apresenta o heat map da vazão posto juntamente com a imagem do escoamento. Com estas imagens podemos notar o novo caminho da água, contornando os gânglios de óleo. Além disso, na Figura 4.39, entre 14.827s e $16.11 s$, observamos uma zona de contato dos fingers, provocando também um grande aumento na pressão.

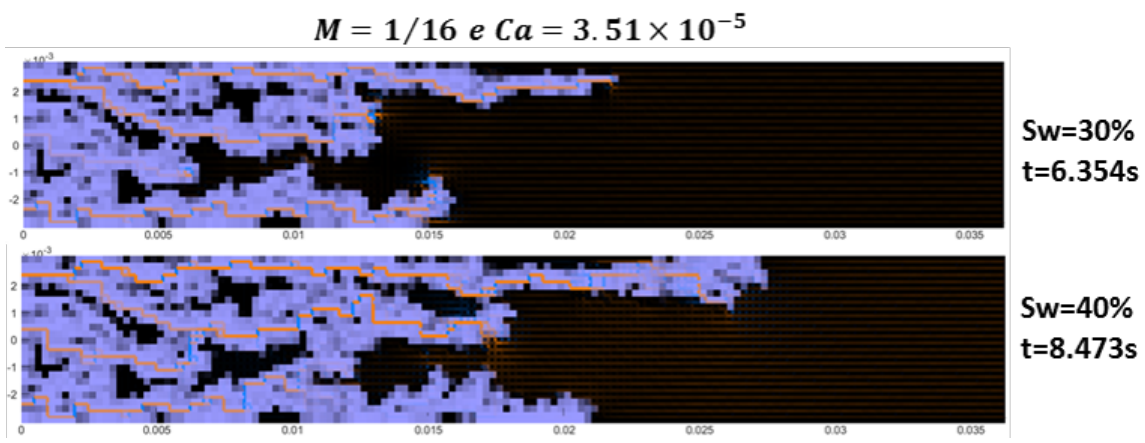

Figura 4.41: Heat Map de vazão nos capilares juntamente com a imagem do escoamento para os instantes $6.354 \mathrm{~s}$ e $8.473 \mathrm{~s}, M=1 / 16$ e $C a=3.51 \times 10^{-5}$. 


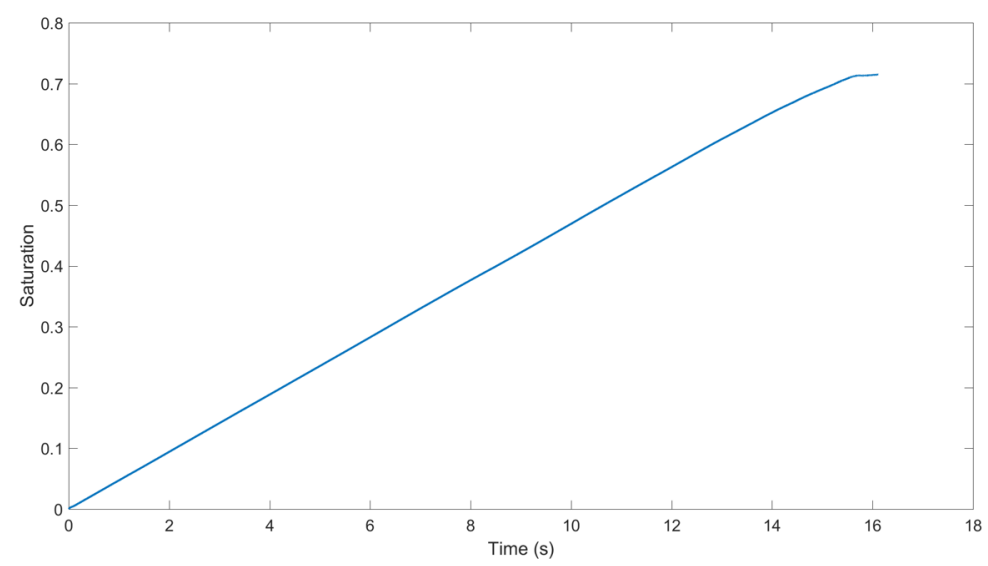

Figura 4.42: Saturação de Água x Tempo, $M=1 / 16$ e $C a=3.51 \times 10^{-5}$.

A simulação considerando número de capilaridade de $4.38 \times 10^{-6}$ foi abortada por apresentar um tempo de simulação inviável para sua conclusão. Instabilidades numéricas contribuíram para a ocorrência de capillary pinning. 


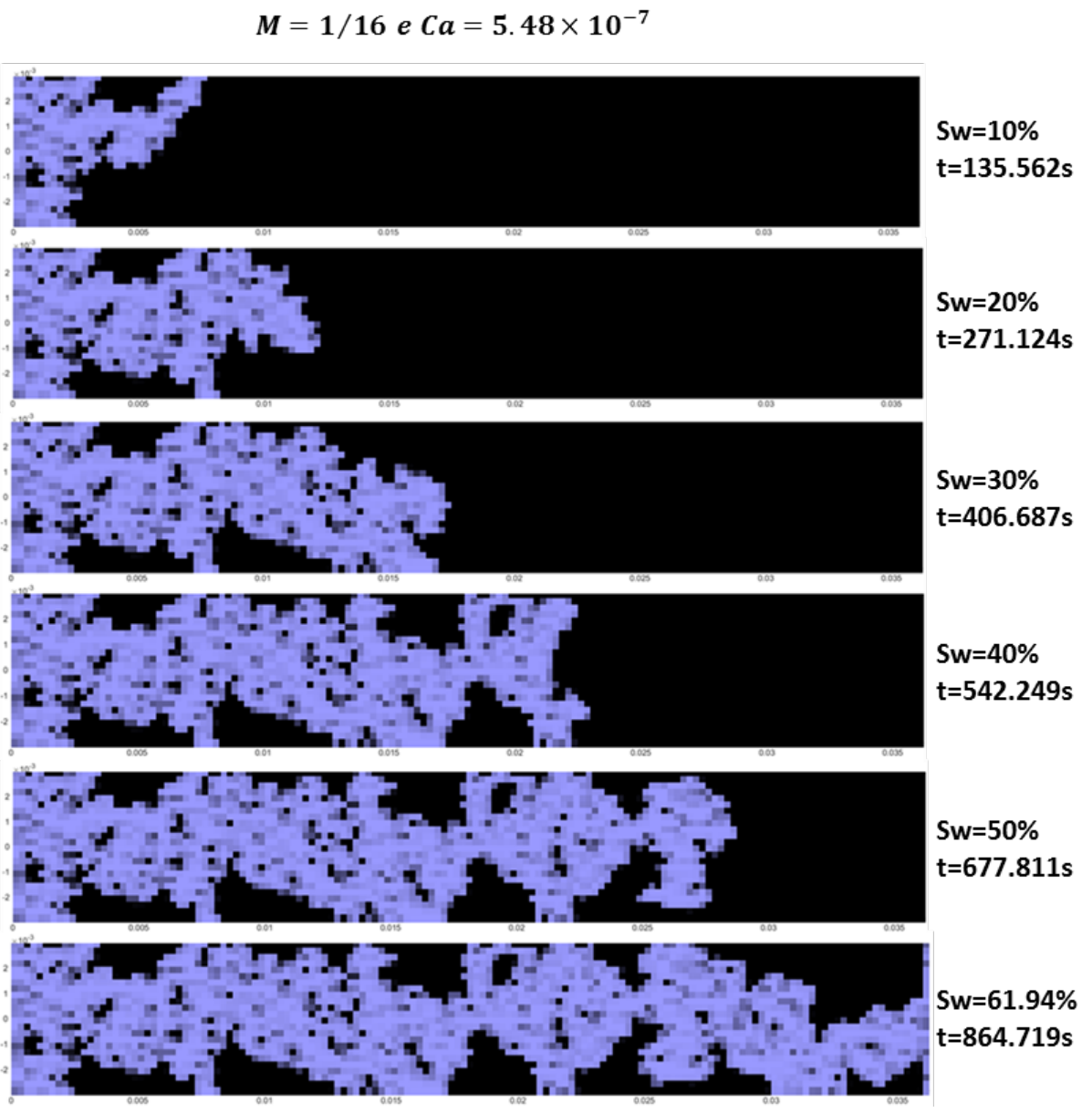

Figura 4.43: Escoamento por Embebição, $M=1 / 16$ e $C a=5.48 \times 10^{-7}$. À direita da imagem mostramos as saturações de água no chip e os tempos correspondentes.

As simulações com números de capilaridade mais baixos, em virtude de menores vazões impostas, presenciaram valores de pressão de entrada negativos (Figuras 4.44 e 4.47 ). 


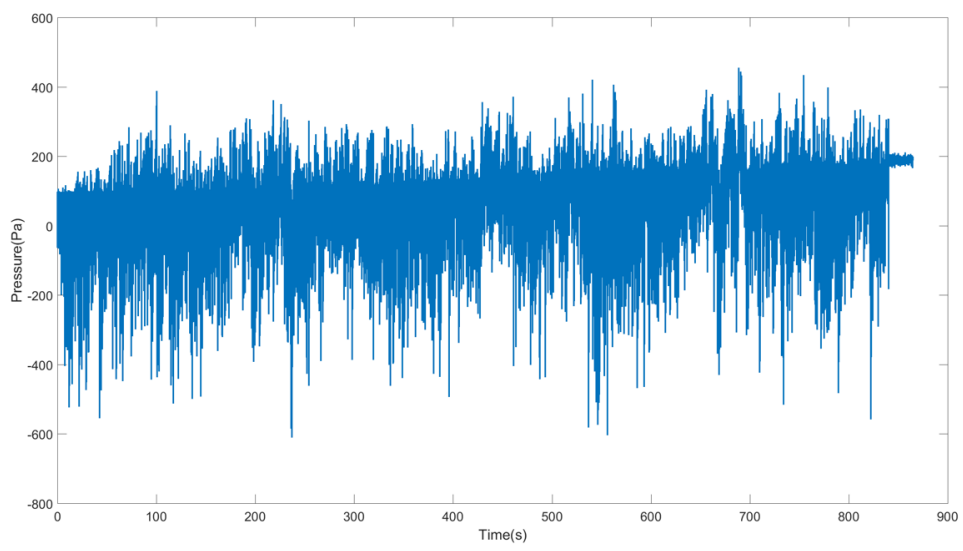

Figura 4.44: Pressão na Entrada x Tempo, $M=1 / 16$ e $C a=5.48 \times 10^{-7}$.

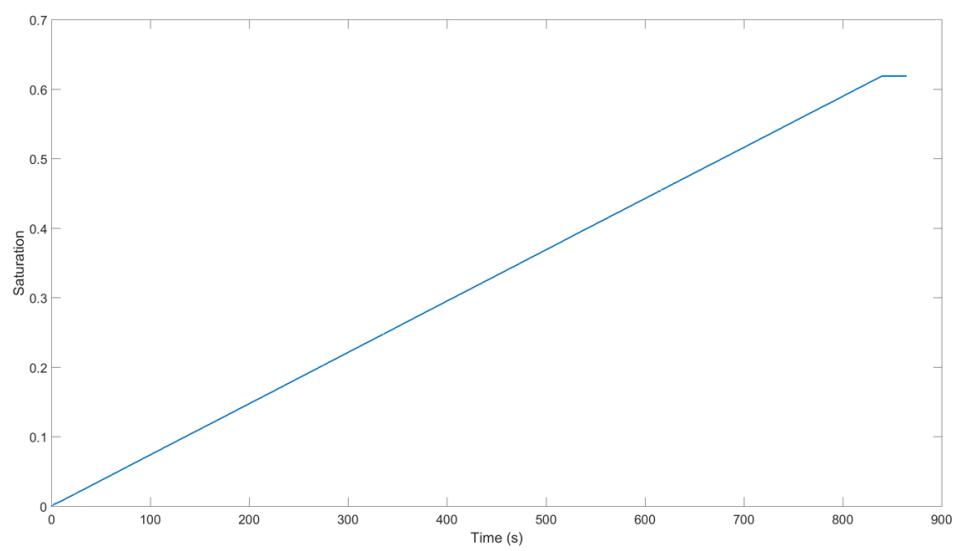

Figura 4.45: Saturação de Água x Tempo, $M=1 / 16$ e $C a=5.48 \times 10^{-7}$. 
$M=1 / 16$ e $C a=2.74 \times 10^{-7}$

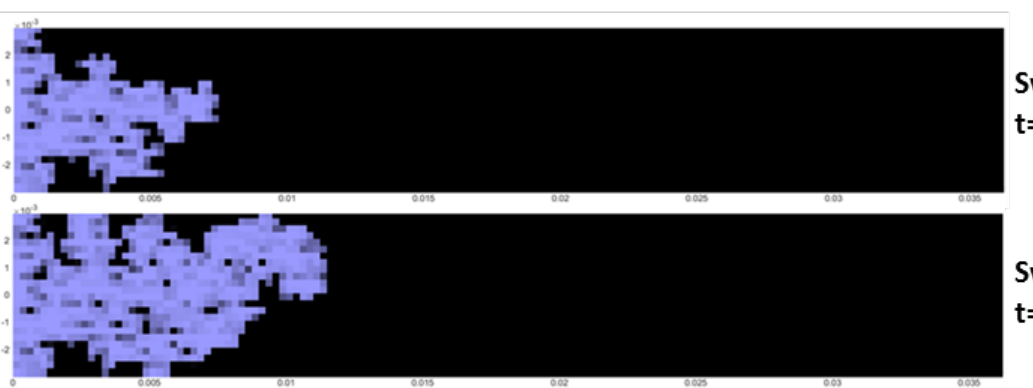

Sw $=10 \%$

$\mathrm{t}=\mathbf{2 7 1 . 1 2 5 \mathrm { s }}$

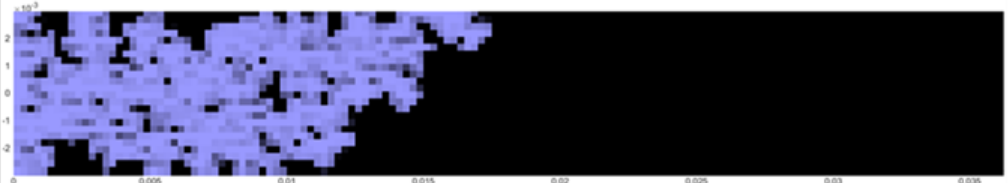

$\mathrm{Sw}=\mathbf{3 0 \%}$

$t=813.373 \mathrm{~s}$

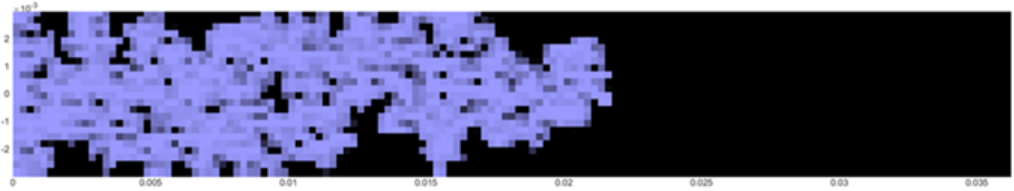

Sw $=40 \%$

$t=1084.497 \mathrm{~s}$

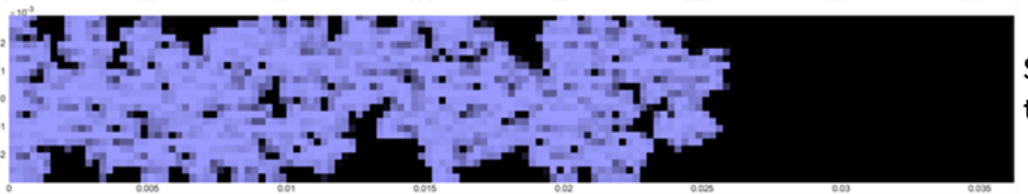

Sw $=50 \%$

$t=1355.622 \mathrm{~s}$

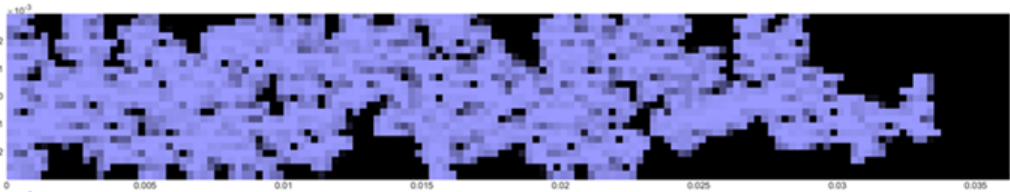

$\mathrm{Sw}=60 \%$

$t=1626.746 s$

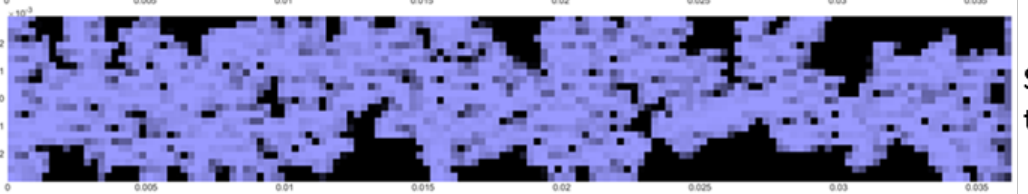

Sw $=67.34 \%$

$t=1858.878 s$

Figura 4.46: Escoamento por Embebição, $M=1 / 16$ e $C a=2.74 \times 10^{-7}$. À direita da imagem mostramos as saturações de água no chip e os tempos correspondentes. 


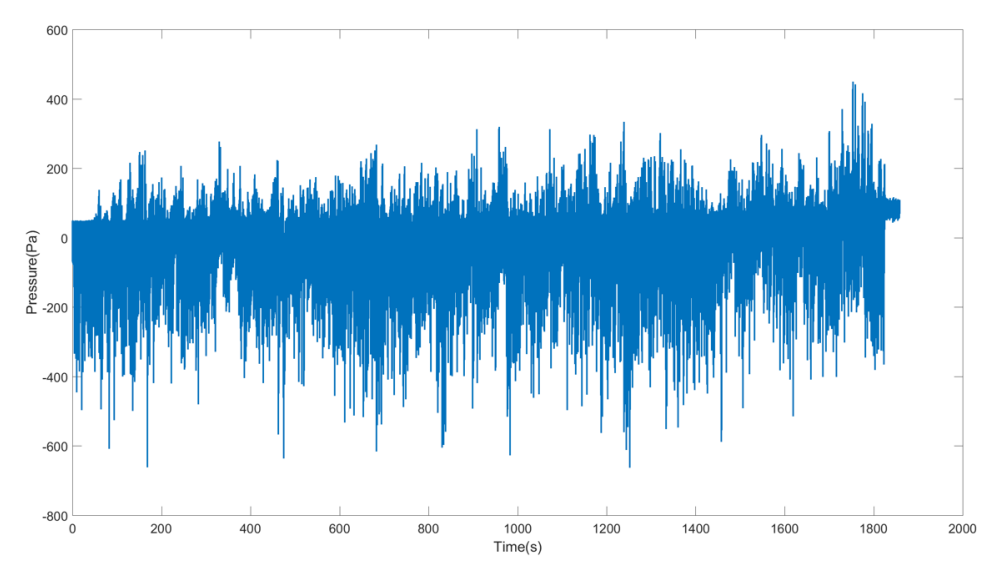

Figura 4.47: Pressão na Entrada x Tempo, $M=1 / 16$ e $C a=2.74 \times 10^{-7}$.

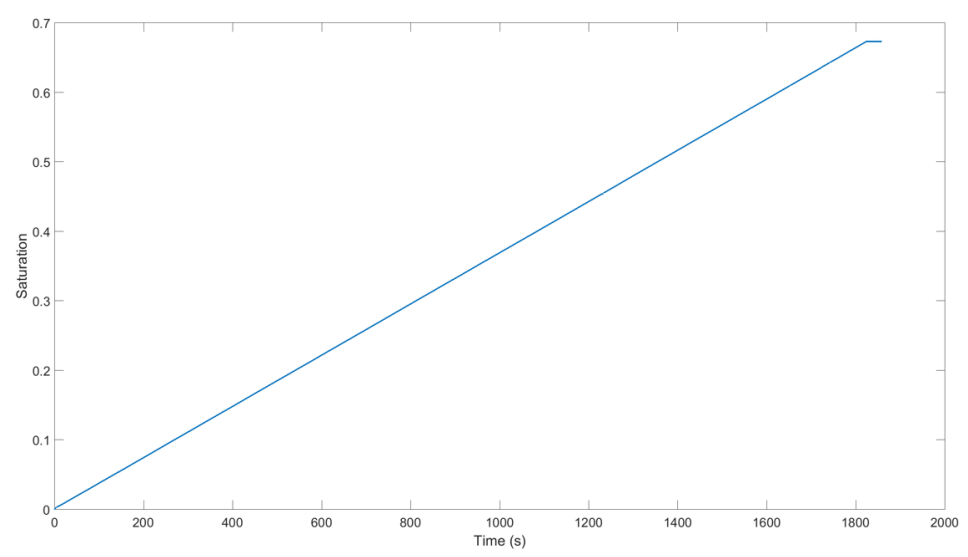

Figura 4.48: Saturação de Água x Tempo, $M=1 / 16$ e $C a=2.74 \times 10^{-7}$.

A Tabela 4.5 mostra as eficiências do deslocamento através da saturação de óleo remanescente, $S_{o r}$, para os diferentes números de capilaridades, tanto para o experimento quanto para o simulador.

Tabela 4.5: Eficiências de Deslocamento (Embebição) - Experimento (12) e Simulador

\begin{tabular}{|c|c|c|}
\hline $\mathbf{C a}$ & $S_{\text {or }}$ (Experimento) & $S_{\text {or }}$ (Simulador $)$ \\
\hline $2.74 \times 10^{-7}$ & $57.50 \%$ & $28.49 \%$ \\
\hline $5.48 \times 10^{-7}$ & $53.80 \%$ & $38.06 \%$ \\
\hline $4.38 \times 10^{-6}$ & $52.00 \%$ & Abortada \\
\hline $3.51 \times 10^{-5}$ & $34.80 \%$ & $27.08 \%$ \\
\hline
\end{tabular}


Para os diferentes números de capilaridade analisados, a saturação de óleo remanescente se manteve praticamente constante. A Figura 2.14 do Capítulo 2 mostra o mesmo resultado na literatura, considerando razão de viscosidade menor que 1 e números de capilaridade menores que $10^{-5}$.

A Figura 4.49 mostra o gráfico de $C a \times S_{o r}$ para o experimento e para o modelo numérico. Nossas simulações apresentaram saturações de óleo remanescente menores que o experimento, isto se deve ao fato de considerarmos deslocamento pistão no simulador, não contemplando o mecanismo de snap-off. Para o processo de embebição, o mecanismo de snap-off é o maior responsável pelo aprisionamento do óleo $(10,24,23,22)$. Como as vazões analisadas são baixas, a camada molhante de água tem tempo suficiente para se acumular e preencher as constrições dos capilares, provocando o trapeamento do óleo.

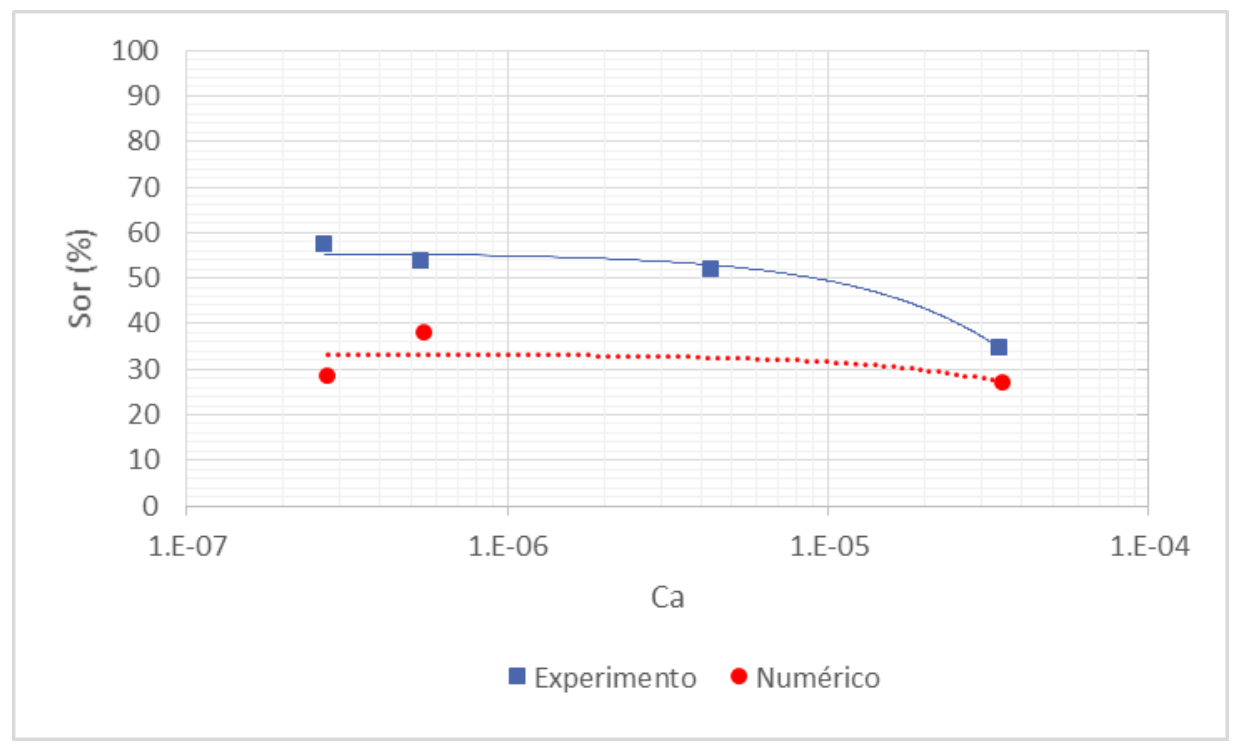

Figura 4.49: Comparação entre o Modelo Numérico e o Experimento através do gráfico de $C a \times S_{o r}$.

\subsection{2}

\section{Variação de Razão de Viscosidade}

A segunda análise do processo de embebição seguiu os mesmos procedimentos da drenagem, variando a razão de viscosidade para os mesmos números de capilaridade. Discutimos o escoamento com uma razão de viscosidade de 1/2, maior que a analisada na Subseção 4.2.1. E, após isto, analisamos os resultados para uma razão de viscosidade menor, de $1 / 50$. Para variação deste parâmetro, modificamos apenas a viscosidade do óleo.

As Figuras 4.50, 4.53, 4.56 e 4.59 mostram as imagens do escoamento para os diferentes números de capilaridade e razão de viscosidade de $1 / 2$. O 
escoamento é marcado por uma frente estável para número de capilaridade mais alto (Figura 4.50). Para os números de capilaridade mais baixos (Figuras 4.53, 4.56 e 4.59), o padrão de escoamento dominante é de fingerings capilares.

As pressões de entrada (Figuras 4.51, 4.54, 4.56 e 4.59) apresentam valores menores comparadas às simulações com razão de viscosidade menos favorável, de 1/16.

Por considerarmos a vazão imposta constante e fluidos incompressíveis, a saturação de água cresce linearmente (Figuras 4.52, 4.55, 4.58 e 4.25) até o momento de breakthrough. 


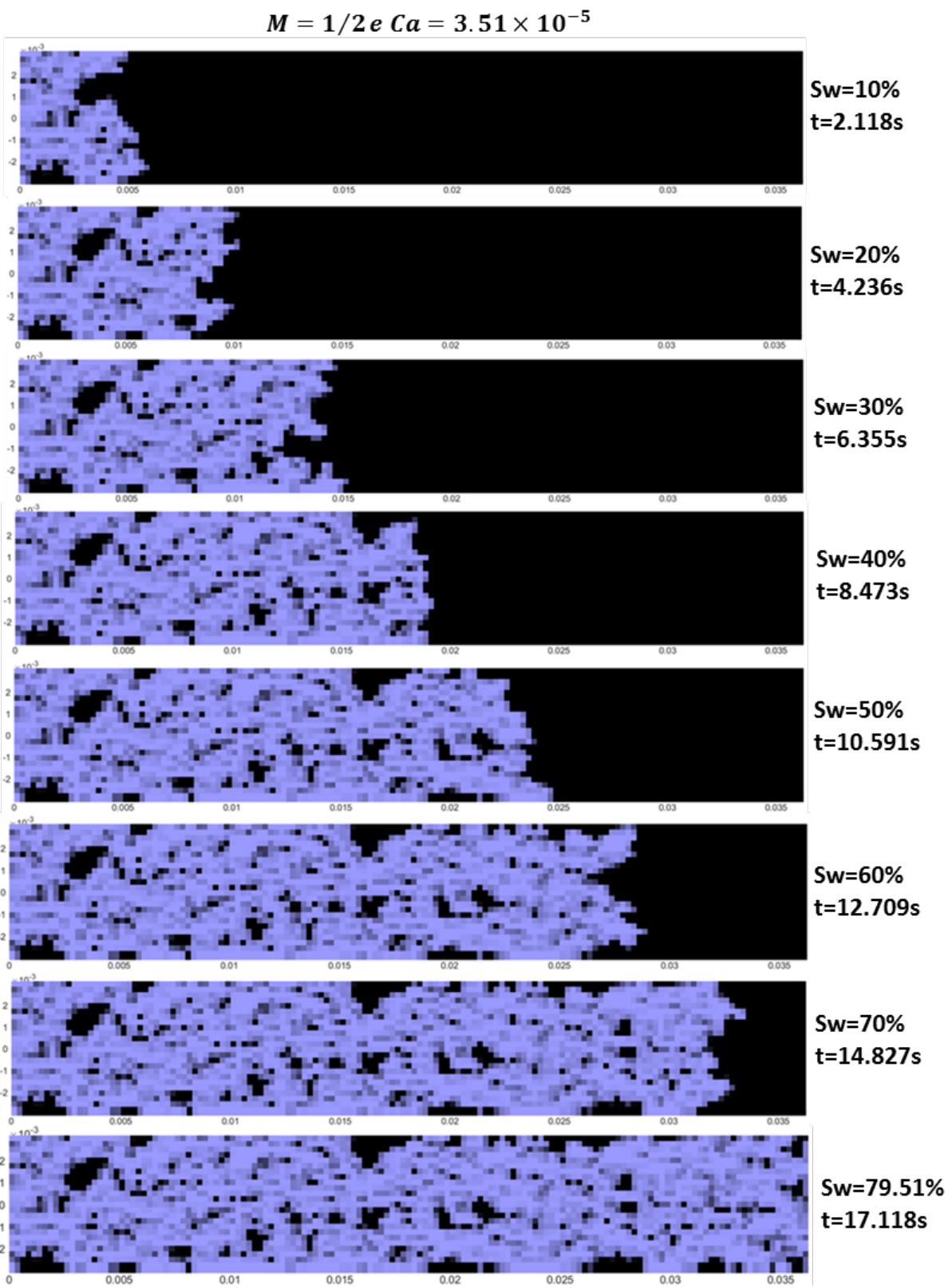

Figura 4.50: Escoamento por Embebição, $M=1 / 2$ e $C a=3.51 \times 10^{-5}$. À direita da imagem mostramos as saturações de água no chip e os tempos correspondentes.

A curva de pressão de entrada com tempo para o número de capilaridade de $3.51 \times 10^{-5}$ (Figura 4.51) apresenta um crescimento praticamente linear, desconsiderando as oscilações devido à pressão capilar. Como a frente estável se desloca ao longo do tempo, capilares em fluxo monofásico de água substituem capilares que antes eram saturados com óleo e possuíam interface água/óleo. A ausência destas interfaces nesta região que aumenta ao longo do tempo, ou seja, a ausência da pressão capilar a favor do fluxo, faz com que a pressão de 
entrada aumente com o avanço da frente para manutenção da vazão imposta.

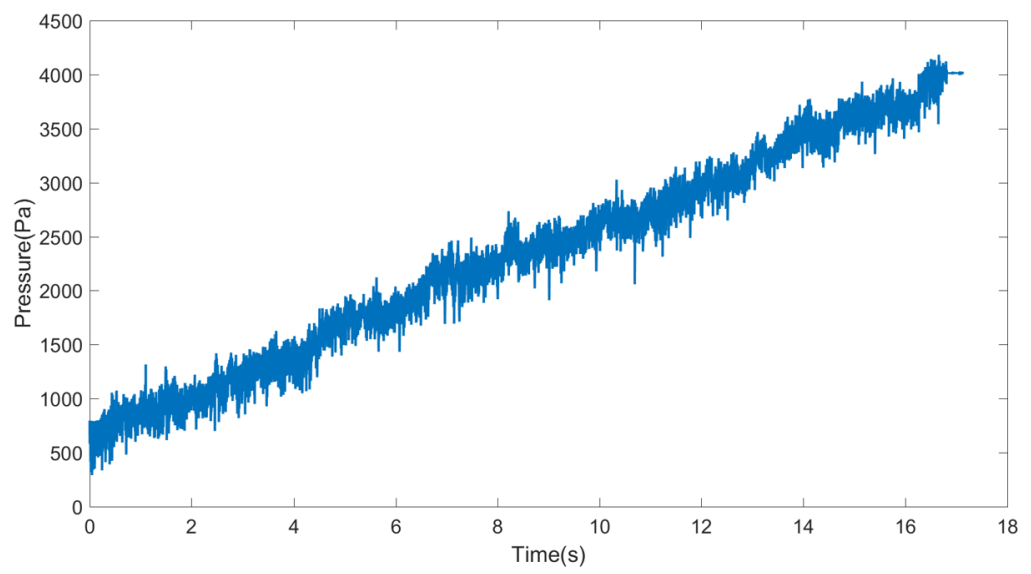

Figura 4.51: Pressão na Entrada x Tempo, $M=1 / 2$ e $C a=3.51 \times 10^{-5}$.

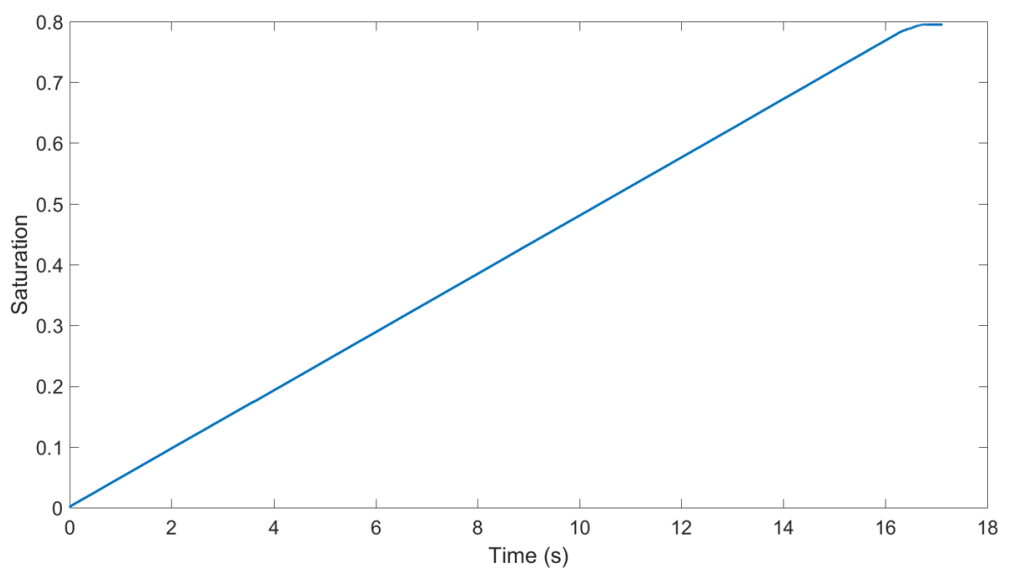

Figura 4.52: Saturação de Água x Tempo, $M=1 / 2$ e $C a=3.51 \times 10^{-5}$. 


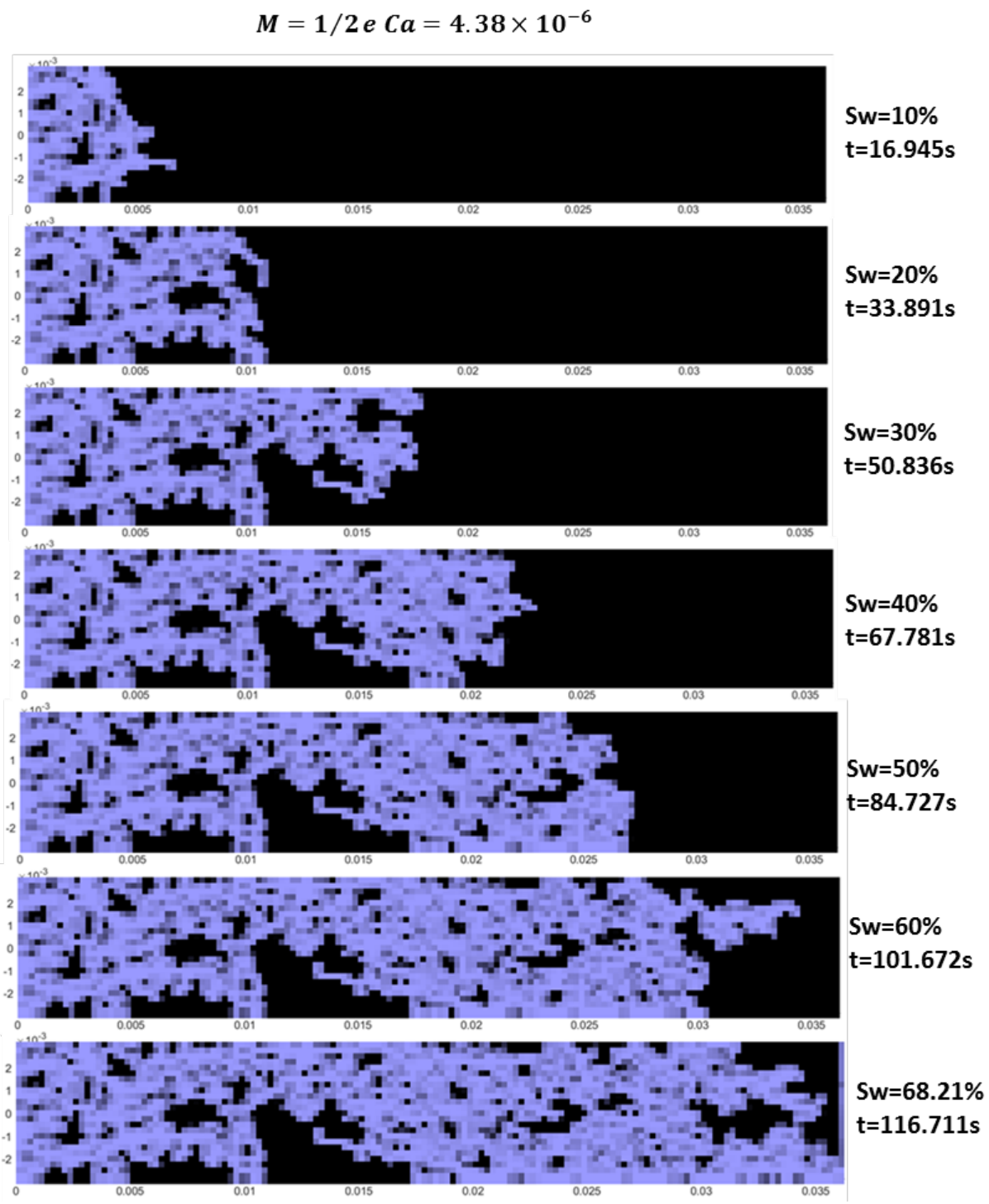

Figura 4.53: Escoamento por Embebição, $M=1 / 2$ e $C a=4.38 \times 10^{-6}$. $\AA$ direita da imagem mostramos as saturações de água no chip e os tempos correspondentes.

A curva de pressão de entrada com tempo para o número de capilaridade de $4.38 \times 10^{-6}$ (Figura 4.54) possui um comportamento similar ao de $C a=3.51 \times 10^{-5}$, apresentando um crescimento praticamente linear, desconsiderando as oscilações devido à pressão capilar. Neste caso, devido a uma vazão imposta mais baixa, a pressão de entrada é ainda menor. Além disso, a frente de avanço menos estável provoca um menor crescimento da pressão. 


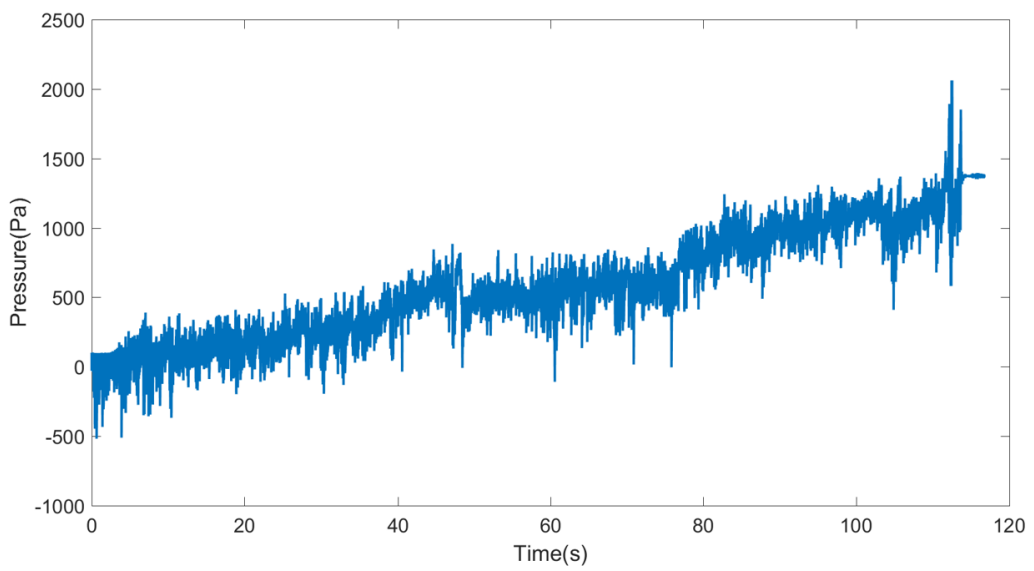

Figura 4.54: Pressão na Entrada x Tempo, $M=1 / 2$ e $C a=4.38 \times 10^{-6}$.

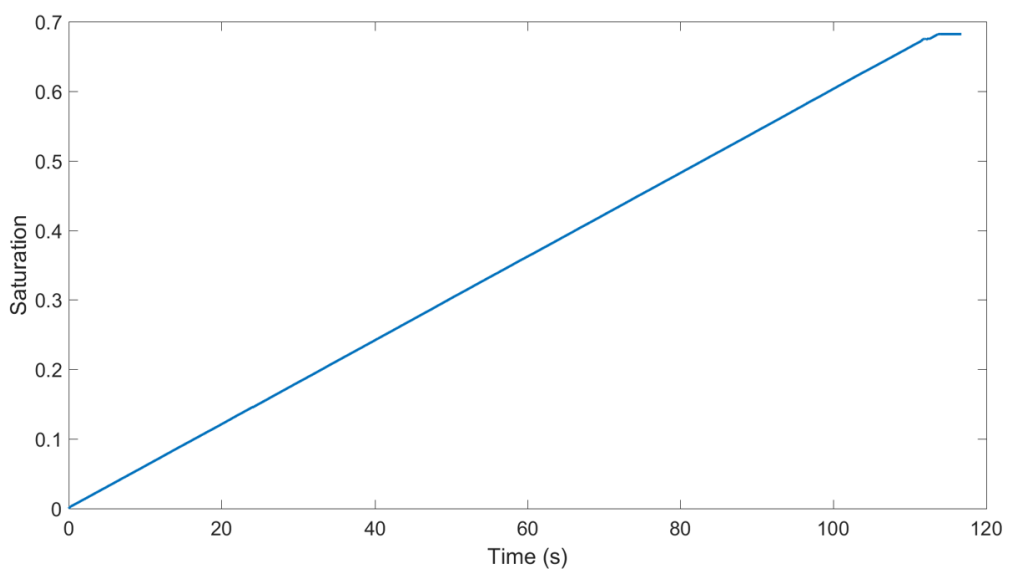

Figura 4.55: Saturação de Água x Tempo, $M=1 / 2$ e $C a=4.38 \times 10^{-6}$. 


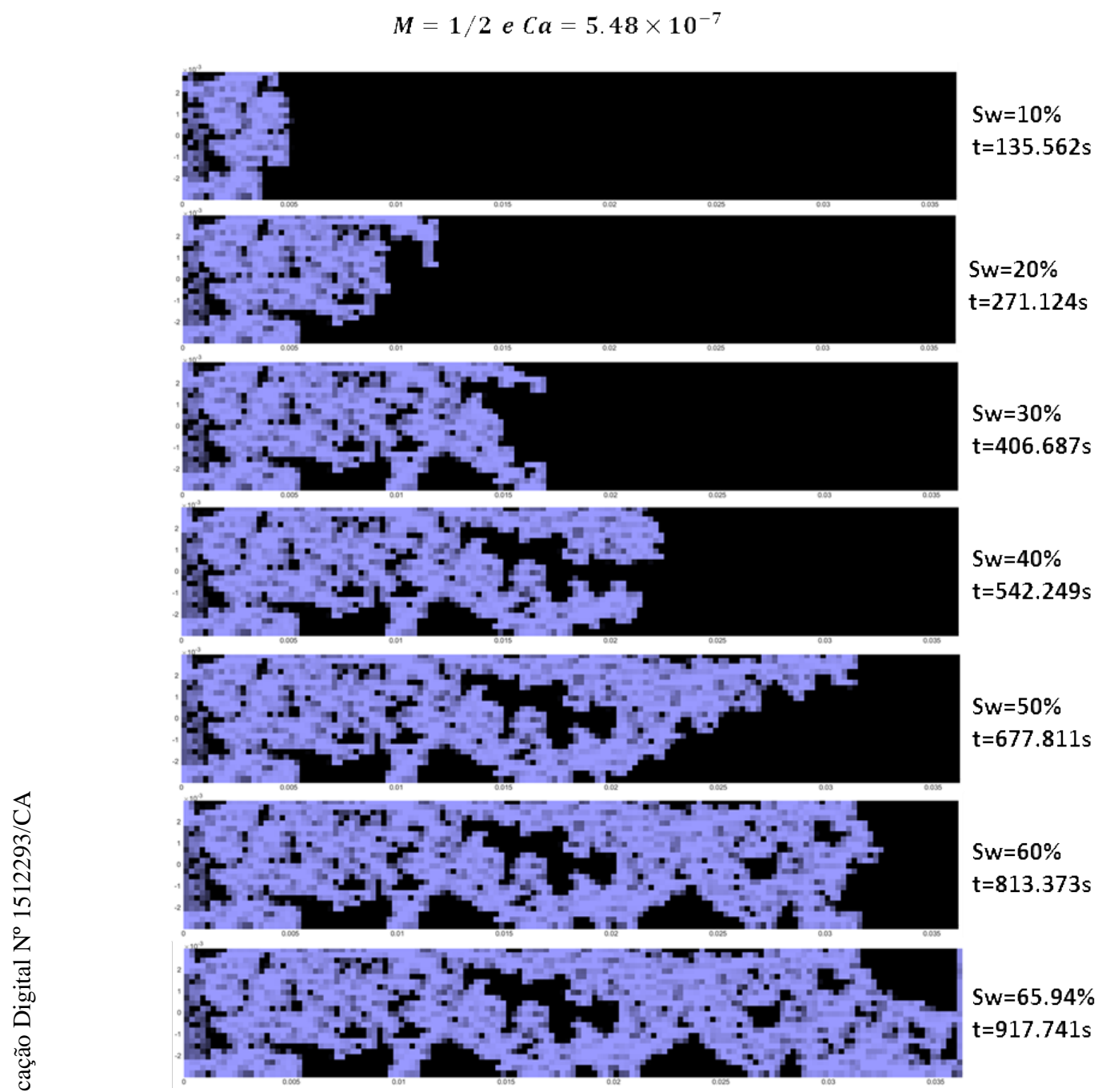

Figura 4.56: Escoamento por Embebição, $M=1 / 2$ e $C a=5.48 \times 10^{-7}$. ̊̀ direita da imagem mostramos as saturações de água no chip e os tempos correspondentes.

Para as simulações com números de capilaridade mais baixos, devido às vazões impostas serem mais baixas, observamos valores de pressão de entrada negativos (Figuras 4.57 e 4.60 ). 


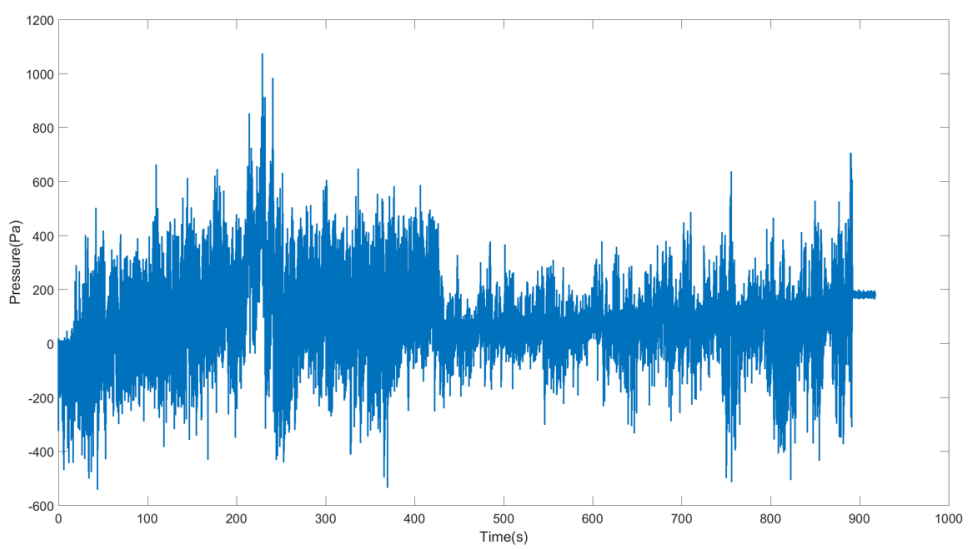

Figura 4.57: Pressão na Entrada x Tempo, $M=1 / 2$ e $C a=5.48 \times 10^{-7}$.

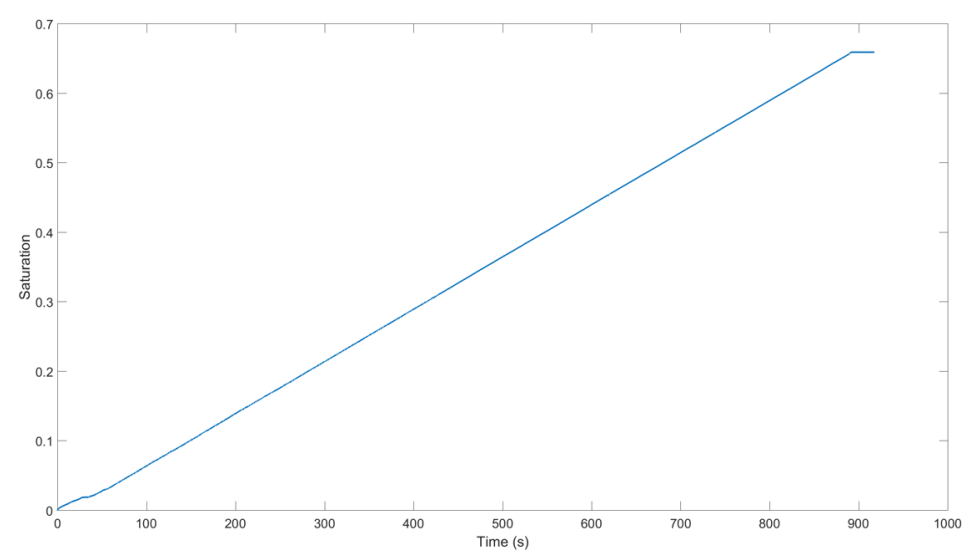

Figura 4.58: Saturação de Água x Tempo, $M=1 / 2$ e $C a=5.48 \times 10^{-7}$. 


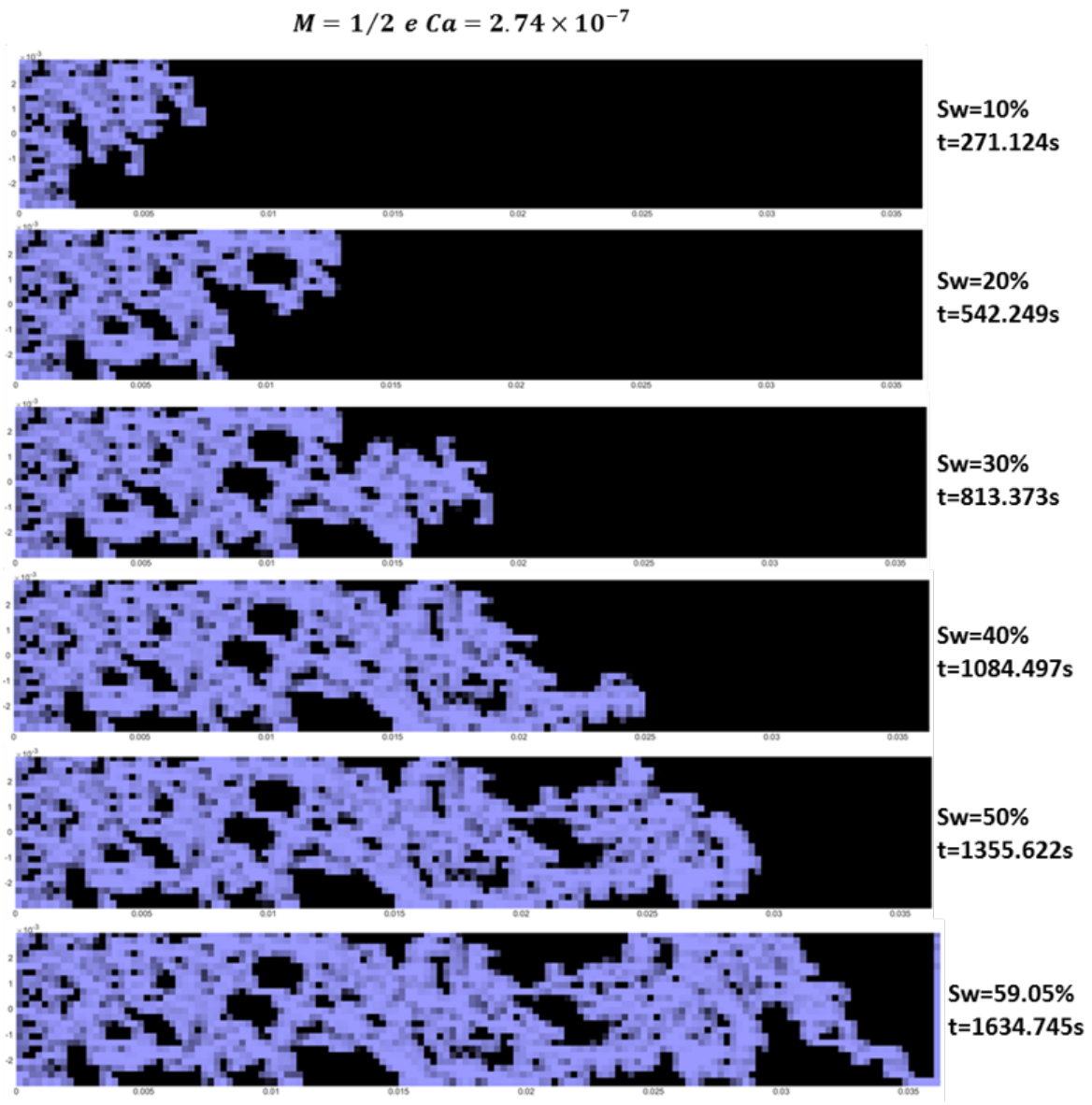

Figura 4.59: Escoamento por Embebição, $M=1 / 2$ e $C a=2.74 \times 10^{-7}$. $\AA$ direita da imagem mostramos as saturações de água no chip e os tempos correspondentes.

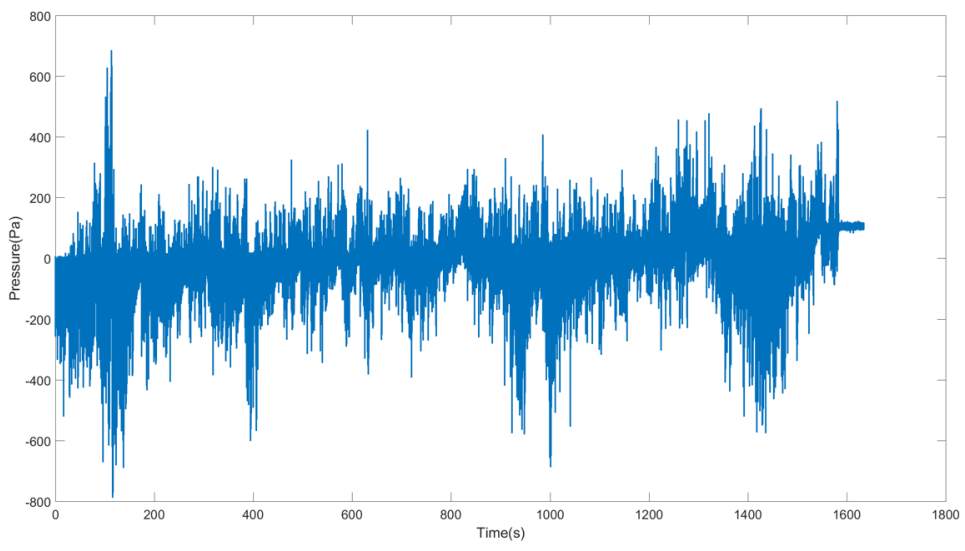

Figura 4.60: Pressão na Entrada x Tempo, $M=1 / 2$ e $C a=2.74 \times 10^{-7}$. 


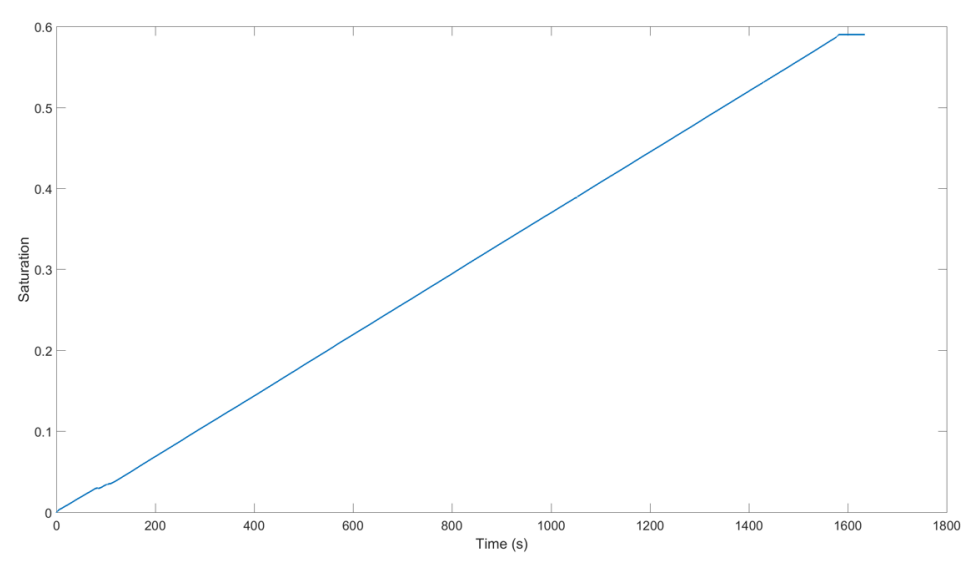

Figura 4.61: Saturação de Água x Tempo, $M=1 / 2$ e $C a=2.74 \times 10^{-7}$.

As Figuras 4.62, 4.65 e 4.68 mostram as imagens do escoamento para os diferentes números de capilaridade e razão de viscosidade de 1/50. Como no escoamento com razão de viscosidade de $1 / 16$, para números de capilaridades mais altos, ocorre a competição entre os fingers viscosos e capilares. Porém, nesse caso, com uma viscosidade do fluido deslocado maior ainda, os fingers viscosos foram mais dominantes nos escoamentos com vazões impostas maiores (Figuras 4.62 e 4.65). Já, para número de capilaridade baixo, o padrão de escoamento continua a ser dominado por fingers capilares (Figura 4.68).

As pressões de entrada (Figuras 4.63, 4.66 e 4.68) são maiores do que nas simulações com razões de viscosidade mais favoráveis, de 1/2 e 1/16.

A saturação cresce linearmente com o tempo até o momento de breakthrough, provando a conservação de massa (Figuras 4.64, 4.67 e 4.37). 


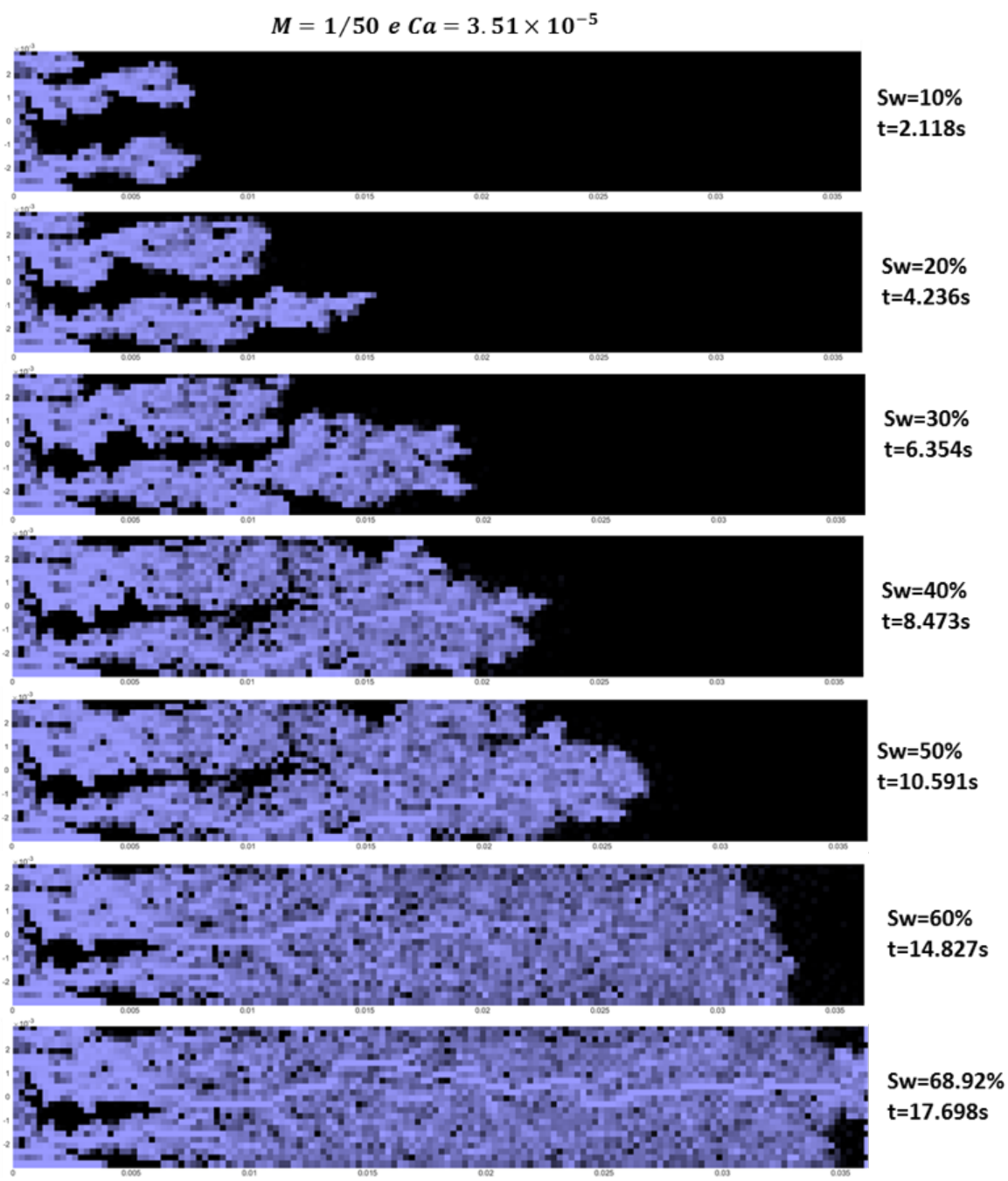

Figura 4.62: Escoamento por Embebição, $M=1 / 50$ e $C a=3.51 \times 10^{-5}$. À direita da imagem mostramos as saturações de água no chip e os tempos correspondentes.

A curva de pressão de entrada com o tempo para o número de capilaridade de $3.51 \times 10^{-5}$ (Figura 4.63), apresenta alguns pequenos crescimentos por conta da junção de alguns fingers de água e criação de gânglios de óleo, como nas simulações com razão de viscosidade de 1/16. Em torno de $10 s$, quando se formou uma frente mais estável, a pressão de entrada tem um grande aumento até o breakthrough. 


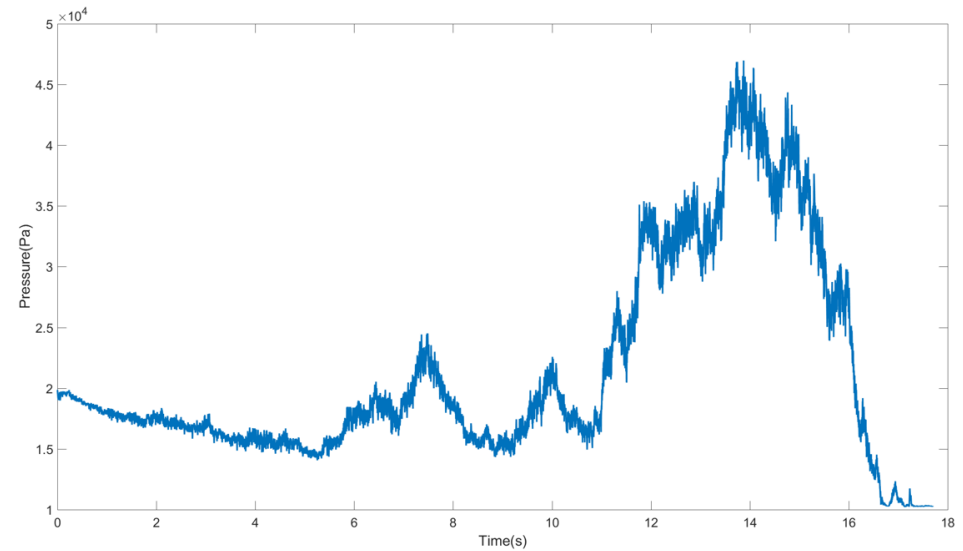

Figura 4.63: Pressão na Entrada x Tempo, $M=1 / 50$ e $C a=3.51 \times 10^{-5}$.

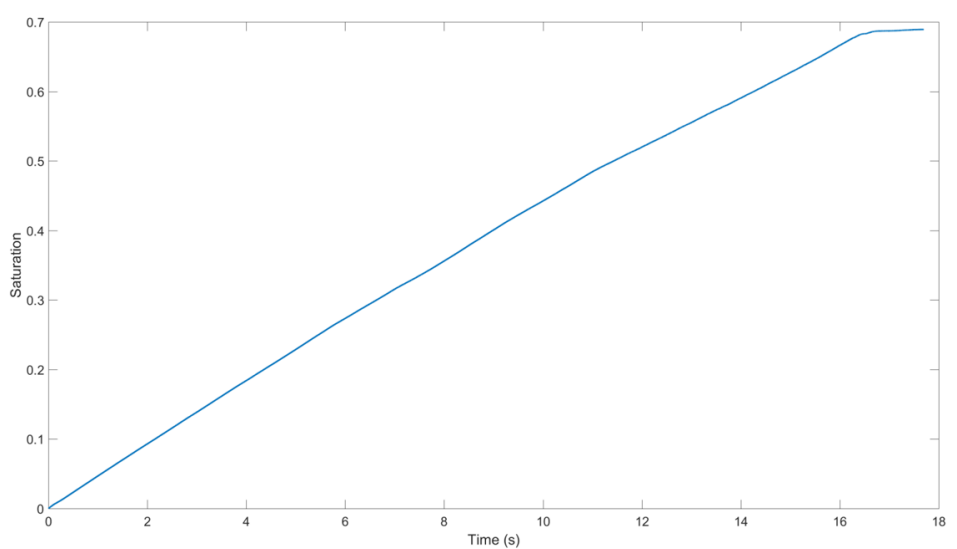

Figura 4.64: Saturação de Água x Tempo, $M=1 / 50$ e $C a=3.51 \times 10^{-5}$. 


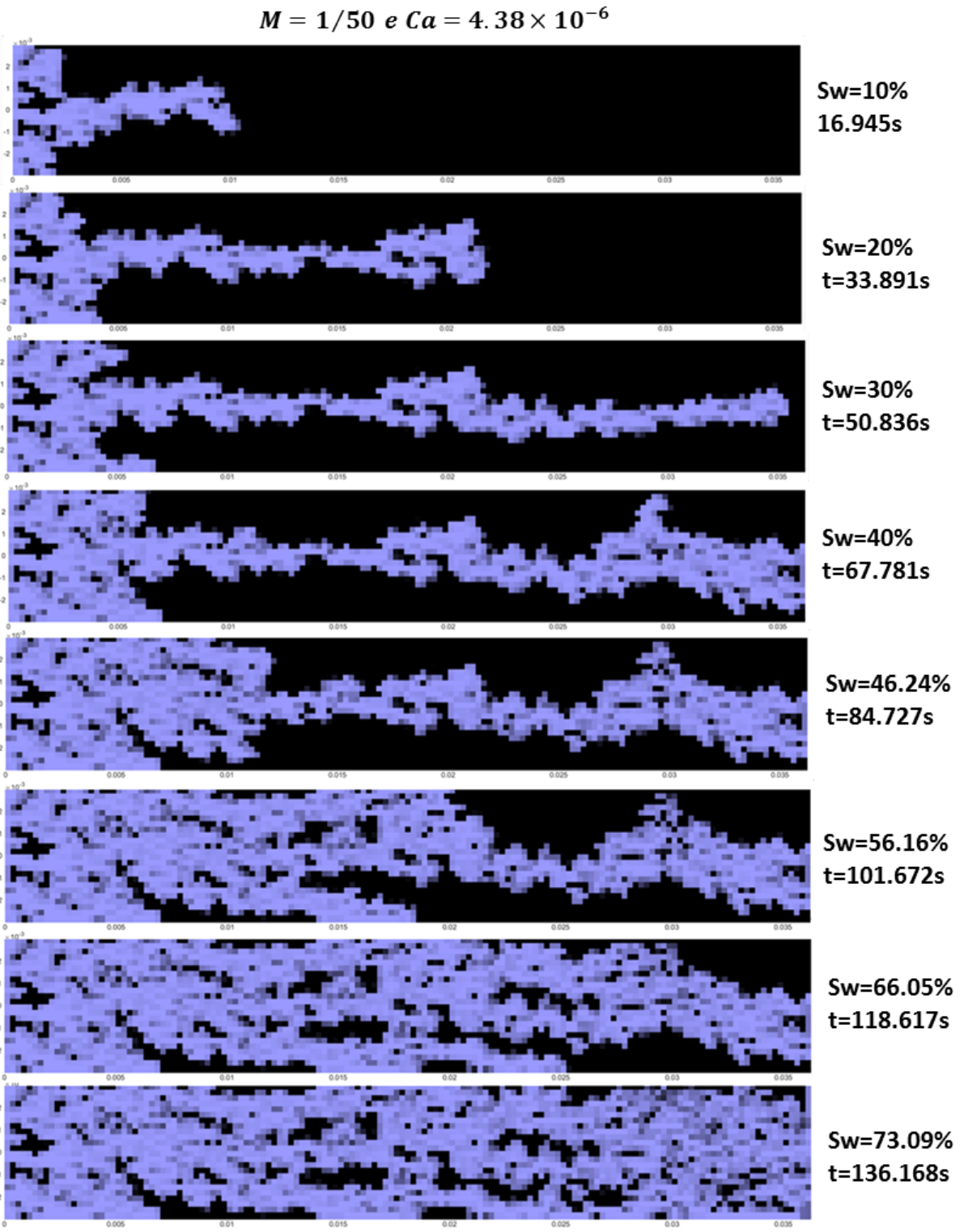

Figura 4.65: Escoamento por Embebição, $M=1 / 50$ e $C a=4.38 \times 10^{-6}$. À direita da imagem mostramos as saturações de água no chip e os tempos correspondentes.

A curva de pressão de entrada com o tempo para o número de capilaridade de $4.38 \times 10^{-6}$ (Figura 4.66), apresentou um grande aumento após o momento de breakthrough, em torno de $67 \mathrm{~s}$. O extenso finger viscoso formado no escoamento fez com a pressão de entrada ficasse cada vez menor, devido à pressão capilar favorável ao movimento, em vista da manutenção de vazão de injeção imposta. Após o breakthrough, a não existência da interface água/óleo, implicou em um aumento de pressão. Este aumento permitiu o escoamento de outros fingers viscosos, com interfaces água/óleo, fazendo com que a pressão 
diminuísse novamente.

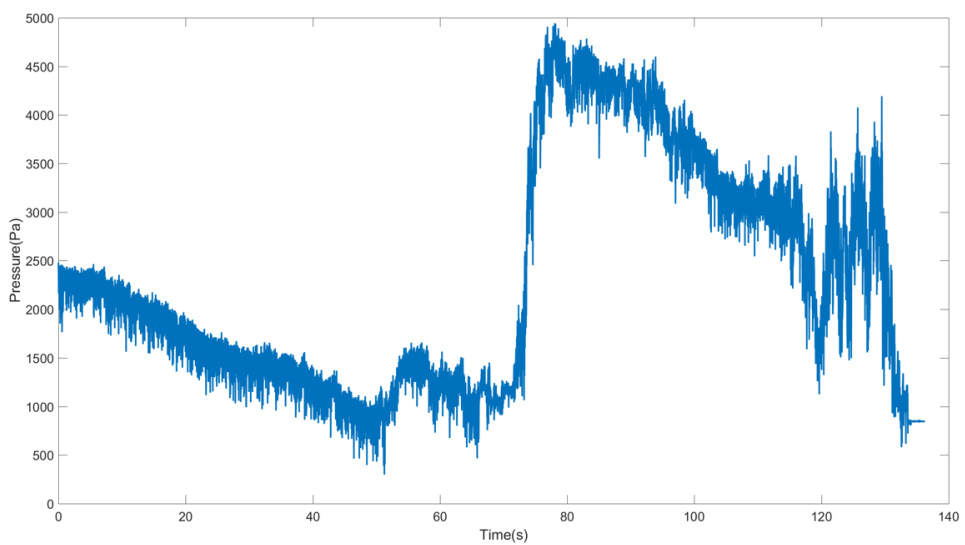

Figura 4.66: Pressão na Entrada x Tempo, $M=1 / 50$ e $C a=4.38 \times 10^{-6}$.

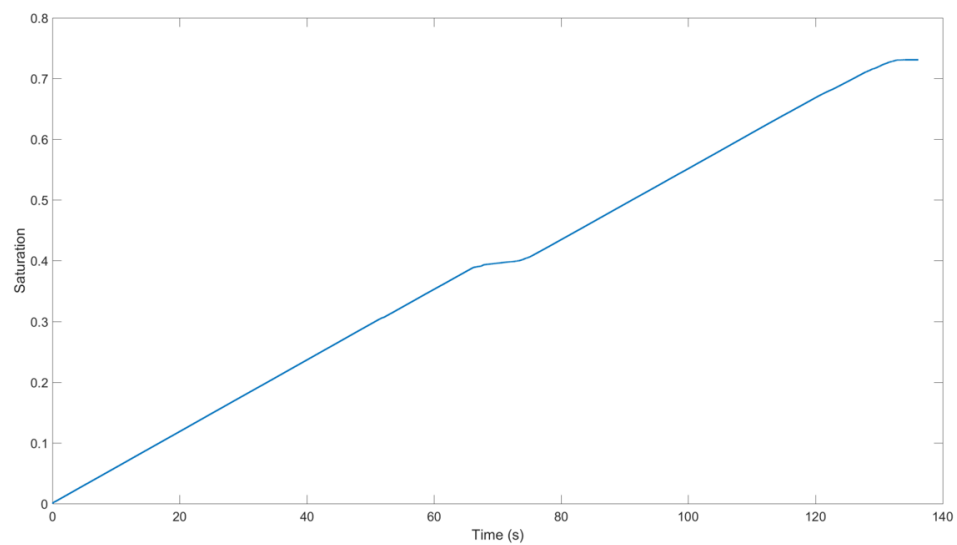

Figura 4.67: Saturação de Água x Tempo, $M=1 / 50$ e $C a=4.38 \times 10^{-6}$.

A simulação considerando número de capilaridade de $5.48 \times 10^{-7}$ foi abortada por apresentar um tempo de simulação inviável para sua conclusão. Instabilidades numéricas contribuíram para a ocorrência de capillary pinning.

Para as simulações com número de capilaridade igual a $2.74 \times 10^{-7}$, devido às vazões impostas mais baixas, observamos valores de pressão de entrada negativos (Figura 4.69). 


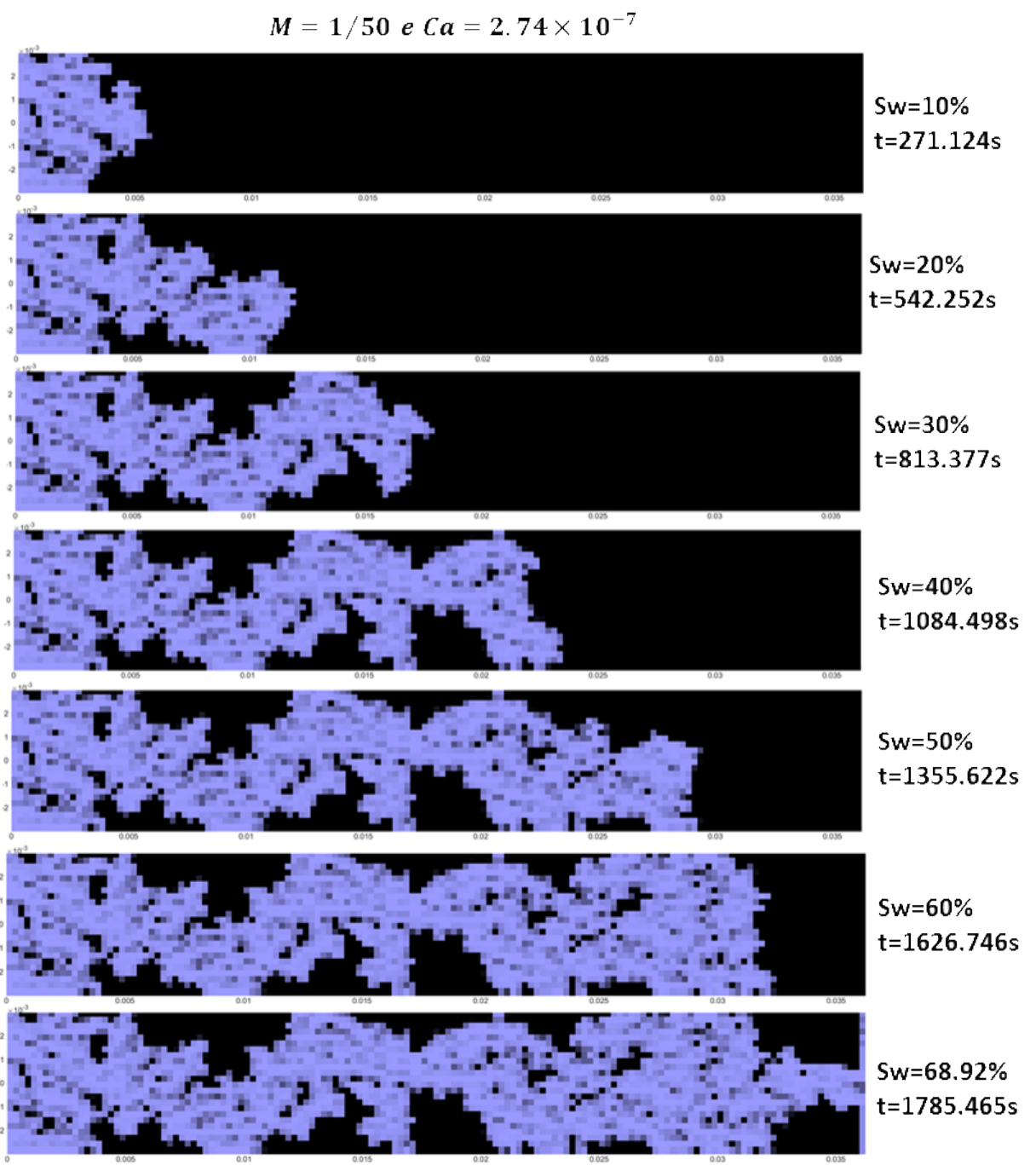

Figura 4.68: Escoamento por Embebição, $M=1 / 50$ e $C a=2.74 \times 10^{-7}$. À direita da imagem mostramos as saturações de água no chip e os tempos correspondentes. 


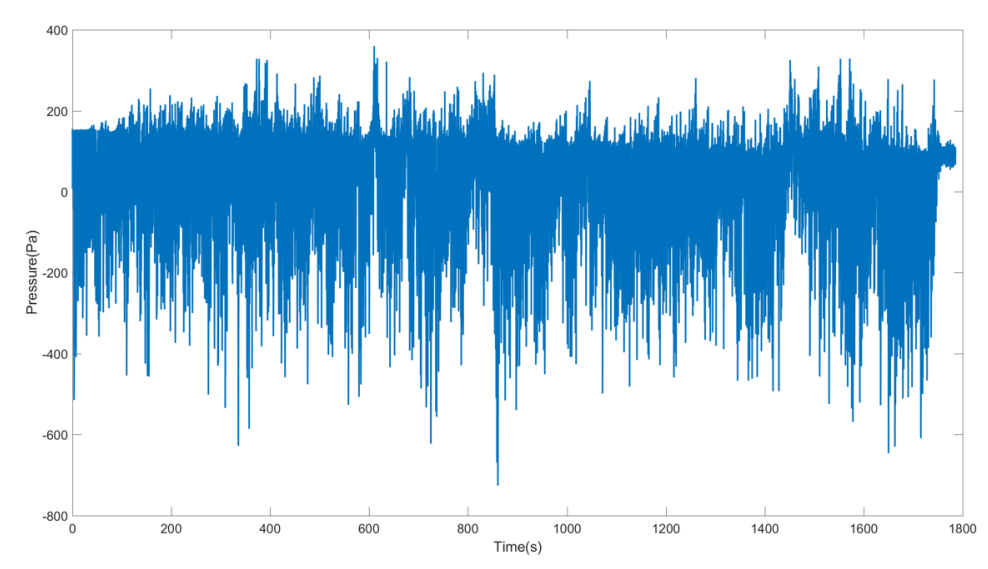

Figura 4.69: Pressão na Entrada x Tempo, $M=1 / 50$ e $C a=2.74 \times 10^{-7}$.

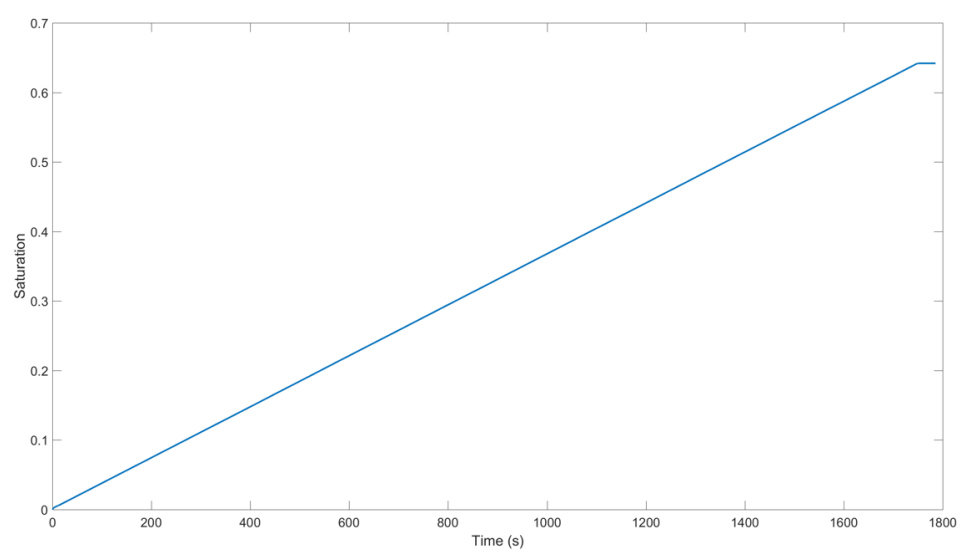

Figura 4.70: Saturação de Água x Tempo, $M=1 / 50$ e $C a=5.48 \times 10^{-7}$.

A Tabela 4.6 apresenta um resumo dos resultados das simulações para os diferentes números de capilaridade e razão de viscosidade:

Tabela 4.6: Eficiências de Deslocamento (Embebição) - Simulador

\begin{tabular}{|c|c|c|c|c|}
\hline $\mathbf{C a}$ & Vazão $\left(\mathrm{m}^{3} / \mathrm{s}\right)$ & $S_{\text {or }} \mathbf{( \mathbf { M } = \mathbf { 1 } / \mathbf { 5 0 } )}$ & $S_{\text {or }} \mathbf{( \mathbf { M } = \mathbf { 1 } / \mathbf { 1 6 } )}$ & $S_{\text {or }}(\mathbf{M}=\mathbf{1} / \mathbf{2})$ \\
\hline $2.74 \times 10^{-7}$ & $5.32 \times 10^{-12}$ & $35.81 \%$ & $28.49 \%$ & $40.95 \%$ \\
\hline $5.48 \times 10^{-7}$ & $1.06 \times 10^{-11}$ & Abortada & $38.06 \%$ & $35.06 \%$ \\
\hline $4.38 \times 10^{-6}$ & $8.51 \times 10^{-11}$ & $26.91 \%$ & Abortada & $31.79 \%$ \\
\hline $3.51 \times 10^{-5}$ & $6.81 \times 10^{-10}$ & $31.08 \%$ & $27.08 \%$ & $20.49 \%$ \\
\hline
\end{tabular}

As saturações de óleo remanescente para diferentes números de capilaridade e razões de viscosidade foram praticamente constante nas simulações de 
embebição, conforme podemos observar no gráfico de $C a \times S_{o r}$ (Figura 4.71). Quanto aos padrões de escoamento e seus impactos nas pressões foram percebidas algumas diferenças. Para números de capilaridade mais altos, o fluxo com razão de viscosidade de 1/50 apresentou maior presença de fingers viscosos comparado aos de 1/2 e 1/16. O fluxo com razão de viscosidade de $1 / 2$ apresentou uma frente mais estável gerada pela competição de fingers capilares e viscosos. Para números de capilaridade mais baixos, o escoamento foi dominado por fingers capilares em todas as simulações.

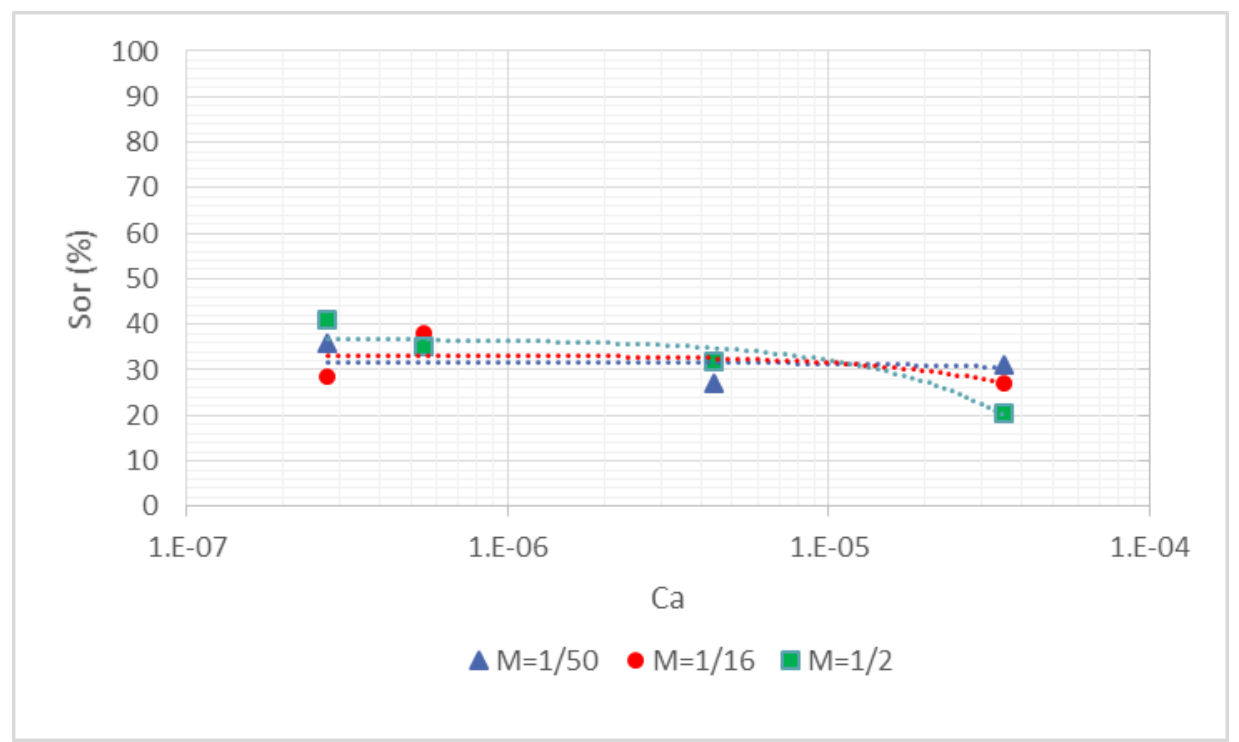

Figura 4.71: Gráfico de $C a \times S_{\text {or }}$ para $M=1 / 50, M=1 / 16$ e $M=1 / 2$.

\section{3}

\section{Tempos de Simulação}

Tanto para as rodadas de drenagem quanto para as de embebição houve uma grande variação com relação ao número de iterações necessárias até atingir a condição de parada do simulador. No caso das rodadas de drenagem, nas quais $100 \%$ do microchip foi considerado para o escoamento, cada iteração leva em média 0.05s. Já, para as rodadas de embebição, com 60\% do microchip, o tempo médio de cada iteração é de $0.025 \mathrm{~s}$. Com o número de iterações variando de 290150 a 18530000 , o tempo das rodadas variou de 4 a 123 horas. A Tabela 4.7 contém as especificações da máquina utilizada para as simulações:

Tabela 4.7: Especificações da Máquina utilizada nas Simulações

\begin{tabular}{|c|c|}
\hline Processador & Intel(R) Core(TM) i7-4500U CPU @ $1.80 \mathrm{GHz} 2.40 \mathrm{GHz}$ \\
\hline Memória instalada (RAM) & $16.0 \mathrm{~GB}$ \\
\hline Sistema Operacional & Windows 7 64 Bits \\
\hline
\end{tabular}




\section{5}

\section{Conclusão e Trabalhos Futuros}

O simulador de rede de poros foi desenvolvido no software Matlab para estudo do escoamento bifásico de fluidos imiscíveis tanto para o processo de drenagem quanto para o de embebição. O mecanismo de deslocamento considerado foi o deslocamento pistão. O modelo representa, em nós e capilares, a geometria e conexões de um microchip, construído pela Dolomite Microfluidics. Este foi inicialmente saturado com óleo e se impõe uma vazão de injeção de água.

Para avaliação dos diferentes padrões de escoamento e eficiências de deslocamento através da saturação de óleo remanescente, utilizamos três razões de viscosidade $(1 / 50,1 / 16$ e 1/2) e simulamos com diferentes números de capilaridade.

Para razão de viscosidade de 1/16 pudemos comparar nossos resultados com experimentos realizados pelo Laboratório de Microhidrodinâmica e Escoamento em Meios Porosos da PUC-Rio (12). Quanto à drenagem, o comportamento da curva de saturação de óleo remanescente versus número de capilaridade apresentou a mesma tendência do experimento. Com o aumento do número de capilaridade, o escoamento apresentou uma maior eficiência de deslocamento, menor saturação de óleo remanescente. As diferenças nos valores se devem ao fato de não contemplarmos o mecanismo de snap-off para a recuperação de óleo, visto durante o experimento. Quanto à embebição, diferentemente dos resultados do laboratório, a saturação de óleo remanescente se manteve praticamente constante para os diferentes números de capilaridade analisados. Isto porque, no processo de embebição, o mecanismo de snap-off é o maior responsável pelo aprisionamento do óleo.

Nossa segunda análise foi através da variação da razão de viscosidade para os mesmos números de capilaridade. Na drenagem, quanto maior a razão de viscosidade, considerando razões de viscosidades menores que 1, maior a eficiência de deslocamento do óleo. O padrão de escoamento observado é de fingering viscoso. Como neste padrão de escoamento a principal força é devido a viscosidade do fluido deslocado, quando a razão de viscosidade aumenta, a frente é mais estável. O escoamento com razão de viscosidade igual a 1/50, apresentou uma maior quantidade de fingers viscosos comparado ao de 1/16. 
Porém, esses se direcionaram rapidamente para a saída do chip, implicando em uma maior saturação de óleo remanescente. Na embebição, as saturações de óleo remanescente foram praticamente as mesmas para as diferentes razões de viscosidade. Quanto aos padrões de escoamento, para números de capilaridade mais altos, o fluxo com razão de viscosidade de 1/50 apresentou maior presença de fingers viscosos comparado aos de $1 / 2$ e 1/16. O fluxo com razão de viscosidade de 1/2 apresentou uma frente mais estável gerada pela competição de fingers capilares e viscosos. Para números de capilaridade mais baixos, o escoamento foi dominado por fingers capilares em todas as simulações.

A competição entre forças capilares e forças viscosas promove uma maior não-linearidade no campo das pressões, sendo agravado quando o fluxo capilar é dominante. Algumas simulações de escoamento por embebição apresentaram certa instabilidade numérica provocando capillary pinning.

Nossa primeira sugestão para trabalhos futuros seria um aperfeiçoamento na modelagem da pressão capilar de forma que suavizasse a descontinuidade presente ao se completar um capilar, preenchendo diretamente o nó e seguindo com a criação de três interfaces. Devido aos problemas de instabilidade numérica vistos, um tratamento para capillary pinning seria de grande valor, principalmente para simulações de embebição. Além disto, como forma de tornar o modelo numérico mais próximo da realidade, sugerimos a implementação dos mecanismos de snap-off e preenchimento de poros. 


\section{Referências bibliográficas}

[1] DAKE, L.. Fundamentals of Reservoir Engineering. Developments in Petroleum Science. Elsevier Science, 1983.

[2] SINHA, P. K.; WANG, C.-Y.. Pore-network modeling of liquid water transport in gas diffusion layer of a polymer electrolyte fuel cell. Electrochimica Acta, 52(28):7936-7945, 2007.

[3] AL-GHARBI, M. S.; BLUNT, M. J.. Dynamic network modeling of two-phase drainage in porous media. Physical Review E, 71(1):016308, 2005.

[4] BEREJNOV, V.; DJILALI, N. ; SINTON, D.. Lab-on-chip methodologies for the study of transport in porous media: energy applications. Lab on a Chip, 8(5):689-693, 2008.

[5] GUNDA, N. S. K.; BERA, B.; KARADIMITRIOU, N. K.; MITRA, S. K. ; HASSANIZADEH, S. M.. Reservoir-on-a-chip (roc): A new paradigm in reservoir engineering. Lab on a Chip, 11(22):3785-3792, 2011.

[6] FATT, I.; OTHERS. The network model of porous media. Americam Institute of Mining, Metallurgical, and Petroleum Engineers (AIME), 1956.

[7] KOPLIK, J.; LASSETER, T. ; OTHERS. Two-phase flow in random network models of porous media. Society of Petroleum Engineers Journal, 25(01):89-100, 1985.

[8] DIAS, M. M.; PAYATAKES, A. C.. Network models for two-phase flow in porous media part 1 . immiscible microdisplacement of non-wetting fluids. Journal of Fluid Mechanics, 164:305-336, 1986.

[9] AKER, E.; SCIENTIARUM, C.. A simulation model for two-phase flow in porous media. University of Oslo, Department of Physics, 1996.

[10] NGUYEN, V. H.; SHEPPARD, A. P.; KNACKSTEDT, M. A.; PINCZEWSKI, W. V. ; OTHERS. A dynamic network model for imbibition. In: SPE ANNUAL TECHNICAL CONFERENCE AND EXHIBITION. Society of Petroleum Engineers, 2004. 
[11] MICROFLUIDICS, D.. Microchip Datasheet, 2017. Acesso em: Setembro de 2017.

[12] AVENDANO, J.; LIMA, N.; QUEVEDO, A. ; CARVALHO, M.. (submitted). Effect of surface wettability on immiscible displacement in a microfluidic porous media.

[13] ROSA, A.; DE SOUZA CARVALHO, R. ; XAVIER, J.. Engenharia de reservatórios de petróleo. Interciência, 2006.

[14] LENORMAND, R.; TOUBOUL, E. ; ZARCONE, C.. Numerical models and experiments on immiscible displacements in porous media. Journal of fluid mechanics, 189:165-187, 1988.

[15] KARADIMITRIOU, N.; HASSANIZADEH, S.. A review of micromodels and their use in two-phase flow studies. Vadose Zone Journal, 11(3), 2012.

[16] CHATENEVER; CALHOUN. Visual examination of fluid behaviour in porous media. Petroleum Transaction, AIME, 195(S1):149-156, 1952.

[17] BONNET, J.; LENORMAND, R.. Réalisation de micromodèles pour l'étude des écoulements polyphasiques en milieux poreux. Revue de l'Institut Français du Pétrole, 32(3):477-480, 1977.

[18] LENORMAND, R.; ZARCONE, C. ; SARR, A.. Mechanisms of the displacement of one fluid by another in a network of capillary ducts. J. Fluid Mech, 135(34):337-353, 1983.

[19] OREN, P.; PINCZEWSKI, W.. Fluid distribution and pore-scale displacement mechanisms in drainage dominated three-phase flow. International Journal of Multiphase Flow, 22(S1):150-150, 1996.

[20] CLARKE, A.; HOWE, A. M.; MITCHELL, J.; STANILAND, J.; HAWKES, L. A. ; OTHERS. How viscoelastic-polymer flooding enhances displacement efficiency. SPE Journal, 21(03):675-687, 2016.

[21] PAYATAKES, A.. Dynamics of oil ganglia during immiscible displacement in water-wet porous media. Annual Review of Fluid Mechanics, 14(1):365-393, 1982.

[22] ZHAO, X.; BLUNT, M. J. ; YAO, J.. Pore-scale modeling: Effects of wettability on waterflood oil recovery. Journal of Petroleum Science and Engineering, 71(3):169-178, 2010. 
[23] WANG, S.; FENG, Q.; DONG, Y.; HAN, X. ; WANG, S.. A dynamic porescale network model for two-phase imbibition. Journal of Natural Gas Science and Engineering, 26:118-129, 2015.

[24] JOEKAR-NIASAR, V.; HASSANIZADEH, S.. Analysis of fundamentals of two-phase flow in porous media using dynamic pore-network models: A review. Critical reviews in environmental science and technology, 42(18):1895-1976, 2012. 